NBER WORKING PAPER SERIES

\title{
MARGINAL JOBS AND JOB SURPLUS: A TEST OF THE EFFICIENCY OF SEPARATIONS
}

\author{
Simon Jäger \\ Benjamin Schoefer \\ Josef Zweimüller \\ Working Paper 25492 \\ http://www.nber.org/papers/w25492 \\ NATIONAL BUREAU OF ECONOMIC RESEARCH \\ 1050 Massachusetts Avenue \\ Cambridge, MA 02138 \\ January 2019
}

\begin{abstract}
We thank the editor, Thomas Lemieux, and anonymous referees, as well as Daron Acemoglu, Josh Angrist, David Autor, Mark Bils, Leo Kaas, Philipp Kircher, Patrick Kline, Moritz Kuhn, Guido Menzio, Thijs van Rens, as well as audiences at conferences at the ASSA Meeting, briq Workshop, ECB/CEPR Labour MarketWorkshop, London-Paris Public Economics Conference, CEPR/IZA Annual Symposium, CEPR Public Economics Symposium, MILLS, Ammersee Workshop, NBER SI Macro Perspectives, NBER Labor Studies, NBER Public Economics, NBER Aging Program, NBER Longer Working Lives Workshop, NYU Search Theory Workshop, SED, CESifo Venice, and at seminars at Banca d'Italia, the Philadelphia Fed, Harvard, IAB, INSEAD, U Mannheim, UC Berkeley, UC Santa Barbara, UCL, and U Penn. Karl Aspelund, Carolin Baum, Nikhil Basavappa, Dominik Egloff, Andreas Kettemann, René Livas, Nelson Mesker, Damian Osterwalder, Nina Roussille, Philippe Ruh, Martina Uccioli, Samuel Young, and Dalton Zhang provided excellent research assistance. Jäger and Schoefer acknowledge financial support from the Boston Retirement Research Center, the National Science Foundation, and the Sloan Foundation. The views expressed herein are those of the authors and do not necessarily reflect the views of the National Bureau of Economic Research.
\end{abstract}

NBER working papers are circulated for discussion and comment purposes. They have not been peerreviewed or been subject to the review by the NBER Board of Directors that accompanies official NBER publications.

(C) 2019 by Simon Jäger, Benjamin Schoefer, and Josef Zweimüller. All rights reserved. Short sections of text, not to exceed two paragraphs, may be quoted without explicit permission provided that full credit, including $\odot$ notice, is given to the source. 
Marginal Jobs and Job Surplus: A Test of the Efficiency of Separations

Simon Jäger, Benjamin Schoefer, and Josef Zweimüller

NBER Working Paper No. 25492

January 2019, Revised June 2020

JEL No. E2,E24,H0,H3,J0,J01,J18,J23,J31,J63,J64,J65

\begin{abstract}
$\underline{\text { ABSTRACT }}$
We present a test of Coasean theories of efficient separations. We study a cohort of jobs from the introduction through the repeal of a large, age- and region-specific unemployment benefit extension in Austria. In the treatment group, $18 \%$ fewer jobs survive. According to the Coasean view, the destroyed marginal jobs had low joint surplus. Hence, after the repeal, the treatment survivors should be dramatically more resilient than the ineligible control group survivors. Strikingly, the two groups instead exhibit identical post-repeal separation behavior. We provide and empirically support an alternative model in which wage rigidity drives the inefficient separation dynamics.

Simon Jäger

Department of Economics

MIT

50 Memorial Drive

Cambridge, MA 02142

and NBER

sjaeger@mit.edu

Benjamin Schoefer

Department of Economics

University of California at Berkeley

530 Evans Hall \#3880

Berkeley, CA 94720-3880

schoefer@berkeley.edu

Josef Zweimüller

Department of Economics

University of Zurich

Schoenberggasse 1

8001, Zurich

Switzerland

josef.zweimueller@econ.uzh.ch
\end{abstract}




\section{Introduction}

Coasean theories of jobs assume that an employer and worker exploit all gains from trade and reach bilaterally efficient outcomes, splitting joint job surplus through unrestricted transferable-utility compensation arrangements. All job separations are mutually preferable and efficient, occurring if and only if joint surplus would otherwise turn negative. Due to its theoretical appeal, bilateral efficiency remains the dominant assumption in models of the labor market. Conversely, non-Coasean frictions such as wage rigidity that can result in inefficient separations (Hall and Lazear, 1984) are often dismissed a priori (starting with Barro, 1977; Becker, Landes, and Michael, 1977). The same properties that underlie the theoretical appeal of the Coasean hypothesis have also shielded it from empirical tests. First, the abstract concept of surplus is not observable, let alone surplus of a terminated job. Second, heterogeneous consequences of separations need not be informative. For example, even though layoffs may leave workers dramatically worse off than quits, both labels can reflect efficient separations (McLaughlin, 1991). Third, insensitivity of wages to shocks can still be consistent with bilateral efficiency (MacLeod and Malcomson, 1993; Hall, 2005; Cahuc, Postel-Vinay, and Robin, 2006: Hall and Milgrom, 2008) 11

We overcome these challenges with a revealed-preference test of group-level separation behavior using a quasi-experimental research design. We study a transitory treatment that, while active, reduces joint job surplus and thereby causes separations. The treatment is then sharply repealed. Now, the group of surviving jobs lacks a mass of marginal (lowsurplus) matches. Under the Coasean view, this group of treatment survivors should subsequently exhibit resilience to any kind of shocks compared to a control group, in which low-surplus jobs have remained.

Our treatment reducing joint job surplus is an unemployment insurance (UI) benefit extension, which boosted workers' outside option (nonemployment). Specifically, the program raised potential benefit duration from originally one to four years in Austria in 1988. Since eligibility was determined by a sharp age cutoff (age 50 and up) and the program was region-specific, we implement a difference-in-differences design comparing age groups and regions in the universe of Austrian social security data. Crucially, the program was abruptly repealed in 1993, which permits our test: after the program repeal, the group of formerly treated job survivors should be more resilient - i.e. have fewer separations - in response to any future shocks, compared to the control group.

Our first empirical step documents that the program triggered an increase in separa-

${ }^{1}$ This challenge also implies that although measured wages in Austria may appear insensitive to (nonemployment) outside option shifts (Jäger et al. forthcoming), such wage insensitivity among stayers need not be allocative for separations. 
tions of 10.9ppt (27\%) over the five-year horizon the program was active: $51.4 \%$ of jobs in the treatment group separated (largely into long-term nonemployment), compared to a counterfactual separation rate of $40.5 \%$ absent the reform 2 Alternatively put, $18 \%$ of the surviving jobs in the control group would have separated had the group also been exposed to the UI extension. Importantly, on their own and without the post-repeal period, this initial treatment effect and separation behavior during the policy period are not directly informative about the efficiency of separations; they simply reflect local densities of low-surplus, marginal jobs.

In a second step, we exploit the abrupt repeal of the policy in 1993. We track the jobs active both already at the onset of the program in 1988 and still active still at the repeal ("survivors"). The repeal realigns the surplus distributions among job survivors in both the former treatment and control groups, except that, at the group level, the treatment survivors now feature a missing mass of marginal matches (the initial separators). By the Coasean view, this set of marginal jobs should have joint surplus between zero and a cutoff equal to the surplus value of the UI program. These marginal matches should be the first to separate in the control group, ahead of any inframarginal program survivors.

Strikingly - and inconsistent with the Coasean prediction - the two groups exhibit identical post-repeal separation behavior in the data, despite the massive depletion in the ranks of the former treatment group, which is around $18 \%$ smaller than the control group due to the treatment. The absence of resilience holds unconditionally as well as in response to negative labor demand events.

To quantify the gap between the Coasean prediction and the data, we construct a benchmark for post-repeal separations among treatment survivors. We exploit the Coasean pecking order of joint job surplus. For small shocks, separations should occur in the control group but not the former treatment group. There, separations only start once the control group post-repeal separation rate crosses the threshold given by the treatment effect size of the initial UI extension. The treatment effect was large, so this Coasean benchmark predicts substantial resilience, which the data reject.

Moreover, we show that variants of the Coasean view can only rationalize the identical post-repeal separation behavior under narrow conditions: idiosyncratic job-level surplus would need to exhibit no persistence whatsoever, so that full reshuffling of surplus replenishes the mass of marginal matches in the former treatment group. Yet, since such full reshuffling would need to occur already within the very first year after the repeal and, we

2Winter-Ebmer (2003) studies inflow effects of the program between two groups (all below 50 vs. 50-65) using a 2\% sample of our data. Lalive, Landais, and Zweimüller (2015), who focus on job finding spillovers among the unemployed during the policy period, also include separations as an outcome (Table 3). 
estimate, in $96 \%$ of jobs, this reconciliation appears implausible. Lastly, we also rule out various potential concerns that might mask Coasean dynamics such as spillovers (using our multiple control groups as well as employer-level treatment intensity), or separations of high- rather than low-surplus jobs.

Which non-Coasean model can account for the inefficient separation dynamics? We propose and then provide empirical support for wage rigidity as a parsimonious and plausible alternative model ${ }^{3}$ By preventing the flexible (re)bargaining underlying the Coasean result, wage rigidity complicates the participation constraint from single-dimensional Coasean joint surplus to two unilateral surpluses: separations occur because either worker or firm surplus turns negative. As a result, jobs can inefficiently separate despite positive joint surplus, such that one party's surplus remains large enough to, in principle, bribe the other party into continuation.

In this non-Coasean setting with wage rigidity, the original UI extension, which boosted worker's outside options, would have destroyed matches with initially low worker surplus. But many marginal matches with low firm surplus can remain. After the repeal, the former treatment group can therefore exhibit just as large a sensitivity to firm surplus shifts as the control group. Non-resilience emerges if most post-repeal separations are due to firm shocks, for example if baseline worker surplus is high and firm surplus is small (and the two are not strongly correlated).

Our alternative non-Coasean model with wage rigidity is plausible and consistent with the data and institutional setting along various dimensions. First, we show that nonresilience holds for negative labor demand shocks, consistent with both groups having retained matches with low firm surplus and the policy having destroyed low workersurplus matches. Second, for our sample of older, high-tenured workers, the required joint distribution - high worker surplus and low firm surplus - is predicted by several models of career trajectories, namely compensation backloading in implicit contract models, (Lazear. 1979, 1981; Frimmel et al., 2018), or rising worker rents from renegotiations in employer competition models (Cahuc, Postel-Vinay, and Robin, 2006). Third, Austria mandates multiple months of severance payments for longer-tenured workers that are foregone in unilateral quits. Fourth, the exceptional generosity of the UI extension - three additional years of eligibility, potentially serving as a bridge into early retirement, proved attractive to otherwise inframarginal workers in high-worker-surplus matches. 4 Fifth, we review wage

\footnotetext{
${ }^{3}$ In contrast to Jäger et al. (forthcoming) studying reforms of replacement rates, we cannot credibly study wage effects in the present setting given the large attrition implied by the separation effects. Importantly, wage dynamics among stayers need not be allocative and hence not be informative about the efficiency of separations as described in our motivation above.

${ }^{4} \mathrm{~A}$ prediction of this view is that smaller shifts in outside options should not induce workers to separate.
} 
setting institutions in Austria. Collectively bargained wage floors often leave considerable scope for deviations. Most importantly, the type of wage rigidity relevant to our study likely includes broader frictions such as constraints on firms' capacity to differentiate wages between very similar workers exposed to idiosyncratic (in our case sharply agespecific) surplus shocks.

Our paper concludes with a direct, constructive test that supports wage rigidity as the plausible friction underlying the inefficient separation dynamics. We construct empirical proxies for the kind of wage rigidity relevant to our setting, which is broader than standard downward rigidity and also reflects firms' ability to differentiate wages due to the sharp age eligibility criterion. We sort our sample into quantiles by these indices, and replicate our full design separately in each cell. First, we find that the initial treatment effect stemmed from pockets of the labor market with high wage rigidity. The flexible-wage cells exhibit no initial separation responses (a pattern not driven by higher baseline surplus). Second, the rigid wage groups exhibit essentially no resilience after the repeal, and confidence intervals permit us to rule out that the data accord with the Coasean benchmark in these groups. Instead, the separation behavior in these cells is consistent with our non-Coasean model with rigid wages. The flexible wage cells do not exhibit resilience either, which is plausibly consistent with more Coasean dynamics in these cells: here, the initial treatment effect was attenuated (perhaps through more efficient bargaining, which we cannot directly measure), thus leaving no "hole" in the joint-surplus distribution. Together, these patterns can also rationalize why the overall labor market we study did not exhibit any resilience whatsoever.

Section 2 presents an overview of the Austrian institutional context, the policy, and our data. Section 3 presents our benchmark Coasean model. In Section 4 , we document the large separation effects entailed by the UI extension. Section 5 reports the results of our core test comparing separation behavior of the treatment and control groups after the program was repealed. Section 6 discusses and dismisses variants of the Coasean model potentially rationalizing the data. Section 7 presents a non-Coasean setting with wage rigidity that can account for the full set of facts. We provide supporting empirical evidence for wage rigidity as driving the inefficient separation dynamics in Section 8 . The last section concludes.

Indeed, different, smaller Austrian UI reforms do not appear to entail separation effects even among older workers and even during the 1980s in Austria (Jäger et al., forthcoming). 


\section{Institutional Context, the Policy Variation, and Data}

We review the Austrian UI system, the reform, other institutional context, and our data.

\subsection{The Austrian UI System and the UI Benefit Extension}

The Austrian UI System During the 1980s and 1990s Two crucial institutional features ensure that UI generosity cleanly shifts the nonemployment outside option of workers in our setting. First, Austrian workers are fully eligible for UI benefits upon quitting after a four-week waiting period. Second, similar to most other European countries, the Austrian system does not feature experience rating, as the Austrian UI system is funded through employer and employee payroll taxes (which were unaffected by the reform we study).

During the 1980s and 1990s, the gross replacement rate was between 40 and $48 \%$ for most employees, and capped below and above at a minimum and maximum amount.5 The potential benefit duration (PBD) of UI benefits during the 1980s was 30 weeks, provided the worker had been employed (and paid UI contributions) for at least three out of the last five years; otherwise, PBD was 20 weeks. After exhaustion of UI, the unemployed can apply for unemployment assistance (UA, "Notstandshilfe"), capped at 92 percent of UI benefits (detailed in Appendix A).

1988-93 Regional Extended Benefit Program (REBP) In 1988, the Austrian government enacted a regional extended benefit program (REBP), a large region- and age-specific PBD expansion from originally 30 weeks to 209 weeks. Figure 1 Panel (a) plots the PBD by age group and region over time. We calculate the present value of the cash value of extended benefits to correspond to about $71 \%$ of a typical worker's annual salary in Appendix A.

A job loser had to satisfy the following criteria at the beginning of the unemployment spell: (i) age 50 or older; (ii) a continuous work history (780 employment weeks during the last 25 years prior to the current unemployment spell); (iii) residence in any of the 28 selected labor market districts for at least 6 months prior to the claim; and (iv) start of a new unemployment spell after June 1988 or spell in progress in June 1988.6

Therefore, the reform induces variation along two dimensions, permitting a differencein-differences design. First, across cohorts as we can compare workers aged 50 and above during the reform period to their younger peers and second, across regions comparing REBP regions to non-REBP regions. The difference-in-differences nature of our research design allows us to control for unobservable confounders at the region and cohort level.

\footnotetext{
${ }^{5} \mathrm{UI}$ benefits are not taxed. See Jäger et al. (forthcoming) for details on replacement rates.

${ }^{6}$ The location requirement was tightened in 1991 to preceding employment in the REBP regions.
} 
We net out region-level shocks (including market-level effects of the reform) by comparing slightly younger and older workers in the same region who were narrowly affected or unaffected by the reform. We also net out age- or cohort-specific factors by comparing the same cohorts across regions.

Figure 1 Panel (a) also plots an economy-wide UI reform in August 1989 that shifted benefit duration nation-wide 7 The nation-wide 1989 reform changed PBD based on age and experience and is thus orthogonal to the cross-regional variation we leverage; it is netted out through our cross-regional difference. In sum, for job losers from August 1989 onward, REBP's incremental effect on duration was 3 years (as then the baseline PBD was 52 weeks) and 3.44 years (= 209 weeks -30 weeks) before August 1989.

REBP aimed to mitigate labor market consequences of a crisis in iron, steel, and other heavy industries ("steel sector" in the following). The state-owned company, the Oesterreichische Industrie AG (OeIAG), had suffered from low commodity prices, shrinking markets, and low productivity since the mid-1970s. In response, the new OeIAG management implemented a sequence of restructuring plans during the 1980s, leading to plant closures and downsizing. The REBP regions were selected due to their larger share of employment in the steel sector: in the REBP regions, about $17 \%$ of workers were employed in the steel sector, compared to around 5\% in the non-REBP-regions. Figure 1 Panel (b) provides a map of the REBP labor market districts.

Importantly, REBP eligibility criteria did not include any industry requirement. Nevertheless, to minimize UI policy endogeneity concerns, our empirical analysis excludes steel sector employees. Moreover, the second difference (between slightly younger, ineligible cohorts in the REBP and non-REBP regions) nets out any potential spillovers from the steel sector decline, or other region-specific shocks or trends. We also dismiss potential spillovers from treatment intensity at the industry or firm level in Section 6.3 .

Repeal of the Program REBP was initially in effect until December 1991 before it was extended in January 1992 8 REBP was then repealed on August 1, 1993, stopping acceptance of new entrants yet also grandfathering in claimants in ongoing spells who had

${ }^{7}$ The reform raised PBD for workers aged 40 to 49 (50 and above) to 39 (52) weeks with an experience requirement of 312 (468) weeks of employment in the last 10 (15) years. The reform also increased the replacement rate from 41 to $47 \%$ in the monthly income bracket from 5,000 to 10,000 ATS, roughly 400 to 800 USD at the time.

8The 1992 extension enacted two changes for new spells. First, the benefit extension was repealed in 6 of the original 28 regions. We exclude from our analysis the set of treated regions that were excluded after the 1991 reform. Second, the 1992 extension tightened eligibility criteria: new beneficiaries had to be not only residents, but also previously employed in a treated region. 
previously established eligibility 9 The repeal decision was formally announced in June 1993, an implementation gap of only two months. The program ended abruptly: as late as January 1993, the Austrian government had considered expanding the program to older workers in the entire country, along with changes in the eligibility requirements.10 In the following months, the government reversed course and repealed REBP.

\subsection{Other Institutional Features}

Wage Setting While collective bargaining coverage is near universal, Austrian institutions also leave substantial room for decentralized, flexible wage setting. Bargaining agreements, often concluded at the industry-by-occupation level, regulate wage floors for worker categories usually by experience or tenure (but not age). However, actually paid wages substantially exceed the wage floors, for example, by more than $20 \%$ in manufacturing during our reform period (Leoni and Pollan, 2011). There is also substantial scope for wage differentiation between firms within an industry, as evidenced, for example, by individual firms sharing rents with workers and large pay dispersion between firms (Jäger et al. forthcoming). In fact, at the individual worker level, downward nominal wage rigidity appears lower or similar in Austria compared to, e.g., Germany or the United States (Dickens et al., 2007; Elsby and Solon, 2019). In our empirical analysis, we include a heterogeneity analysis along proxies of firms' ability to differentiate wages across workers to probe the role of wage flexibility in our results.

Interaction of UI with Other Social Policies By interacting with other policies, REBP could serve as a bridge into permanent nonemployment. In the absence of REBP, unemployed men could effectively retire early at age 58 by claiming unemployment benefits for one year, special income support for another, and then drawing a regular public pension at age 60.11 Since REBP extended the maximum duration of UI benefits by three years, eligible workers could permanently withdraw from the labor force as early as age 55 .

Another important program was disability insurance (DI), which can interact with UI in labor supply (Staubli, 2011). During the study period, the Austrian system granted

\footnotetext{
${ }^{9}$ In addition, a grandfathering clause (\$81) covered separations occurring post-repeal due to the advance notice period. Empirically, we thus analyze post-repeal resilience starting in 1994q1.

${ }^{10} \mathrm{We}$ confirm this course of events in a newspaper analysis. For instance, a major newspaper (Der Standard) reported in an article entitled "Länger Geld für alle Altersarbeitslosen (Longer benefits for all older unemployed workers)" from January 9, 1993: "All older unemployed workers throughout Austria - and not only in [REBP regions] as in the past - will be eligible for unemployment benefits of four years instead of one. Minister of Social Affairs, Josef Hesoun, and the social partners have agreed in principle on this [...]." (Our translation.)

${ }^{11}$ Special income support is equivalent to UI but 25 percent higher and paid for a period of at most 12 months. Male workers with at least 35 years of contributions may retire at age 60 .
} 
relaxed access to a DI pension from age 55 onward, allowing job losers in REBP regions to retire by age 51 while being on some kind of benefit up until age 60 , when they could then start claiming their public pension.12 (Inderbitzin, Staubli, and Zweimüller, 2016) study effects of the program on disability insurance entry.

Advance Notice for Layoffs, Works Councils, and Severance Pay While employment protection is not as stringent as in many other countries, an Austrian firm laying off a worker has to obey a set of rules. At the time of REBP, the firm had to give advance notice, which amounted to $5(4,3,2,1.5)$ months for workers with at least $25(15,5,2,0)$ years of tenure. Workers, too, are obliged to give a one-month advance notice.

By law, the firm has to inform and consult the works council (which workers may organize in establishments with 5 or more employees) when a layoff is planned.

In our sample period, severance payments are mandated for all separation types except for dismissals for cause and some quits (one-sided rather than agreed-upon quits as well as quits into retirement with fewer than ten years of tenure). The amount is a step function of worker tenure: $3(5,10,15,20,25)$ years of tenure map into $2(3,4,6,9,12)$ monthly salaries, and zero below three years. We discuss potential implications of the severance pay system and the interpretation of our results in Sections 6.3 and Appendix $\mathrm{F}$.

\subsection{Data and Sample}

Our main data set is the Austrian Social Security Database (ASSD), a matched employeremployee data set covering the universe of private-sector, dependently employed and nontenured public sector employees from 1972 onward (Zweimüller et al. 2009). We focus on workers born after 1933, as older cohorts had already reached the regular retirement age at the repeal of REBP. We include men and birth cohorts up to 1948, so that our slightly younger control cohorts are those born between 1943 and 1948, who were younger than 50 at the time the program was repealed in 1993. We report summary statistics in Table 1

To assign workers to REBP or control region, we draw on the location of their establishment and, if missing, the residence based on data from the Austrian employment agency. We drop the six regions covered by REBP only until 1991 (partial treatment regions in Figure 1 Panel (b)). We also drop the steel sector, which the reform targeted. To broadly rule out any remaining concerns associated with the steel sector as the policy motivation, we also show that the effects are pronounced in a variety of industries in Appendix

${ }^{12} \mathrm{DI}$ applicants below (above) age 55 get a DI pension when a health impairment reduces the work capacity by more than 50 percent in all (their original) occupation. In practice, this means that not only health but also employability criteria establish DI access after age 55. 
Figure A.4, and study growing and shrinking industries separately in Appendix Figure A.7. Moreover, the difference-in-difference design compares slightly older and younger workers in the same region and thus nets out region-specific shocks. We further discuss potential spillover effects in Section 6.3. We drop women for data reasons (reliability of the experience data) and institutional reasons (men could retire at age 60, women could retire at age 55). To assess experience with pre-1972 data, we also draw on data from the Austrian Ministry of Social Affairs (AMS). The vast majority of our sample fulfilled the experience requirement (see last two columns in Appendix Table A.2); since this sample restriction turned out to not affect our estimates, we present the unconditional results.

\section{Deriving the Test of the Coasean Model: Resilience from Missing Mass of Marginal Matches}

We now provide a formal derivation of the predictions from the Coasean framework; namely, that following the repeal of the large, separation-inducing UI extension, the treated group should exhibit resilience. Appendix $B$ contains detailed derivations. Figures 2. the leftmost panels of Figure 3, and Figure 4 illustrate the intuitions.

Jobs and Surplus Jobs carry worker surplus $S^{W}$ and firm surplus $S^{F}$, each of which must be non-negative: each party $i \in\{W, F\}^{\prime}$ s inside job value $V_{\text {In }}^{i}$ (amenities, productivity,...) plus/minus wage $w$ (with which the parties can transfer utility in terms of, e.g., present values) must amount to at least her (separation) outside value $V_{\text {Out }}^{i}$ (unemployment, retirement, working for another firm, the value of a vacancy and hiring another worker,...):

$$
\begin{aligned}
S^{W}\left(w, \mathbf{V}^{W}\right) & =V_{\text {In }}^{W}+w-V_{\text {Out }}^{W} \geq 0 \\
S^{F}\left(w, \mathbf{V}^{F}\right) & =V_{\text {In }}^{F}-w-V_{\text {Out }}^{F} \geq 0
\end{aligned}
$$

where $\mathbf{V}^{i}=\left(V_{a}^{i}\right)_{a \in\{\text { In,Out }\}}$, and we also use $\mathbf{V}=\left(\mathbf{V}^{i}\right)_{i \in\{W, F\}}$.

Figure 2 plots the two-dimensional job space. The $\mathrm{x}$-axis denotes worker surplus, and the y-axis denotes firm surplus. The figure plots various case studies of jobs characterized by different surplus coordinates. The solid circles $(\bullet)$ denote gross-of-wage surpluses, i.e. $V_{\text {In }}^{W}-V_{\text {Out }}^{W}$ for the worker and $V_{\text {In }}^{F}-V_{\text {Out }}^{F}$ for the firm. This is the surplus combination these job "fundamentals" would carry before wage setting, or equivalently in the scenario of a zero wage. The empty circles (o) denote net-of-wage surpluses: for each gross job, we provide various examples of potential wages. Wages achieve transfers of utility that move net surpluses of the parties along 135-degree, iso-joint-surplus lines. 
Figure 2 also partitions jobs into four regions: feasible jobs (top right, solid lines), quits (top left, dashed lines), layoffs (bottom right, dotted lines) and mutual separations (bottom left, dot-dash-patterned line). For a job to be viable net of the wage, it must be in the top right corner, providing positive surplus to both parties. Three natures of separations are represented by the three remaining corners. Quits emerge with negative worker but positive firm surplus. Job $A$ is "born" a quit but the positive wage transforms it into viable job $A_{1}$. The wage can also "overshoot" to job $A_{2}$, leading to a layoff due to negative firm surplus. Job $B$ is born viable even with a zero wage, e.g., an internship or a high-amenity job. Here, too positive (negative) a wage, $B_{1}\left(B_{2}\right)$, leads to a layoff (quit). Job $C$ is a layoff case with a zero wage, so viability needs a negative wage. Doomed jobs such as $X$ are born with negative surplus for both parties. It provides negative joint surplus; no wage can render it viable, and both parties are better off outside this match (mutual separation). Finally, $M$ is a marginal job, with zero joint surplus. Born a quit, a unique positive wage moves it to the origin with zero surplus for either party.

Coasean Bargaining The essence of the Coasean setup is that the parties find a wage within the bargaining set of reservation wages $w \in\left[\underline{w}^{W}, \bar{w}^{F}\right]$, where $S^{W}\left(\underline{w}^{W}, \mathbf{V}^{W}\right)=0$ and $S^{F}\left(\bar{w}^{F}, \mathbf{V}^{F}\right)=0$, any of which implements the bilaterally efficient allocation: forming and maintaining matches that carry non-negative joint - rather than private - job surplus (i.e. whenever $\left.\bar{w}^{F} \geq \underline{w}^{W}\right){ }^{13}$ As a result, the two-dimensional surpluses that determine job viability and separations, Equations (1) and (2), collapse to a one-dimensional, single allocative concept of joint job surplus, defined as:

$$
S(\mathbf{V})=\overbrace{V_{\text {In }}^{W}+V_{\text {In }}^{F}-V_{\text {Out }}^{W}-V_{\text {Out }}^{F}}^{S^{W}\left(w, \mathbf{V}^{W}\right)+S^{F}\left(w, \mathbf{V}^{F}\right)} .
$$

The wage splits this joint surplus between the worker and firm to satisfy both participation constraints. Figure 2 illustrates that Coasean, i.e. efficient, bargaining renders feasible all jobs born upwards or to the right of the marginal-jobs frontier (i.e. those with positive joint surplus), by moving jobs along the iso-joint-surplus curve. With Coasean bargaining, jobs can therefore be sorted along the one-dimensional attribute of joint job surplus $S(\mathbf{V})$.

${ }^{13}$ For example, by Nash bargaining, the worker [firm] receives their outside option (or reservation wage), plus fraction $\beta$ [resp. $1-\beta$ ], the party's bargaining power, of the surplus (the reservation wage difference):

$$
\max _{w}\left(\left[V_{\text {In }}^{W}+w\right]-V_{\text {Out }}^{W}\right)^{\beta} \cdot\left(\left[V_{\text {In }}^{F}-w\right]-V_{\text {Out }}^{F}\right)^{1-\beta} \Rightarrow w^{N}=\left[V_{\text {Out }}^{W}-V_{\text {In }}^{W}\right]+\beta \cdot S=\underline{w}^{W}+\beta \cdot\left[\bar{w}^{F}-\underline{w}^{W}\right] .
$$


Efficient Separations With Coasean bargaining, we observe a separation if joint surplus moves into negative territory. To capture idiosyncratic shocks to specific matches, job values evolve following a Markov process $k\left(\mathbf{V}^{\prime} \mid \mathbf{V}\right)$, where, going forward, $x^{\prime}$ denotes the next-period value of $x$. Then, for a job of value vector $\mathbf{V}$, the probability of separating next period is the probability of transitioning to job values $\mathbf{V}^{\prime}$ that yield negative joint surplus. To consider aggregate shocks (such as the policy), we define $\widetilde{S}\left(\mathbf{V}^{\prime}\right)$ as the short-hand for the surplus level gross of some given aggregate surplus shifter $-\varepsilon^{\prime}<0$, such that, for an aggregate shock, $\widetilde{S}\left(\mathbf{V}^{\prime}, \varepsilon^{\prime}=0\right)=S\left(\mathbf{V}^{\prime}, \varepsilon^{\prime}\right)-\varepsilon^{\prime}$ and $\widetilde{S}(\mathbf{V})<\varepsilon^{\prime} \Leftrightarrow S\left(\mathbf{V}^{\prime}, \varepsilon^{\prime}\right)<0$. Due to Coasean bargaining, the incidence of worker or firm shocks do not matter, so we consider here their sum $\varepsilon^{\prime}=\varepsilon^{W^{\prime}}+\varepsilon^{F^{\prime}}$. Therefore, the job-level separation probability is:

$$
\widetilde{\mathbb{d}}\left(\mathbf{V}, \varepsilon^{\prime}\right)=\int_{\mathbf{V}^{\prime}} \mathbb{1}\left(\widetilde{S}\left(\mathbf{V}^{\prime}\right)<\varepsilon^{\prime}\right) k\left(\mathbf{V}^{\prime} \mid \mathbf{V}\right) d \mathbf{V}^{\prime}
$$

Group-Level Separations Figure 3 Panel (a) plots an example distribution of joint surplus. Without loss of generality, we have normalized $\varepsilon^{\prime}=0$ for aggregate shocks absent REBP. Separations occur in the black portion, where jobs would yield negative surplus. Formally, the group-level separation rate is, for a given idiosyncratic shock distribution, a given aggregate shock and a given distribution of job attributes $f($.$) :$

$$
\delta=\int_{\mathbf{V}} \widetilde{d}\left(\mathbf{V}, \varepsilon^{\prime}\right) f(\mathbf{V}) d \mathbf{V}
$$

Crucially, this formulation separating gross surplus and an aggregate shock $\varepsilon$ implies that we can think of jobs as being ordered by surplus $\widetilde{S}(\mathbf{V})$ gross of an aggregate shock $\varepsilon$, which in turn shifts the cutoff into separations along the gross surplus dimension $\widetilde{S}(\mathbf{V})$. To maintain this "cutoff" interpretation, our convention is that a positive shock $\varepsilon$ denotes a negative surplus shock. Small shocks destroy jobs with small joint surplus, larger shocks will additionally sweep up jobs with larger joint surplus.

The UI Extension (REBP) We think of the REBP treatment as one that primarily lowers joint surplus by improving the worker's outside option $V_{\text {Out }}^{W}(b)$. That is, the reduction of joint surplus is $\varepsilon_{b}^{W \prime}=V_{\text {Out }}^{W}\left(b_{0}+\Delta b\right)-V_{\text {Out }}^{W}\left(b_{0}\right)$. In the Austrian context described in Section 2, this modeling approach is suitable because even worker-sided quits receive full benefits (after a brief waiting period), there is no experience rating, and UI take-up is high. We ballpark the cash value of extended benefits to about $71 \%$ of a typical worker's annual salary in Appendix A. In Section 6.3, we also empirically evaluate whether heterogeneous valuations of the reform could shroud resilience and thus the results of our test. 
Treatment and Control Groups, and Netting Out Equilibrium Effects In our quasiexperimental study, we have a treatment and a control group. Formally, UI generosity $b_{Z}=b_{0}+Z \times \Delta b$ may deviate from baseline level $b_{0}$ depending on group indicator $Z$, which is $Z=1$ for the treatment group and $Z=0$ for the control group. We assume that initial distributions of job values are the same across groups $f^{0}()=.f^{1}(.){ }^{14}$

Our empirical difference-in-differences design has multiple control groups: eligible cohorts in control regions, and slightly younger (ineligible) workers in both treated and control regions. The slightly younger, untreated control group in the same region permits us to net out equilibrium effects of REBP, such as effects on the firm's separation value through shifts in recruitment costs or quality of replacement hires. More precisely, the treatment is then the differential exposure of the treatment group to the program on the outside option of treated workers, net of market-level effects. In our notation we therefore suppress such market-level or spillover effects. We more thoroughly discuss this argument and related considerations in Section 6.3 .

Separation Effects The incremental separations caused by REBP should stem from jobs with joint surplus between zero and the size of the REBP surplus shift. Figure 3 Panel (a) illustrates this logic. During REBP, all jobs with negative joint surplus (i.e. all jobs in the left, black area) separate both in the control and in the treated regions, as their surplus is $\widetilde{S}\left(\mathbf{V}^{\prime}\right)<0$. The gray set of jobs separates only if exposed to REBP, but would remain active absent REBP. These marginal jobs have surplus $0 \leq \widetilde{S}\left(\mathbf{V}^{\prime}\right)<\varepsilon_{b}^{W \prime}$. The remaining jobs - which survive in either group - have surplus $\widetilde{S}\left(\mathbf{V}^{\prime}\right) \geq \varepsilon_{b}^{W \prime}$. The figure also references separation rates for the treatment and control groups $\left(\delta^{1}\right.$ and $\left.\delta_{0}\right)$.

Repeal of REBP The repeal of REBP restores each surviving, formerly treated match's surplus to the level of its peer in the control group. Except, the repeal does not bring back to life the previously destroyed jobs (since we track survivors only). We depict the surplus distributions of REBP survivors right after the repeal in Figure 3 Panels (d) and (g) separately for the former treatment and control groups, respectively. The former treatment group features a missing mass of marginal matches. By contrast, these low-surplus jobs continue to be present in the former control group.

\footnotetext{
${ }^{14}$ In our difference-in-differences design, this condition need not hold in levels but in between-cohort differences across regions. In the initial working paper version of our paper, which also featured an analysis of complier characteristics, we empirically confirmed this assumption for observable characteristics. See also Table 1 for summary statistics.
} 
Coasean Prediction: Resilience The testable prediction characterizing the Coasean view is that right after the REBP repeal, the former treated group of REBP survivors should exhibit attenuated sensitivities - should be more resilient - to post-repeal joint-surplus shocks compared to the control group, where these marginal, low-surplus jobs have remained. Going from example distributions as in Figure 3 Panels (d) and (g) (i.e. imagining rightward shifts in the separation thresholds in the form of a shock), we trace out predicted separation responses to a series of negative post-repeal aggregate shocks $\varepsilon^{\prime \prime}$ in Figure 4 Panel (a), separately for the former treatment (solid line) and control (dashed line) groups.

We denote post-repeal functions with capital letters: $\Delta$ for $\delta, K$ for $k$, and $\widetilde{\mathbb{D}}$ for $\widetilde{d}$. Post-repeal aggregate shocks and job values are denoted by " rather than '. Post-repeal separation rates in the treatment (control) group $Z=1(=0)$ are:

$$
\Delta^{Z}=\int_{\mathbf{V}^{\prime}} \underbrace{\int_{\mathbf{V}^{\prime \prime}} \mathbb{1}\left(\widetilde{S}\left(\mathbf{V}^{\prime \prime}\right)<\varepsilon^{\prime \prime}\right) K\left(\mathbf{V}^{\prime \prime} \mid \mathbf{V}^{\prime}\right) d \mathbf{V}^{\prime \prime}}_{=\widetilde{\mathbb{D}}\left(\mathbf{V}^{\prime}, \varepsilon^{\prime \prime}\right)} f_{\text {post }}^{Z}\left(\mathbf{V}^{\prime}\right) d \mathbf{V}^{\prime} .
$$

Post-repeal, differences in separation rates will arise from differences in $f_{\text {post }}^{Z}$, the densities of job qualities between the treatment and the control groups, due to the selective separations induced by REBP (rather than from differences in aggregate shocks $\varepsilon^{\prime \prime}$, which in turn we here assume to be the same across the groups).

Intuitively, if there were no idiosyncratic change in job surplus, perfect resilience (no separations) would emerge as long as the subsequent aggregate shock size $\varepsilon^{\prime \prime}$ is smaller than the size of REBP, i.e. for $\varepsilon^{\prime \prime} \leq \varepsilon_{b}^{W \prime}$. For larger shocks $\varepsilon^{\prime \prime}>\varepsilon_{b}^{W \prime}$, separations start emerging even in the former treatment group, with the marginal REBP survivors carrying $\widetilde{S}\left(\mathbf{V}^{\prime}\right)=\varepsilon_{b}^{W \prime}$ being the first to separate.

Full Idiosyncratic Shocks During REBP, Short-Run Persistence Post-Repeal This prediction of resilience relies on (some) persistence in job-level surplus between the repeal of REBP and the horizon over which we track survivors' post-repeal separations. Crucially, our specification does permit arbitrary idiosyncratic shock processes $k(. \mid$.) during the five-year REBP policy period. By contrast, below we assume perfect persistence (i.e. post-repeal $K(. \mid$.$) is an identity matrix) solely for the shorter post-repeal horizon of our$ resilience analysis, e.g., as low as one single year (1994-95). Appendix B formalizes this feature. We discuss implications of lack of post-repeal persistence in Section 6.

Coasean Benchmark: Predicted Separation Rates If we could directly observe the REBP shock size $\varepsilon_{b}^{W \prime}$ and the subsequent surplus shocks $\epsilon^{\prime \prime}$, we could implement this test 
of efficiency of job separations now by comparing realized post-repeal separations in former treatment group against the Coasean benchmark. But since surplus is not directly observable, we need one additional step.

Crucially, our empirical strategy circumvents the empirical elusiveness of surplus concepts by inferring the Coasean benchmark from the directly observed control separation rates, which encode the shock size, and the during-REBP-separation rates, which encode the size of the REBP surplus shock $\varepsilon_{b}^{W \prime}$. To illustrate this transformation of impossibleto-measure surplus concepts into observable separation rates, Panel (b) of Figure 4 takes Panel (a) and juxtaposes the two separation rates, permitting us to express the post-repeal former treatment group separation rates $\left(\Delta^{1}\right)$ to that of the former control group $\left(\Delta^{0}\right)-$ under the assumption of Coasean bargaining. The kink location in the $\Delta^{0}$ range is now given by $\Delta^{0}=\frac{\delta^{1}-\delta^{0}}{1-\delta^{0}}$. As long as control group post-repeal separation rate $\Delta^{0}$ is lower than the fraction of marginal matches among the survivors $\frac{\delta^{1}-\delta^{0}}{1-\delta^{0}}$, no separations should occur in the treatment group, simply because these matches are missing. Once control group separations cross that threshold, separations commence in the former treatment group (with a slope steeper than one, $\frac{1-\delta^{0}}{1-\delta^{1}}$, because the incremental separator count is over a smaller count of survivors there). Both groups will have, on average, indistinguishable separation rates if all control jobs dissolve (100\% separation rate) or if the initial REBP treatment effect is zero, so that no marginal matches were destroyed. In that sense, the design has power if the initial treatment effect during REBP is large - shifting the kink far to the right and away from zero on the x-axis - and if $\Delta^{0}$ is smaller than one.

In summary, the predicted $\Delta^{1}$ of the formerly treated survivors can be written as a piece-wise linear function of $\Delta^{0}$ with slopes and kink positions given by $\left(\delta^{0}, \delta^{1}\right)$ :

$$
\Delta^{1}\left(\Delta^{0}\left(\varepsilon^{\prime \prime}\right), \delta^{0}, \delta^{1}\right)=\max \left\{0, \frac{1-\delta^{0}}{1-\delta^{1}}\left[\Delta^{0}\left(\varepsilon^{\prime \prime}\right)-\frac{\delta^{1}-\delta^{0}}{1-\delta^{0}}\right]\right\} .
$$

This is the function plotted as the solid line in Figure 4 Panel (b).

We use this structural equation to benchmark the actual post-repeal separation rates in the formerly treated group against the model prediction given by Equation (7). This comparison constitutes our revealed-preference test, which does not rely on observable characteristics, and is light on distributional assumptions (see Section 6.3). The test relies on an empirical setting covering the introduction and then sharp repeal of a negative surplus shock that indeed leads to large separations in the affected treatment group compared to an unaffected control group.

This revealed-preference test is the key contribution of our paper. 
Preview of Alternatives To rationalize comovement, we discuss two chief extensions in the later parts of the paper. First, here we implicitly considered the case immediately following the repeal of REBP. As time progresses after the repeal, reshuffling of idiosyncratic surplus may weaken this prediction by somewhat "filling" the hole again (although our framework already allows for such idiosyncratic shocks to have hit during REBP). We permit such idiosyncratic shocks in Section 6. Second, we consider departures from efficient bargaining in Section 7, specifically wage rigidity, which provides an alternative framework that can rationalize our empirical findings.

\section{Large Separation Effects of the UI Benefit Extension}

In this section, we estimate that the differential benefit extension (from 52 to 209 weeks increased job separations among eligible workers by 10.9ppt (compared to a baseline separation rate of $40.5 \%$ in the peer cohorts in the control region) among initial matches over the five year program horizon. Interpreted through the lens of our Coasean model, our estimates imply that $\frac{\delta^{1}-\delta^{0}}{1-\delta^{0}}=\frac{0.109}{1.0-0.405}=18 \%$ of surviving matches in the control group are marginal low-surplus matches that would not have survived the extension.

Our analysis uses the sharp region and cohort variation in a difference-in-differences design, comparing treated cohorts in REBP regions to their ineligible slightly younger peers in the same region and contrasting this difference with the analogous one in the control regions. Most of the excess separations went into long-term nonemployment, perhaps followed by early retirement, rather than to employment with other firms. We next present visual evidence of raw data and assess the parallel trends assumption before turning to regression estimates.

Plotting Raw Data: Cohort Gradients of Separations We sort the population of job holders in 1988 (the onset of the reform) by month-of-birth cohorts and by REBP and non-REBP regions, and then plot outcomes in Figures 5 and 6 . Each figure presents levels for each cohort by region, and the within-cohort, between-region difference.

Younger cohorts born after 1943 turned 50 after REBP was repealed in 1993 and therefore could never claim extended benefits under the program. Older cohorts born before 1933, while eligible for extended benefits, were older than 55 at the time REBP was initiated in 1988 and, at that age, also had access to more generous disability/early retirement benefits with relaxed entry conditions, as described in Section 2 . For completeness, we

\footnotetext{
${ }^{15}$ Both groups had at most 30 weeks PBD in 1988, but a national reform in 1989 increased that level to 52 weeks, leading us to choose this benchmark given the program duration through 1993.
} 
plot these cohorts but exclude them in subsequent regression samples. Moreover, they had reached the retirement age of 60 before the repeal in 1993 in both regions. The intermediate cohorts, born between 1933 and 1943, were exposed to the reform in REBP regions. Exposure was maximal for the cohort born in 1938, who turned 50 at the onset of the reform in 1988 and was eligible in 1993, when the 1938 cohort turned 55.

In Figure 5 Panel (a) we plot raw data of the cohort-region share that separates from the 1988 job (worker-establishment match) by 1993q3, the first quarter after REBP had been repealed. The red dashed and blue solid lines refer to the REBP and control regions respectively; Panel (b) shows the cross-regional difference by cohort. The figure reveals a baseline cohort gradient in the control regions for the 1943 cohort and older, but flat for younger cohorts (born after 1943).

We start our analysis of REBP on separations from the right, with the ineligible young control cohorts born after 1943. These exhibit a separation rate of roughly 40 percent in both regions, and differences between REBP and control regions are flat (in fact close to zero). The parallel trends among younger cohorts provide support for the identification assumptions of our difference-in-differences design, as cohort trends (and even levels) of separations were similar across the regions. Appendix Figure A.5 confirms this overlap of the trends among even younger cohorts.

For potentially eligible cohorts born between 1933 and 1943, separations are markedly higher in REBP regions than in the non-REBP regions. This vertical difference represents the treatment effect of REBP and is about 20 percentage points at its peak. Finally, a slight treatment effect emerges even on the very old workers born before 1933, who, regardless of region, had mostly retired by 1993 anyway.

By comparing slightly older and younger cohorts within the same region, we net out any differences between regions that are constant across cohorts (including market-level effects of the program). Potential remaining confounders are shocks or unobservables varying at the region-by-age level. For instance, pathways to retirement could differ between regions as a consequence of different industry structures. To address this concern, we switch to separations during a fixed age window, 50 to 55, rather than between time periods (years 1988 to 1993) 16 Panels (a) (levels) and (b) (differences) in Figure 6 show a similar treatment effect and support of the parallel trends assumption for this separation definition. By construction, this figure also eliminates the age trends.

Finally, Figure 6 plots quarters nonemployed (Panels (c) and (d)) and unemployed (UI/UA benefit receipt) (Panels (e) and (f)) between 1988q2 and 1993q3, mirroring Figure

\footnotetext{
${ }^{16}$ We measure separations between the quarter before 50 (REBP eligibility), and the quarter before 55 (when disability and early retirement incentives change).
} 
5. Trends in control cohorts again lie on top of each other for the two regions. Among the eligible cohorts, a treatment effect of nonemployment and unemployment opens up. Similar results emerge for the 50-55 age horizon, in Appendix Figure A.6.

Regression Estimates of Treatment Effect Reporting results in Table 2, we now estimate the average treatment effect in a difference-in-differences regression specification in the population of pre-reform, 1988 job holders, for various outcomes $D_{r c i}$, for worker $i$ in region $r$ in birth cohort $c$ :

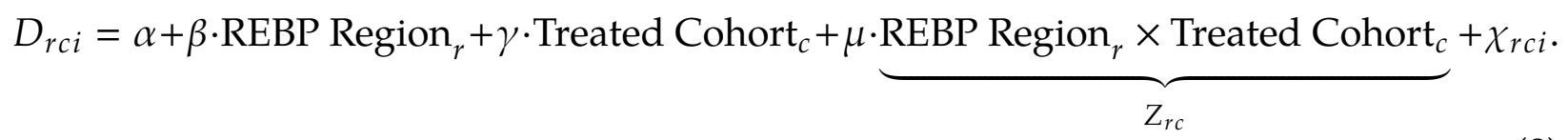

The coefficient of interest $\mu$ captures the effect of REBP eligibility $Z_{r c}$, defined by region and birth cohort. Interpreted through the lens of the model, $\mu$ captures the (subsequently, postrepeal missing) mass of marginal matches, $\delta_{1}-\delta_{0}$. We set $Z_{r c}=1$ for workers in the REBP region born before August 1943, so that they were older than 50 at some point during REBP (and zero otherwise, for our control groups). Here and in subsequent regression analyses, we exclude workers born before August 1933 because an overwhelming majority had retired by August 1993 anyway. The model includes baseline effects for REBP region and eligible cohort. Our regression specification thus exploits within-region, within-cohort variation. 17 We cluster standard errors at the level of administrative regions (groups of districts, Arbeitsamtsbezirke) but have also assessed robustness for clustering at other levels. Table 2 reports results from the cohort-based design (1998-93 outcomes); we report the age-based estimates (50-55) in Appendix Table A.3, finding similar results. We keep the young control cohorts to a five-year range. We also assess outcomes for even younger cohorts, which we discuss in our analysis of spillovers in Section 6.3 .

Table 2 column (1) reports a treatment effect of 10.9ppt on separations by 1993q3 from the 1988q2 employer. This effect represents a $27 \%$ increase from a counterfactual separation share of $40.5 \%$ in the absence of REBP (regression constant plus the baseline effects for treatment region and old cohorts). The 95\% confidence interval for the separation effect ranges from 2.9 to 18.9 ppt. In turn, our estimates imply that $\frac{\delta^{1}-\delta^{0}}{1-\delta^{0}}=\frac{0.109}{1.0-0.405}=18 \%$ of surviving matches in the control group are marginal, low-surplus matches that would not have survived the benefit extension.

We also decompose separations into persistent nonemployment (i.e. those without

\footnotetext{
${ }^{17}$ We shied away from a triple-diff specification with a placebo reform in 1978 since the long program duration would require long lags for a placebo reform analysis, and additionally the post-repeal analysis.
} 
employment at another employer between 1988 and 1993) and the complement. REBPinduced separations are entirely made up of the former. In column (2), we report a sizable increase in nonemployment separations of 12.0ppt (SE 4.3ppt). Column (3) of Table 2 reports effects on quarters nonemployed between 1988 and 1993, finding a positive effect of 1.46 quarters (SE 0.38). Column (4) reports that quarters unemployed (UI/UA receipt) increased by 0.95 quarters (SE 0.53). Column (5) shows that a large share of the increase in nonemployment can be accounted for by a reduction of 1.05 quarters (SE 0.37) in continuous employment with the initial employer.

\section{Puzzle to Coase: No Resilience After the Repeal}

We now exploit the sudden repeal of the reform in August 1993 (described in Section 2) to study whether REBP survivors - jobs that existed before the onset of the reform in 1988 and continued through its repeal in 1993 - subsequently exhibited lower separation rates unconditionally and in response to negative labor demand shifts.

Recall that the missing mass of low-surplus jobs in the former treatment group is large in the data: by the end of REBP, the eligible older cohorts in the REBP region shed 10.9ppt of workers from their ranks. Among older cohorts in the control group, who had a $40.5 \%$ separation rate, these marginal, low-surplus jobs still comprise $\frac{0.109}{1.0-0.405}=18 \%$ of active jobs. As a result, our test of the Coasean hypothesis in the form of post-repeal resilience has power, as we should see few separations in the previously treated group as long as the control group separation rates remain below $18 \%$.

Yet we find in the data that, after the reform was repealed, the survivors in the dramatically shrunk former treatment group exhibited exactly the same separation behavior as the control group - on average, and in response to labor demand shifts. Together, the large quantity of REBP-induced separations before 1993, and the zero differential postrepeal behavior, are inconsistent with the core prediction of resilience from our Coasean benchmark. We dedicate the rest of the paper to understanding this result.

\subsection{Empirical Post-Repeal Separation Behavior}

We study post-repeal separation behavior as our core test of the Coasean prediction that extraction of marginal jobs from the treatment group will lead to post-repeal resilience, compared to the former group control group, where the marginal matches are still present.

Our sample consists of "REBP survivors" in the former treatment and control regions: jobs already active right before the onset of REBP in 1988 that continued through its repeal 
in 1993. In practice, we allow for REBP spillovers over time due to layoff notices and explicit grandfathering that the law permitted for pre-scheduled layoffs (see Section 2), so we focus on jobs that survived through the first quarter of 1994 for the post-repeal analysis and our cutoff defining the survivor sample is 1994q1. Barring this sample restriction, the figures mirror the structure of Figures 5 and 6 . We explore the fraction of REBP survivors subsequently separating at various horizons.

Plotting Raw Data: Post-Repeal Separation Rate Gradients by Cohort In Figures 7 (1994-96 horizon) and 8 (other horizons) we plot the post-repeal separation cohort gradient among the surviving jobs, for the former control region (blue solid line) and the former treatment region (red short-dashed line). Panel (a) [(a), (c), (e) in Figure 8] shows levels, while Panel (b) [(b), (d), (f)] shows differences between regions. These raw data convey nonparametric evidence for our main finding, the absence of resilience. There are no post-repeal separation differences among surviving jobs previously exposed to REBP, compared to control cohorts, despite its large initial separation effects.

Quantifying the Differences in Separation Behavior Figure 7 also reports the average difference-in-differences estimate for the effect on post-separation behavior analogous to specification (8) for the survivor sample. Quantitatively, we find a 0.6ppt (SE 0.9ppt) estimate, indicating that the former treatment group, if anything, had a slightly higher separation rate in the post-repeal period rather than exhibiting resilience. The tight confidence intervals include zero and allow us to rule out effects smaller than $-1.2 \mathrm{ppt}$. We report the full estimation result in Table 3 , column (1), along with the other outcomes from the initial treatment effect Table 218

\subsection{Coasean Benchmark for Post-Repeal Separations}

Predicted Separation Rates By Cohort To gauge the gap between the former treatment group's post-repeal separations in the data and the Coasean prediction, we compute the predicted separations following a strictly interpreted Coasean view with full post-repeal persistence in idiosyncratic job surplus as presented in Equation (7). Specifically, for each (monthly) cohort $c$, we collect during-REBP separation rates in the control and REBP

\footnotetext{
${ }^{18}$ Table 3 reports on 1994-1996; Appendix Tables A.4 A.6 report on the other horizons. We also report a version dropping workers close to the retirement age, in Appendix Table A.7. In Table 3, we find similar effects on the separation-into-nonemployment margin in column (2). In columns (3) through (5), we consider more continuous measures of time in nonemployment, time on unemployment benefits or assistance, and continuous employment with the original employer. Across all margins, we detect no resilience and the point estimates are small with tight confidence intervals.
} 
regions to proxy for $\left(\delta_{c}^{0}, \delta_{c}^{1}\right)$ (the blue solid and red dashed lines respectively in Figure 5 Panel (a)). We feed in post-repeal cohort-specific separation rates from the peer cohorts in the control group $\Delta_{c}^{0}$ (blue solid line in Figure 7 ).

In the cohort-based Figure 7, we include these predicted Coasean separation rates as a yellow dashed line. Intuitively, the Coasean model predicts smaller separation effects in the formerly treated group post-repeal for larger initial treatment effects of REBP on separations in a given cohort (in turn depicted in Figure 5 Panel (b)). This is because these cohorts feature a larger mass of marginal matches, and separations in these formerly treated cohorts pick up only once the counterfactual - proxied by the peer cohort in the control region - exceeds the initial treatment effect.

The gap between the Coasean prediction and the observed separation rates in the control group is quantitatively large, confirming that our test has power. For instance, by 1996 (Figure 7(a)), the benchmark model would predict close to zero separations in the formerly treated group for the majority of formerly treated cohorts, whereas the control group's actual post-repeal separation rate is $20 \%$ or higher. Even multiple years later, the design retains power but the differences shrink (since $\Delta^{0}$ grows) as Figures 8(c) through (f) clarify. Yet, at those multi-year horizons such as from 1994 to 1998, the assumption of persistence in idiosyncratic job-level surplus may serve as a weaker approximation.

Quantitative Benchmark We also calculate the Coasean benchmark for the DiD regression coefficient. We aggregate the yellow predicted line across cohorts, weighing cells by their 1994 employment. The Coasean view would predict an average DiD separation effect of -12.5ppt. This predicted resilience is clearly outside of the confidence interval of the actual DiD estimate 0.6ppt (SE 0.9ppt) for the post-repeal separation rates.

\subsection{Labor Demand Shocks}

We now show that the absence of resilience persists even in response to negative aggregate shocks to job surplus (i.e. $\varepsilon^{\prime \prime}$ in our model), for which we construct empirical proxies in the form of negative industry and establishment labor demand shifts.

Heterogeneity by Industry Growth We plot the differential post-repeal separation rates separately for the top, middle and bottom tercile of the industry growth distribution from 1994 to 1996 in Figure 9 (a). Appendix Figure A.7 reports on the other horizons. Even in declining industries (bottom tercile), the formerly treated cohorts do not exhibit resilience compared to the control group. 
Establishment-Level “Hockey Sticks” We construct establishment labor demand shocks by tracing out "hockey stick" graphs (Davis, Faberman, and Haltiwanger, 2013): separation rates sharply increase when firms shrink (largely driven by layoffs), feature a kink around zero employment growth, and also grow slightly in growing firms (due to turnover associated with net hiring). We replicate these graphs in the full population data for Austria in Figure 9 Panel (b), where we plot establishment-level annual separation rates for all male employees employed in Q1, by bins of annual net employment growth.

Figure 9 Panel (c) plots cohort-region-specific separation rates through 1996 (other horizons in Appendix Figure A.7). The Coasean view would predict that separations occur by a pecking order following the ranking of job surplus within an establishment, so that, as a group compared to the control cohorts, the formerly treated program survivors would be less sensitive to negative surplus shocks proxied by establishment shrinkage. We estimate linear slopes separately for shrinking and growing establishments and for four separate groups: by birth cohort eligibility and region. The slopes for the former control and treatment workers essentially lie on top of each other. Hence, the massive extraction of marginal jobs does not seem to affect subsequent layoffs (or separators) at firms.

Lastly, in Figure 9 Panel (d) we report cohort-specific slopes of separations with respect to establishment employment growth. For each birth-year cohort and region cell, we regress an indicator for separating from 1994-96 on the worker's establishment's 199496 growth for shrinking establishments (other horizons in Appendix Figure A.7). Both regions exhibit a downward-sloping sensitivity gradient in birth date, indicating that older workers appear shielded. Yet, the lines lie on top of each other (if anything, the REBP lines appear slightly more sensitive).

\section{Can a Coasean Model Rationalize the Absence of Re- silience?}

We clarify that the Coasean setting can explain the absence of resilience only under narrow conditions: no persistence in job-level surplus whatsoever. We find that in order to account for our empirical results, nearly all labor market cells of our sample must exhibit this feature. We review and dismiss several other alternative Coasean model variants.

\subsection{Coasean Reconciliation: No Persistence in Job Surplus}

While our Coasean model accommodated idiosyncratic surplus shocks during the program period, our Coasean prediction for the post-repeal period drew on an assumption 
of persistence of surpluses. What types of alternative assumptions about surplus evolution would reconcile the observed similarity of post-repeal separation rates $\left(\Delta^{1}=\Delta^{0}\right)$, on average and across cells, with our Coasean model? The answer is that one would need to assume no persistence in job-level surplus (such that the idiosyncratic Markov process reshuffles the position of jobs into the same, stationary surplus distribution in each period). This "reshuffling" of the surplus distribution of survivors would render inconsequential the extraction of marginal jobs during REBP, such that the former treatment and control groups fully reconverge already within a year after the repeal (in our 1995 specification), filling in the "hole" left by REBP. We relegate the formal derivations to Appendix B.

\subsection{Estimating a Mixed Model}

Neither a full-persistence nor the perfect-reshuffling setting will completely and accurately describe the labor market as a whole. To gauge the quantitative explanatory power of each extreme view, we present a simple structural estimation of a "mixed model" of the Coasean setting that asks which fraction of labor market cells must exhibit perfect reshuffling to rationalize the observed separation dynamics. That is, we essentially estimate the weight the data put on the 45 degree line or the kinked line in Figure 4 Panel (b).

Consider a labor market cell $i$ (for example, cohort or industry-occupation group) present in both regions. A given cell $i$ is either of the full reshuffling or the perfect persistence benchmark. We posit that share $\kappa$ is of the full-reshuffling type; share $1-\kappa$ is of the perfect-persistence type. (An alternative interpretation of our setup is that we permit a share $\kappa$ of matches within a cell to be of the full-reshuffling type and the remainder of the perfect-persistence type.) Perfect reshuffling implies $\Delta_{i}^{1}=\Delta_{i}^{0}$ while perfect persistence implies that $\Delta_{i}^{1}$ follows the piece-wise linear curve as predicted from Equation (7) (also depending on cell-specific truncation points given by policy-period separation rates $\left(\delta_{i}^{0}, \delta_{i}^{1}\right)$.). We estimate $\kappa$ in the following econometric model:

$$
\Delta_{i}^{1}=\kappa \times \underbrace{\Delta_{i}^{0}}_{\text {Coasean: Reshuffling }}+(1-\kappa) \times \underbrace{\max \left\{0, \frac{1-\delta_{i}^{0}}{1-\delta_{i}^{1}} \cdot \Delta_{i}^{0}-\frac{\delta_{i}^{1}-\delta_{i}^{0}}{1-\delta_{i}^{1}}\right\}}_{\text {Coasean: Persistence }}+v_{i} .
$$

Error $v_{i}$ captures region-cohort-specific shocks and other model misspecification.

Our main strategy estimates model (9) at the birth-year cohort cell level. We take quarterly data points from the cohort separation gradients in Figure 7 of the predicted Coasean (persistence) benchmark, along with the original realized post-repeal separation rates by cohort for the treatment and control groups. Intuitively, the data selects weights on 
the yellow dashed line (perfect persistence) versus the blue solid line (perfect reshuffling). Here, we estimate coefficients $\hat{\alpha}^{\kappa}$ as estimate for $\kappa$ and $\hat{\alpha}^{1-\kappa}$ as estimate for $1-\kappa$ (and do not constrain coefficients to add to one).

Table 4 reports the estimates for various horizons after the repeal of REBP. For the short run, 1995, the estimates imply an essential unit weight on the perfect reshuffling scenario as $\alpha^{\kappa}=1.027$ (SE 0.034) and an insignificantly different from zero, small negative weight on the perfect persistence scenario $\alpha^{1-\kappa}=-0.037$ (SE 0.035). In later years, when the power of the resilience prediction likely decreases, the estimate of weight $\alpha^{1-\kappa}$ becomes more negative and even statistically significant. That is, if we were in a Coasean world, we would fully reject any persistence of job surplus whatsoever, even in the short run. The lower limit of the $95 \%$ confidence interval for $\kappa$ is 0.96 at the 1995 horizon (and even higher for longer horizons), indicating that at least $96 \%$ of separations had to come from full reshuffling of job surplus for the data to be consistent with a Coasean setting.

In Appendix E, we confirm these results from the simple cohort-based design in a richer model with (i) variation at the industry-by-occupation level, (ii) constraining $\alpha^{\kappa}+\alpha^{1-\kappa}=1$, and (iii) estimation with non-linear GMM. There, in our most conservative specification, the lower limit of the $95 \%$ confidence interval for $\kappa$ is 0.890 .

\subsection{Alternative Coasean Explanations}

Here, we discuss and dismiss several potential alternative mechanisms that could prima facie rationalize our findings under a Coasean framework.

Some Persistence in Idiosyncratic Job Surplus The model and its estimation above have clarified that the Coasean model can only rationalize the evidence under a narrow and strong assumption: with no persistence whatsoever in job-level surplus. We believe that this assumption is unlikely to explain our results. First, such full convergence would be required already at the one-year horizon. Second, the reform was large such that the idiosyncratic shocks would need to be accordingly large to replenish the mass of marginal matches: REBP increased separations by about $27 \%$; and as discussed above, REBP amounted to around $71 \%$ of the average worker's annual salary. Third, our sample contains older workers with high labor force attachment, whose baseline turnover is typically low, perhaps suggesting, if anything, higher persistence of surplus. Fourth, we reiterate that our Coasean prediction permits arbitrary idiosyncratic shocks during the five-year policy period (and only for the short-run window right after the appeal does the simple benchmark appeal to persistence). 
Market-Level and Firm-Level Spillovers on Control Workers A potential concern is that, for instance through spillovers, REBP also affected separation-relevant factors (surplus distribution or the shock processes) of the control group in the treated region during and after REBP. Importantly, our difference-in-differences design eliminates the wide class of factors that would affect both groups equally, namely by studying within-region differences between treatment and control cohorts.

The remaining mechanisms that would pose a problem for our design would be differential and persistent indirect effects on separation-relevant factors on the control cohorts in the REBP region, compared to the treatment cohorts and their control region counterparts. For instance, firms could have shifted training to younger workers in the REBP regions, lowering their post-repeal separation rate, leading us to underestimate relative resilience among the formerly treated cohorts.

We present two pieces of evidence against the concern that spillovers on younger workers in the treatment region might mask resilience among treated older workers. First, such spillovers are not indicated by our second difference, between young control groups across regions, in Figure 5 and 7 . The corresponding coefficients on the REBP region indicator in column (1) of Tables 2 and 3 are essentially zero (0.003 and -0.003), although this test implicitly assumes no other differences between regions absent the reform and related spillovers. Thus, to further probe potential spillovers on our slightly younger control group, Appendix Figure A.5 confirms this result with essentially a third difference for substantially younger control cohorts through 1958 (which are arguably less close substitutes in production or search in other markets, and hence less prone to certain spillovers, as in Card and Lemieux, 2001; Lalive, Landais, and Zweimüller, 2015), for which we also find zero differences between regions.

Second, we provide an employer-level test of spillovers. Since such spillovers (retraining or diminishing products) may occur primarily within industries or firms, we construct industry- or firm-level treatment intensity measures, specifically the share of workers in program-eligible cohorts (1933-43) pre-reform (1987). We then divide our worker sample into four quartiles of this exposure measure. The kind of spillovers that would dilute our younger control group would appear as lower post-repeal separation rates in the top quartile. In Appendix Figure A.8, we plot the differences between treatment and control regions in post-repeal separation behavior by cohort for top (dashed black line) and bottom (solid blue line) quartiles, for firms (Panel (a)) and industries (Panel (b)). The graph shows no increased resilience among the younger control group workers in the most heavily treated industries or firms, and neither among the slightly older treated cohorts. 
Heterogeneous Sensitivity to the REBP Treatment Our model assumes homogeneous shifts in outside options and, thus, in the level of surplus - such that the jobs marginal to REBP are low-surplus jobs. Yet there could exist jobs whose surplus is treatmentsensitive for a variety of reasons (e.g., due to heterogeneous valuation of the extension). If, specifically, REBP-induced separations have (initially, and, absent the treatment) higher surplus, then the program would have removed high-surplus workers. In principle, such a positive correlation between surplus valuation $\varepsilon_{b}^{W \prime}$ and gross-of-REBP surplus $\widetilde{S}$ could rationalize our findings even in a Coasean world with persistent surplus.

We empirically assess the broadest possible version of this concern: that the incremental separators would, absent REBP, have had a higher separation rate. We use complier analysis methods to characterize the marginal jobs destroyed by REBP with regards to separation-relevant attributes 19 In a first step, we estimate a model regressing realized separations on pre-separation attributes in a separate, pre-reform sample. Second, using the estimated coefficients we predict the probability of separating in the sample of workers employed in 1988 and create a predicted separation score. Third, we study the predicted separation rates in the sample of actual separators in the treatment and control region. Appendix Table A.8 presents the full results, and its note details the prediction model.

Reassuringly, we find that these compliers (i.e. marginal jobs) had higher predicted separation rates $(0.67, \mathrm{SE} 0.098)$ compared to the treatment region survivors $(0.33, \mathrm{SE}$ 0.078). In turn, the predicted separation rate of the treatment group survivors is lower than that of the control group survivors (0.37, SE 0.080), a small, insignificant negative difference that, if anything, points in the opposite direction of the concern.

Homogeneity Our test relies on surplus heterogeneity within the treatment/control groups, such that the separations leave behind a hole of low-surplus jobs. Conversely, complete homogeneity of surplus absent REBP could, in principle, rationalize our findings in a Coasean setting. In this case, REBP lowers surplus among the treated group and leads to separations, but absent REBP and after the repeal, all cohorts will have homogeneous surplus again, leaving no room for resilience. (Here, baseline separations may occur through i.i.d. shocks.) Crucially, our framework applies as long as there is some heterogeneity within each age group. In light of a vast body of evidence on, for example, large dispersion of separation rates between firms and worker types and our evidence above that predicted separation rates differ between compliers and non-separators, we find the case of perfect homogeneity of little empirical relevance and hence not a plausible

\footnotetext{
${ }^{19}$ The longer NBER working paper version of the paper (Jäger, Schoefer, and Zweimüller. 2019) provides the methodology of extending complier analysis to difference-in-differences settings such as ours.
} 
candidate to reconcile the evidence with a Coasean framework.

Large Firms and Perfect Substitutes As a related alternative, we discuss a large-firm model with homogeneous workers (e.g., by types broader than age) and decreasing marginal products, in which old and young workers are perfect substitutes. Here, separations could occur because of firm-wide shocks to, e.g., productivity, which change the optimal employment levels. REBP-eligible workers optimally separate first, shielding the young control group during REBP. But absent heterogeneity, the repeal of REBP restores the homogeneity of surplus, such that no post-repeal resilience emerges (as in the hockey sticks in Figure 9 Panel (c)), even through a Coasean lens. We do not find empirical evidence for the predicted shielding in the spillover tests on average and by firm-level treatment intensity discussed above, plausibly because there is considerable heterogeneity in surplus within the treatment and control cohorts.

Severance Payments In Appendix F, we recap that the presence of severance payments is neutral in a Coasean setting. Moreover, we show that the Coasean wage dynamics required to neutralize the actual institutional tenure-severance pay schedule in Austria could be easily offset in small shifts in the wage-tenure gradient.

\section{A Non-Coasean Model With Wage Rigidity}

An alternative interpretation of the absence of resilience is that the separations were not Coasean, due to frictions that prevent the efficient (re-)bargaining. Consequently, we develop and discuss a non-Coasean model with wage rigidity that can rationalize our findings. Section 8 provides direct empirical support for wage rigidity as the driver of the inefficient separations we have documented.

\subsection{Model}

A non-Coasean model with fixed wages can rationalize the empirically documented similarity of the post-repeal separation rates even with persistence in idiosyncratic surplus, if post-repeal separations are largely due to firm surplus shocks. We present the core features of the model here and relegate the full derivations to Appendix C.

Fixed Wages The strong Coasean result of efficient separations arises from the assumption of flexible (re-)bargaining of compensation, from which joint job surplus stems as the 
sole allocative concept. Wage rigidity precludes exactly this step. Intuitively, in Figure 2. wage rigidity prevents the parties from moving towards a wage in the feasible-jobs frontier even though the job carries positive joint surplus, thereby shrinking the set of feasible jobs to the upper right quadrant.

Separations Separations occur if at least one of worker surplus or firm surplus turns negative at the given wage, and due to fixed wages the parties do not move beyond the two-dimensional participation constraints given in Equations (1) and (2). Hence, inefficient separations - i.e. of jobs with positive joint surplus - can emerge. In this non-Coasean setting, we therefore think of wage $w$ as one additional job attribute that can evolve or be fixed, such that jobs are now characterized by $(w, \mathbf{V})$. Besides unilateral worker and firm surpluses net of the (fixed) wage and net of the surplus shifter $S^{W}\left(w, \mathbf{V}^{W}, \varepsilon^{W \prime}\right)$ and $S^{F}\left(w, \mathbf{V}^{F}, \varepsilon^{F \prime}\right)$, we also define unilateral surpluses gross of the aggregate shifters (which we now cannot simply sum into joint-surplus shifters) as $\widetilde{S}^{W}\left(w, \mathbf{V}^{W}\right)$ and $\widetilde{S}^{F}\left(w, \mathbf{V}^{F}\right)$. Formally, the job-level separation probability is given by:

$$
\widetilde{\mathbb{d}}\left(w, \mathbf{V} ; \varepsilon^{W^{\prime}}, \varepsilon^{F^{\prime}}\right)=\int_{\left(w^{\prime}, \mathbf{V}^{\prime}\right)} \mathbb{1}(\underbrace{\widetilde{S}^{W}\left(w^{\prime}, \mathbf{V}^{W \prime}\right)<\varepsilon^{W}}_{\text {Quit }} \overbrace{\mathbf{V}}^{\text {Mutual Sep: } \wedge} \underbrace{\widetilde{S}^{F}\left(w^{\prime}, \mathbf{V}^{F \prime}\right)<\varepsilon^{F \prime}}_{\text {Layoff }}) k\left(\left(w^{\prime}, \mathbf{V}^{\prime}\right) \mid(w, \mathbf{V})\right) d\left(w^{\prime}, \mathbf{V}^{\prime}\right),
$$

where separations can be labeled as quits (negative worker surplus but positive firm surplus), layoffs (reversed), or mutual separations (both negative). The non-Coasean expression also formalizes that here the initial incidence of a shock matters for separations for lack of automatic Coasean rebargaining, such that worker and firm values are not "fungible", and we must separately track $\varepsilon^{W \prime}$ and $\varepsilon^{F \prime}$. Analogously to the Coasean case, group level separation rates are $\delta=\int_{(w, \mathbf{V})} \widetilde{\mathbb{d}}\left(w, \mathbf{V} ; \varepsilon^{W^{\prime}}, \varepsilon^{F \prime}\right) f(w, \mathbf{V}) d(w, \mathbf{V})$.

REBP Effects in a Non-Coasean Setting We now provide a narrative of REBP and its aftermath in the non-Coasean setting. We largely rely on intuitive graphs in Figure 3 (which assume perfect persistence in job-level surpluses after - but not necessarily during - REBP), and relegate the formal derivations of the full model (permitting evolution of idiosyncratic job surplus post-repeal) into Appendix C.

In the non-Coasean model, the participation constraints remain two-dimensional and cannot be collapsed into joint surplus, as in the left panels of Figure 3 . Instead, we illustrate the logic of the model by plotting example contour maps of the joint distribution 
of firm (y-axis) and worker (x-axis) net of wage and shifter surpluses $S^{W}\left(w, \mathbf{V}^{F}, \varepsilon^{F^{\prime}}\right)$ and $S^{W}\left(w, \mathbf{V}^{W}, \varepsilon^{W}\right)$. We do so in the right panels of Figure 3. Here, the participation constraints are given by the $y$-axis and $x$-axis. Figure 3 Panel (c) illustrates that REBP improved worker's outside option (i.e. lowered worker surplus), so the treated jobs shift left.

For comparison, we also plot the Coasean analogues of the contour maps of grossof-wage surpluses in the middle panels of Figure 3, generalizing the one-dimensional distribution from the left panels of Figure 3. In the Coasean setting, separations occur only for jobs that fall below the zero-joint-surplus diagonal.

Post-Repeal (Non-)Resilience After the repeal of REBP, Figure 3 Panel (f) depicts the former treatment group at the original position but with a missing mass of matches with low worker surplus (but not necessarily low firm surplus) compared to the control group, depicted in Panel (i). Formally, this gray set of marginal matches is defined by $\left\{\left(w^{\prime}, \mathbf{V}^{\prime}\right): 0 \leq \widetilde{S}^{W}\left(w^{\prime}, \mathbf{V}^{W \prime}\right)<\varepsilon_{b}^{W \prime} \wedge \widetilde{S}^{F}\left(w^{\prime}, \mathbf{V}^{F \prime}\right) \geq 0\right\}$.

As in the Coasean case, the post-repeal separation behavior of the former treatment group tracks that of the former control group, except for the contribution of the marginal jobs. But in the non-Coasean case, these marginal jobs feature low worker surplus - the dimension along which REBP selects them into separation. Thus, resilience need not arise to firm surplus shocks. That is, unlike in the Coasean case, the initial incidence of shocks, on the worker or firm, is no longer fungible, and they can no longer be collapsed into joint surplus shock $\varepsilon^{\prime \prime}$. Below we consider worker and firm shocks separately for exposition.

For worker surplus shocks, resilience emerges. Figure 4 Panel (c) reflects this intuition and plots post-repeal separations in response to worker-surplus shifters. Resilience emerges as separations in the former treatment group are zero until the shock size crosses the truncation point of surplus, i.e. the REBP shock size. Starting then, the slope is steeper than in the control group. This resilience is analogous to the Coasean case in that REBP selected jobs by worker surplus. Formally, this line is the conditional CDF of worker surplus truncated at the REBP shock size. Panel (c) reflects that few workers are marginal to worker shocks in the control group, so separations only weakly respond to such shocks.

For firm shocks, separations start immediately, and can be very similar in both groups, as in Figure 4 Panel (d), because the former treatment group has retained jobs marginal to firm shocks. In the control group, separations are more responsive to firm than to worker shocks in Panel (c), reflecting low baseline firm surplus but high worker surplus. ${ }^{20}$ Absence of resilience can therefore arise even with perfect persistence in job surplus.

\footnotetext{
${ }^{20}$ Identical separation responses to firm shocks arise, for example, if worker and firm surpluses are independently distributed.
} 


\subsection{Reinterpreting the Mixed Model}

Combining the worker and firm shock cases in Figure 4 Panels (c) and (d), we can reconstruct a non-Coasean version of Panel (b), relating the groups' post-repeal separations. Analogously, we can reinterpret the same mixed model in Equation (9) within the nonCoasean framework as putting weight $\kappa$ on firm shocks driving post-repeal separations (leading to perfect comovement, i.e. the 45 degree line) and $1-\kappa$ on worker shocks driving post-repeal separations (leading to resilience, i.e. the kinked piece-wise linear function). ${ }^{21}$ While we cannot directly observe the worker vs. firm shocks, the estimated $\kappa$ of essentially one would point to a large share of post-repeal separations due to firm-side shocks.

\subsection{Discussion of the Non-Coasean Framework}

Which ingredients enable the non-Coasean model to rationalize the data?

High Initial Worker Surplus Strictly interpreted, our firm-shocks setting assumes that no aggregate worker shocks hit. A more realistic interpretation is that, in order for the sizable truncation along worker surplus to be quantitatively inconsequential for subsequent separation behavior, it must be that worker shocks are smaller than firm shocks compared to the baseline (no-REBP) surplus levels. The figure depicts a version of this property as worker surplus is far to the right.

High worker (but low firm) surplus is particularly plausible for our sample: older, high-tenured workers. In fact, this exact constellation is predicted by the long-standing hypotheses of implicit contract models, in the form of backloading of compensation over the job spell (Lazear, 1979, 1981): in a period-by-period consideration, young workers are "underpaid," while older workers are "overpaid." This backloading is supported by implicit contracts or formal institutions.22 Perhaps additionally supporting such implicit contracts (and also limiting the selectivity of layoffs, as in Bewley, 2002) is the Austrian institutional setting, which features an explicit consultation role for works councils in the separation process. Lastly, Austria mandates multiple months of severance payments in the case of layoffs or retirement, which are foregone for quitters, thus raising workers' inside value. We discuss the role of severance payments in Appendix $\mathrm{F}$

\footnotetext{
${ }^{21}$ Both interpretations assume persistence. (Full) reshuffling in the non-Coasean model would further load on the 45 degree line.

${ }^{22}$ While models of job ladders and negotiation capital such as Cahuc, Postel-Vinay, and Robin (2006) generate this joint distribution for high-tenured jobs, they feature efficient (re-)bargaining and separations.
} 
Large Worker Surplus Shift From REBP In the above scenario of initially high worker surplus, the boosts to worker outside option must be large to sweep up otherwise inframarginal workers. The exceptional size of the initial REBP UI treatment - three additional years of full UI eligibility, hence also serving as a bridge into early retirement - plausibly achieved this. In Appendix A, we benchmark that, for the average worker, the cash value is $71 \%$ of annual earnings. This view is consistent with the fact that in response to other UI shifts that were smaller in magnitude or apply to younger workers, there is little evidence for separation effects (as shown in Jäger et al., forthcoming, and often shown to support the identification assumption when studying unemployment duration effects).

\section{Limited Correlation Between Baseline Firm and Worker Surpluses In the non-Coasean} setting, the low-worker surplus jobs REBP extracted evidently were not marginal with respect to firm surplus. Such limited correlation can arise if firm and worker gross-of-wage fundamentals $\mathbf{V}^{F}$ and $\mathbf{V}^{W}$ are uncorrelated, or if net-of-wage surpluses are in an extreme case independently distributed, for example, due to wage frictions. ${ }^{23}$ (By contrast, in the Coasean setting, the correlation of the fundamentals is irrelevant due to rebargaining.) In Section 5 we documented evidence consistent with firm surplus not being correlated with the REBP selection along worker surplus, in light of non-resilience in response to proxies for industry- and firm-level labor demand shocks.

\section{Evidence for Wage Rigidity as Source of Non-Coasean Job Dynamics}

We close by providing evidence for wage rigidity as the source of the non-Coasean separation behavior. Our test investigates heterogeneity of separation behavior during and after the treatment, across cells of the labor market sorted by proxies of wage rigidity. We find that the cells with more wage rigidity, and hence less efficient renegotiation, experience higher initial treatment effects on separations. Accordingly, we continue to find no evidence for resilience in these high wage-rigidity cells despite the large previous separation effects. Turning to the flexible-wage cells substantiates our main interpretation. In fact, the heterogeneity in the initial REBP-induced separations across cells is so stark that the effect shrinks to zero in the flexible-wage cells - perhaps because of more efficient

${ }^{23}$ The non-Coasean model could even generate higher separations among the former treatment group in response to firm shocks, e.g., under a "random" wage triggering a negative correlation between worker and firm surplus: REBP quitters would then be particularly valuable to firms. In contrast, Figure 9 Panels (c) and (d) documents similar slopes for the treated group compared to, e.g., older cohorts in the control region. 
bargaining. As a consequence, these "more Coasean" cells are not predicted to exhibit resilience.

\subsection{Empirical Strategy}

Intuitively, if we could cleanly isolate rigid and flexible wage cells, we would partition the workers in our initial pre-reform sample in 1988 into the Coasean and non-Coasean regime. We approximate this design with proxies for the degree of wage rigidity.

For each rigidity proxy, we split firms into quartiles. We keep these quartiles (determined in 1988, i.e. pre-reform) fixed throughout the analysis period for each match. We can think of the bottom quartiles are being closer to the non-Coasean, rigid-wage world, and the upper quartiles as being closer to the Coasean benchmark.

We then study, within each quartile, first the initial treatment effect on separations. In this first step, we predict that wage rigidity proxies are associated with larger separation effects, because only worker (rather than joint) surplus needs to turn negative and wages are not renegotiated. Second, we study post-repeal resilience. In this second step, we predict that - conditional on a given initial treatment effect - the flexible-wage cells will exhibit more resilience and thus accord more closely with the Coasean model (whereas the rigid cells need not exhibit resilience).

\subsection{Proxies for Wage Rigidity}

The type of wage friction relevant for our sharply cohort-specific treatment would constrain firms' differentiation of wages between similar workers. Moreover, downward rigidity would not suffice, as the initial REBP treatment induces wage increases (but subsequent shocks may go either way). As a caveat, we stress that identifying allocative consequences of wage rigidity remains a notorious empirical challenge in the literature - motivating our strategy as we described in our introduction. We now introduce our proxies for wage rigidity. Further details on their construction are in Appendix $D$.

Within-Firm Standard Deviation of Log Wages For each firm, we take the panel of male workers from 1982 to 1987 and calculate the standard deviation of log wages by firm-year. Then, we average these observations across years to get a single observation per firm. This proxy reflects firms' revealed ability to differentiate wages between workers, e.g., slightly older and slightly younger ones. 
Within-Firm Standard Deviation of "Distance from CBA Cell Average" We construct a proxy of wage flexibility controlling for collective bargaining agreement (CBA) cell averages (as in Jäger et al., forthcoming). It mirrors the previous procedure, but we take residuals from a regression of winsorized log earnings on tenure-experience-occupationindustry-year fixed effects, with standard deviations calculated at the firm-year level ${ }^{24}$ We thereby also provide a composition adjustment of the raw wage dispersion measure above, capturing the wage differentiation between more similar workers.

Within-Firm Standard Deviation in Wage Growth Cross-sectional dispersion in wage levels may be partially driven by unobservables. We therefore also consider the within-firm standard deviations of worker-level changes in the two wage measures above, studying the five year horizon in the firm's pre-reform period. This measure may also more closely proxy firms' ability to adjust wages in response to worker- or worker-group-specific shocks such as REBP. We choose the five-year specification since that time window (i) corresponds to the duration at which we study the initial separation response to the REBP policy, (ii) imposes a tenure threshold somewhat similar to the bottom quartile for our sample, and (iii) captures longer-run shifts in wages perhaps less subject to year to year noise.25

Summary Statistics and Correlations Appendix Table A.9 presents, quartile by quartile, ranges and means of and correlations between the proxies. The four measures are positively correlated, so they capture some underlying similarities of the firms. But the correlations are far from perfect, with rank correlations as low as 0.33 .

\subsection{Empirical Results}

We show heterogeneity across quartiles of our four wage rigidity measures in Figure 10. for firm-level standard deviation of log wages (Panel (a)), their residuals (Panel (b)), changes of log wages (Panel (c)), and their residuals (Panel (d)). We show post-repeal separations through 1996; Appendix Figure A.9 presents the other horizons.

For the initial REBP separation effects (plotted in red circles), all panels reveal larger effects for cells with higher wage rigidity, consistent with our theoretical predictions.

${ }^{24}$ Tenure $n(i, t)$ is made up of 5 three-year categories and a category for those with more than 15 years of tenure. Experience $e(i, t)$ is made up of 5 five-year categories and a category for those with more than 25 years experience. (Importantly, neither we nor CBAs define wage groups based on age.) Occupation refers to white- vs. blue-collar.

${ }^{25}$ We have confirmed robustness to shorter horizons. At the shortest, one-year horizon, results turn noisier, perhaps due to, e.g., wage fluctuations of workers with short tenure dominating the variance or reflecting adjustment to shorter-lived shocks. 
Specifically, in the top quartile - with lowest wage rigidity i.e. closest to the flexible-wage setting - we find essentially a zero treatment effect from REBP. Hence, wage rigidity did mediate the initial REBP separation responses.

We plot post-repeal separations in hollow blue circles. The yellow dashed line represents each quartile's benchmark for post-repeal separations, calculated as an analogous difference-in-differences effect, as in Section 5.2 but within each rigidity quartile. It describes the Coasean benchmark for any shock or the non-Coasean one for worker shocks.

For the high-rigidity quartiles, we find essentially no resilience across wage rigidity proxies. The benchmarks are between $-30 \%$ and $-20 \%$ for the rigid-wage cells, due to the large initial treatment effect in these cells. Yet, the actual post-repeal separation DiD effect is close to zero. Interestingly, this point estimate is negative and statistically significant, but very small at around -0.025 (SE 0.009) in the rigid-wage cells.

For each proxy, the high-rigidity cells provide a resounding rejection of the predicted Coasean resilience of efficient separations. Instead, the post-repeal patterns for the highrigidity group is consistent with the non-Coasean, fixed-wage model we put forth, specifically if post-repeal separations are overwhelmingly driven by firm shocks rather than worker-sided shocks (some worker-driven separations may explain the small degree of resilience). A similar pattern emerges in the second group of wage rigidity, where initial treatment effects are smaller, hence the predicted resilience is weaker, but the point estimates for empirical post-repeal resilience effects fall to zero.

Importantly, we do not find resilience in the lowest-rigidity quartile either. But this absence of resilience is of a different nature than that in the rigid-wage cells: the flexiblewage cells did not have a treatment effect to begin with, perhaps exactly due to wage flexibility, and hence also have no missing mass after the repeal. Therefore, the flexiblewage group should not exhibit resilience according to the Coasean model, the prediction of which we plot in the yellow dashed line, which is zero for this group.

A potential worry might be that sorting firms by our wage rigidity proxies would also sort them by overall surplus, so that baseline separation rates would differ even absent any shock. To assess this concern, we also plot for each quartile the separation rate for the control group during the REBP period (hatched navy line). This gradient is flat, rather than steeply declining, limiting the relevance of this concern. This flat gradient perhaps again reflects that, aside from the tremendous shock induced by REBP, most separations in our sample of older workers are generally not driven by worker-side shocks.

Overall Assessment The heterogeneity analysis by wage rigidity of both the initial REBP introduction and the aftermath of its repeal provides evidence consistent with wage 
rigidity as a source of non-Coasean job dynamics. First, the REBP separations stem from rigid-wage pockets of the Austrian labor market, which in the aftermath of the repeal show no resilience. By contrast, the flexible-wage group turns out to not exhibit an initial separation effect to begin with, perhaps exactly due to wage flexibility - and hence did not have a missing mass. ${ }^{26}$ As a caveat, this investigation is limited by the difficulty of measuring wage rigidity on the basis of observables and flow wage behavior.

\section{Conclusion}

We have provided an empirical test of the Coasean theory of efficient separations. We overcame the challenge of the unobservability of job surplus by tracking a cohort of jobs through a transitory policy that led to separations, but then was repealed. In contradiction to the Coasean view, the survivors did not exhibit resilience to subsequent shocks. Our resilience test concerns the fungibility of surplus factors through efficient bargaining. It requires panel data and a transitory, sharply ending treatment lowering surplus. The strategy could be implemented beyond our setting and perhaps beyond the labor market. Our test adds a robust tool to a small empirical literature studying the efficiency of employment determination (Brown and Ashenfelter, 1986; Card, 1990; Bils, Chang, and Kim, 2012; Mui and Schoefer, 2020).

Wage rigidity emerges as the friction plausibly underlying the inefficient separations. Theoretically, the non-Coasean model with wage rigidity provides a parsimonious account of the full set of empirical results. Empirically, we find that the inefficient separation dynamics stemmed from high wage rigidity cells, supporting this interpretation.

We close by reiterating that the type of wage rigidity relevant to our treatment (a sharply age-specific boost to the worker outside option) is firms' ability to differentiate wages between similar workers. Such frictions may reflect broader forces than formal institutions, such as equity concerns, which appear present in a variety of institutional arrangements and countries (Card et al., 2012; Dube, Giuliano, and Leonard, 2019; Saez, Schoefer, and Seim, 2019; Drenik et al., 2020), and are inherent to models of wage posting and monopsony.

\footnotetext{
${ }^{26}$ As a complement to our wage rigidity proxies, Appendix Figure A.4 presents a more speculative heterogeneity analysis by industry, a tangible category. We do find larger REBP treatment effects - but no post-repeal resilience - in industries where wages may plausibly be more rigid, for example in manufacturing, than in industries such as finance or entertainment, where, e.g., due to performance pay, wages may be more flexible, as in Lemieux, MacLeod, and Parent (2012).
} 


\section{Bibliography}

Barro, Robert. 1977. “Long-Term Contracting, Sticky Prices, and Monetary Policy.” Journal of Monetary Economics 3 (3):305-316.

Becker, Gary, Elisabeth Landes, and Robert Michael. 1977. "An Economic Analysis of Marital Instability." Journal of Political Economy 85 (6):1141-1187.

Bewley, Truman. 2002. Why Wages Don't Fall during a Recession. Harvard University Press.

Bils, Mark, Yongsung Chang, and Sun-Bin Kim. 2012. "Comparative Advantage and Unemployment." Journal of Monetary Economics 59 (2):150-165.

Brown, James and Orley Ashenfelter. 1986. "Testing the Efficiency of Employment Contracts." Journal of Political Economy 94 (3, Part 2):S40-S87.

Cahuc, Pierre, Fabien Postel-Vinay, and Jean-Marc Robin. 2006. "Wage Bargaining with On-the-Job Search: Theory and Evidence." Econometrica 74 (2):323-64.

Card, David. 1990. "Unexpected Inflation, Real Wages, and Employment Determination in Union Contracts." American Economic Review 80 (4):669-88.

Card, David and Thomas Lemieux. 2001. "Can Falling Supply Explain the Rising Return to College for Younger Men? A Cohort-Based Analysis." Quarterly Journal of Economics 116 (2):705-746.

Card, David, Alexandre Mas, Enrico Moretti, and Emmanuel Saez. 2012. "Inequality at Work: The Effect of Peer Salaries on Job Satisfaction." American Economic Review 102 (6):2981-3003.

Davis, Steven, Jason Faberman, and John Haltiwanger. 2013. “The Establishment-Level Behavior of Vacancies and Hiring." Quarterly Journal of Economics 128 (2):581-622.

Dickens, William, Lorenz Goette, Erica Groshen, Steinar Holden, Julian Messina, Mark Schweitzer, Jarkko Turunen, and Melanie Ward. 2007. "How Wages Change: Micro Evidence from the International Wage Flexibility Project." Journal of Economic Perspectives (2):195-214.

Drenik, Andres, Simon Jäger, Pascuel Plotkin, and Benjamin Schoefer. 2020. "Paying Outsourced Labor: Direct Evidence from Linked Temp Agency-Worker-Client Data." NBER Working Paper No. w26891. 
Dube, Arindrajit, Laura Giuliano, and Jonathan Leonard. 2019. "Fairness and Frictions: The Impact of Unequal Raises on Quit Behavior." American Economic Review 109 (2):62063.

Elsby, Michael and Gary Solon. 2019. "How Prevalent Is Downward Rigidity in Nominal Wages? International Evidence from Payroll Records and Pay Slips." Journal of Economic Perspectives 33 (3):185-201.

Fink, Martina, Esther Kalkbrenner, Andrea Weber, and Christine Zulehner. 2010. "Extracting Firm Information from Administrative Records: The ASSD Firm Panel." Austrian Center for Labor Economics and the Analysis of the Welfare State Working Paper No. 1004.

Frimmel, Wolfgang, Thomas Horvath, Mario Schnalzenberger, and Rudolf Winter-Ebmer. 2018. "Seniority Wages and the Role of Firms in Retirement." Journal of Public Economics 164:19-32.

Hall, Robert and Edward Lazear. 1984. "The Excess Sensitivity of Layoffs and Quits to Demand." Journal of Labor Economics 2 (2):233-257.

Hall, Robert and Paul Milgrom. 2008. "The Limited Influence of Unemployment on the Wage Bargain." American Economic Review 98 (4):1653-74.

Hall, Robert E. 2005. "Employment Fluctuations with Equilibrium Wage Stickiness." American Economic Review 95 (1):50-65.

Inderbitzin, Lukas, Stefan Staubli, and Josef Zweimüller. 2016. “Extended Unemployment Benefits and Early Retirement: Program Complementarity and Program Substitution." American Economic Journal: Economic Policy 8 (1):253-288.

Jäger, Simon, Benjamin Schoefer, Samuel Young, and Josef Zweimüller. forthcoming. "Wages and the Value of Nonemployment." Quarterly Journal of Economics .

Jäger, Simon, Benjamin Schoefer, and Josef Zweimüller. 2019. "Marginal Jobs and Job Surplus: A Test of the Efficiency of Separations." NBER Working Paper No. 25492.

Lalive, Rafael, Camille Landais, and Josef Zweimüller. 2015. "Market Externalities of Large Unemployment Insurance Extension Programs." American Economic Review 105 (12):3564-3596.

Lazear, Edward. 1979. "Why Is there Mandatory Retirement?" Journal of Political Economy 87 (6):1261-1284. 
_. 1981. "Agency, Earnings Profiles, Productivity, and Hours Restrictions." American Economic Review 71 (4):606-620.

Lemieux, Thomas, Bentley MacLeod, and Daniel Parent. 2012. "Contract Form, Wage Flexibility, and Employment." American Economic Review 102 (3):526-31.

Leoni, Thomas and Wolfgang Pollan. 2011. "Lohnentwicklung und Lohnunterschiede in der Industrie seit 2000." WIFO Monatsberichte, WIFO October .

MacLeod, Bentley and James Malcomson. 1993. "Investments, Holdup, and the Form of Market Contracts." American Economic Review 83 (4):811-837.

McLaughlin, Kenneth. 1991. "A Theory of Quits and Layoffs with Efficient Turnover." Journal of Political Economy 99 (1):1-29.

Mui, Preston and Benjamin Schoefer. 2020. "Reservation Raises: The Aggregate Labor Supply Curve at the Extensive Margin." CEPR Discussion Paper No. DP14209 .

Saez, Emmanuel, Benjamin Schoefer, and David Seim. 2019. "Payroll Taxes, Firm Behavior, and Rent Sharing: Evidence from a Young Workers' Tax Cut in Sweden." American Economic Review 109 (5):1717-63.

Staubli, Stefan. 2011. “The Impact of Stricter Criteria for Disability Insurance on Labor Force Participation." Journal of Public Economics 95 (9-10):1223-1235.

Winter-Ebmer, Rudolf. 2003. "Benefit Duration and Unemployment Entry: A QuasiExperiment in Austria." European Economic Review 47 (2):259-273.

Zweimüller, Josef, Rudolf Winter-Ebmer, Rafael Lalive, Andreas Kuhn, Jean-Philippe Wuellrich, Oliver Ruf, and Simon Buchi. 2009. "Austrian Social Security Database." Austrian Center for Labor Economics and the Analysis of the Welfare State Working Paper No. 0903. 


\section{Tables}

Table 1: Summary Statistics

\begin{tabular}{lcccc}
\hline \hline & \multicolumn{2}{c}{ Treatment Region } & \multicolumn{2}{c}{ Control Region } \\
& $\begin{array}{c}\text { Eligible Cohort } \\
\text { Ineligible Cohort }\end{array}$ & $\begin{array}{c}\text { Eligible Cohort } \\
\text { Ineligible Cohort }\end{array}$ & $(4)$ & $(4)$ \\
\hline \multirow{3}{*}{ Birth Year } & & $(2)$ & & \\
& 1938.636 & 1945.704 & 1938.749 & 1945.692 \\
Experience & $(2.800)$ & $(1.526)$ & $(2.802)$ & $(1.544)$ \\
& 22.138 & 20.536 & 20.988 & 19.150 \\
Tenure & $(5.408)$ & $(5.509)$ & $(6.006)$ & $(6.100)$ \\
& 11.168 & 9.630 & 10.075 & 8.719 \\
Annual Earnings (1,000 EUR) & $(5.885)$ & $(6.027)$ & $(5.941)$ & $(5.932)$ \\
& 36.332 & 35.747 & 36.466 & 35.908 \\
White Collar & $(10.002)$ & $(10.103)$ & $(10.787)$ & $(11.025)$ \\
& 0.378 & 0.401 & 0.470 & 0.483 \\
Observations & $(0.485)$ & $(0.490)$ & $(0.499)$ & $(0.500)$ \\
\hline \hline
\end{tabular}

Note: The table reports summary statistics, means and standard deviations (in parentheses), for our sample of workers employed at the onset of the reform (1988q2). Columns (1) and (2) do so for the treatment regions and columns (3) and (4) for the control regions, described in Section 2 and outlined in Panel (b) of Figure 1. Columns (1) and (3) report on the eligible cohorts (cohorts born between 1933 and 1943 who were 50 or older at some point while REBP was active), columns (2) and (4) for the ineligible control cohorts (cohorts born between 1943 and 1948 who did not turn 50 during the policy period). Details on the sample selection are in Section 2.3. Annual earnings (in logs) are based on 2018 EUR (in 1,000s) . 
Table 2: Initial Treatment Effect: Difference-in-Differences Effects on Separations (1988-93) Among Pre-Reform Job Holders

\begin{tabular}{|c|c|c|c|c|c|}
\hline & $\begin{array}{c}(1) \\
\text { Separation }\end{array}$ & $\begin{array}{c}(2) \\
\text { Separation } \\
\text { Into Nonemployment }\end{array}$ & $\begin{array}{c}\text { (3) } \\
\text { Nonemployment } \\
\text { (Quarters) }\end{array}$ & $\begin{array}{c}(4) \\
\text { Unemp. (Benefits) } \\
\text { (Quarters) }\end{array}$ & $\begin{array}{c}\text { (5) } \\
\text { Cont. Empl. } \\
\text { (Quarters) }\end{array}$ \\
\hline REBP Region $\times$ Treated Cohort & $\begin{array}{c}0.109^{* * *} \\
(0.041)\end{array}$ & $\begin{array}{c}0.120^{* * *} \\
(0.043)\end{array}$ & $\begin{array}{c}1.461^{* * *} \\
(0.378)\end{array}$ & $\begin{array}{l}0.951^{*} \\
(0.531)\end{array}$ & $\begin{array}{c}-1.048^{* * *} \\
(0.365)\end{array}$ \\
\hline REBP Region & $\begin{array}{c}0.003 \\
(0.044)\end{array}$ & $\begin{array}{l}-0.003 \\
(0.008)\end{array}$ & $\begin{array}{l}-0.230 \\
(0.280)\end{array}$ & $\begin{array}{l}-0.101 \\
(0.182)\end{array}$ & $\begin{array}{c}0.024 \\
(0.677)\end{array}$ \\
\hline Treated Cohort & $\begin{array}{c}0.030 \\
(0.026)\end{array}$ & $\begin{array}{c}0.108^{* * *} \\
(0.005)\end{array}$ & $\begin{array}{c}0.805^{* * *} \\
(0.126)\end{array}$ & $\begin{array}{c}0.150^{* * *} \\
(0.056)\end{array}$ & $\begin{array}{c}0.146 \\
(0.391)\end{array}$ \\
\hline Constant & $\begin{array}{c}0.372^{* * *} \\
(0.098)\end{array}$ & $\begin{array}{c}0.057^{* * *} \\
(0.017)\end{array}$ & $\begin{array}{l}1.518^{* *} \\
(0.668)\end{array}$ & $\begin{array}{c}0.665 \\
(0.445)\end{array}$ & $\begin{array}{c}16.017^{* * *} \\
(1.820)\end{array}$ \\
\hline $\begin{array}{l}\text { Observations } \\
\text { Adjusted } R^{2} \\
\text { No of Clusters }\end{array}$ & $\begin{array}{c}390,791 \\
0.008 \\
100\end{array}$ & $\begin{array}{c}390,791 \\
0.046 \\
100\end{array}$ & $\begin{array}{c}390,791 \\
0.023 \\
100\end{array}$ & $\begin{array}{c}390,791 \\
0.018 \\
100\end{array}$ & $\begin{array}{c}390,791 \\
0.002 \\
100\end{array}$ \\
\hline
\end{tabular}

Note: The table reports results of the econometric specification in (8). The coefficient of interest is that on REBP Region $\times$ Treated Cohort and captures the effect of REBP-eligibility on the outcomes listed in columns (1) through (5) on a sample of workers employed at the onset of the reform (1988q2). We exclude workers born before 1933 and after 1948. Separation denotes an indicator function that is 1 if a worker separated from their 1988-employer by the end of the REBP period (1988q2 to 1993q3). Separation into Nonemployment denotes an indicator for Separation from the initial employer interacted with an indicator for not taking up employment with another employer. Nonemployment (Quarters), Unemployment (Benefits) (Quarters), and Continuous Employment (Quarters) denote the quarters of nonemployment, unemployment benefits, and continuous employment with the initial employer between 1988q2 and 1993q3. Standard errors clustered at the administrative region level are reported in parentheses. Levels of significance: ${ }^{*} 10 \%$, ${ }^{*} 5 \%$, and ${ }^{* *} 1 \%$. 
Table 3: Resilience Test: Difference-in-Differences Effects on Post-Repeal Separations (1994-96) Among Program Survivors

\begin{tabular}{|c|c|c|c|c|c|}
\hline & $\begin{array}{c}(1) \\
\text { Separation }\end{array}$ & $\begin{array}{c}(2) \\
\text { Separation } \\
\text { Into Nonemployment }\end{array}$ & $\begin{array}{c}\text { (3) } \\
\text { Nonemployment } \\
\text { (Quarters) }\end{array}$ & $\begin{array}{c}(4) \\
\text { Unemp. (Benefits) } \\
\text { (Quarters) }\end{array}$ & $\begin{array}{c}\text { (5) } \\
\text { Cont. Empl. } \\
\text { (Quarters) }\end{array}$ \\
\hline REBP Region $\times$ Treated Cohort & $\begin{array}{c}0.006 \\
(0.009)\end{array}$ & $\begin{array}{c}0.005 \\
(0.008)\end{array}$ & $\begin{array}{c}0.017 \\
(0.027)\end{array}$ & $\begin{array}{l}-0.072 \\
(0.045)\end{array}$ & $\begin{array}{r}-0.052 \\
(0.034)\end{array}$ \\
\hline REBP Region & $\begin{array}{l}-0.003 \\
(0.019)\end{array}$ & $\begin{array}{c}0.008 \\
(0.011)\end{array}$ & $\begin{array}{l}-0.007 \\
(0.056)\end{array}$ & $\begin{array}{c}0.005 \\
(0.041)\end{array}$ & $\begin{array}{c}0.116 \\
(0.088)\end{array}$ \\
\hline Treated Cohort & $\begin{array}{c}0.140^{* * *} \\
(0.009)\end{array}$ & $\begin{array}{c}0.164^{* * *} \\
(0.002)\end{array}$ & $\begin{array}{c}0.718^{* * *} \\
(0.010)\end{array}$ & $\begin{array}{l}0.145^{* *} \\
(0.069)\end{array}$ & $\begin{array}{c}-0.630^{* * *} \\
(0.057)\end{array}$ \\
\hline Constant & $\begin{array}{c}0.157^{* * *} \\
(0.051)\end{array}$ & $\begin{array}{l}0.068^{* *} \\
(0.030)\end{array}$ & $\begin{array}{l}0.324^{* *} \\
(0.142)\end{array}$ & $\begin{array}{c}0.136 \\
(0.107)\end{array}$ & $\begin{array}{l}8.166^{* * *} \\
(0.241)\end{array}$ \\
\hline $\begin{array}{l}\text { Observations } \\
\text { Adjusted } R^{2} \\
\text { No of Clusters }\end{array}$ & $\begin{array}{c}207,785 \\
0.026 \\
99\end{array}$ & $\begin{array}{c}207,785 \\
0.047 \\
99\end{array}$ & $\begin{array}{c}207,785 \\
0.038 \\
99\end{array}$ & $\begin{array}{c}207,785 \\
0.006 \\
99\end{array}$ & $\begin{array}{c}207,785 \\
0.018 \\
99\end{array}$ \\
\hline
\end{tabular}

Note: The table reports results of the specification in [8]. Here, the sample is restricted to workers employed at the same establishment in May 1988 and February 1994, i.e. survivors. The coefficient of interest is REBP Region $\times$ Treated Cohort and captures the effect of REBP-eligibility on the outcomes listed in columns (1) through (5), with outcomes measured by February 1996. We exclude workers born before 1933 and after 1948. Separation denotes an indicator function that is 1 if a worker is not employed by their employer from February 1994 (and May 1988) in February 1996. Separation into Nonemployment denotes an indicator for Separation from the initial employer interacted with an indicator for not being employed in February 1996. Nonemployment (Quarters), Unemployment (Benefits) (Quarters), and Continuous Employment (Quarters) denote the quarters of nonemployment, unemployment benefits, and continuous employment with the initial employer between February 1994 and 1996. Standard errors clustered at the administrative region level are reported in parentheses. Levels of significance: ${ }^{*} 10 \%$, ${ }^{* *} 5 \%$, and ${ }^{* * *} 1 \%$. 
Table 4: Estimating the Mixed Model of Two Coasean Model Variants: Full Persistence vs. Full Reshuffling of Post-Repeal Job-Level Surplus

\begin{tabular}{lcccc}
\hline \hline & & & & \\
& 1995 & 1996 & 1997 & 1998 \\
\hline$\alpha^{\kappa}$ (Reshuffling) & 1.027 & 1.084 & 1.237 & 1.338 \\
& $(0.034)$ & $(0.030)$ & $(0.040)$ & $(0.047)$ \\
$95 \%$ CI & 0.960 & 1.025 & 1.158 & 1.245 \\
(Lower Limit) & & & & \\
& & & & \\
$\alpha^{1-\kappa}$ (Persistence) & -0.037 & -0.070 & -0.208 & -0.289 \\
& $(0.035)$ & $(0.030)$ & $(0.041)$ & $(0.048)$ \\
& & & & \\
$R^{2}$ & 0.929 & 0.960 & 0.971 & 0.978 \\
$N$ & 181 & 181 & 181 & 181 \\
\hline \hline
\end{tabular}

Note: The table reports estimates of the coefficients in Equation (9). We regress the post-repeal separation rate from February 1994 to February of each year among REBP survivors in the REBP region, by month of birth, on both the separation rate among stayers in the non-REBP region and the predicted separation rate based on a perfect persistence Coasean model. We weight the observations of the month of birth by the number of employed workers born in that month and report standard errors clustered at the administrative region level. 


\section{Figures}

\section{Figure 1: The Regional Extended Benefit Program (REBP)}

(a) Timeline of Potential Benefit Duration During REBP

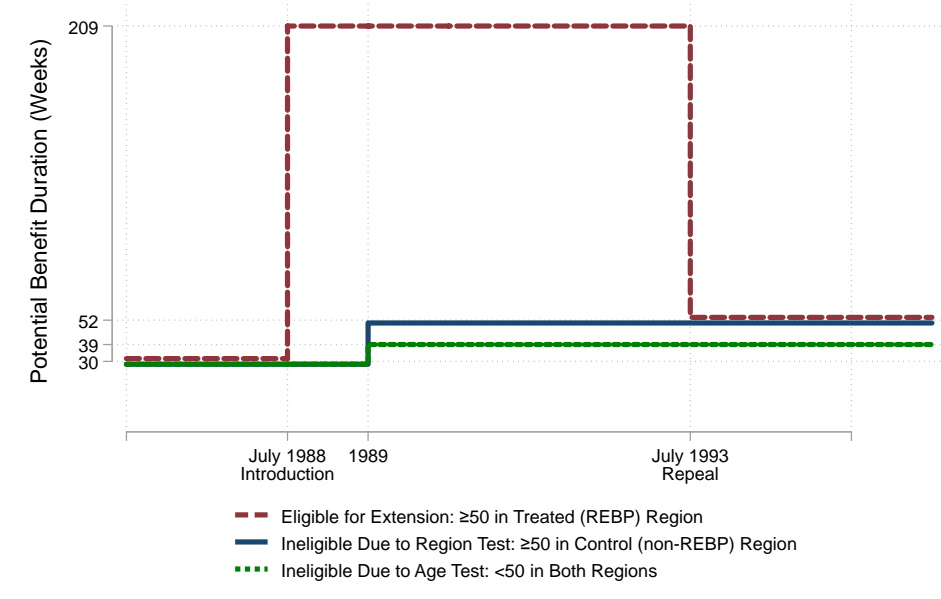

(b) Map of REBP Treatment and Control Regions

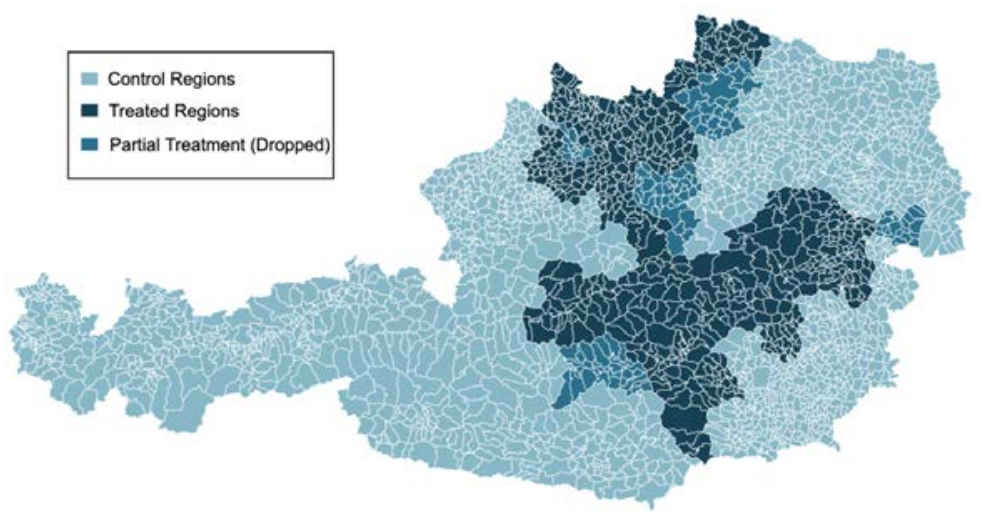

Note: Panel (a) shows the timeline of reform changes in potential benefit duration (PBD) for eligible workers in treatment (REBP) and control (non-REBP) regions. It first shows the PBD for individuals aged 50 or older in the REBP region, which increased from 30 to 209 weeks starting July 1988. Second, individuals 50 or older but in the control (non-REBP) region were ineligible. Lastly, individuals not meeting the age requirement were ineligible in either region. The figure also shows a smaller, nation-wide PDB reform in 1989, which our difference-in-differences design nets out. Section 2 summarizes further details on eligibility. Panel (b) depicts a map of Austrian municipalities categorized into REBP treatment and control regions. We drop the partially treated regions, where REBP was repealed in 1991. Source for map: Inderbitzin, Staubli, and Zweimüller (2016), Figure 1. 
Figure 2: Case Studies of Jobs

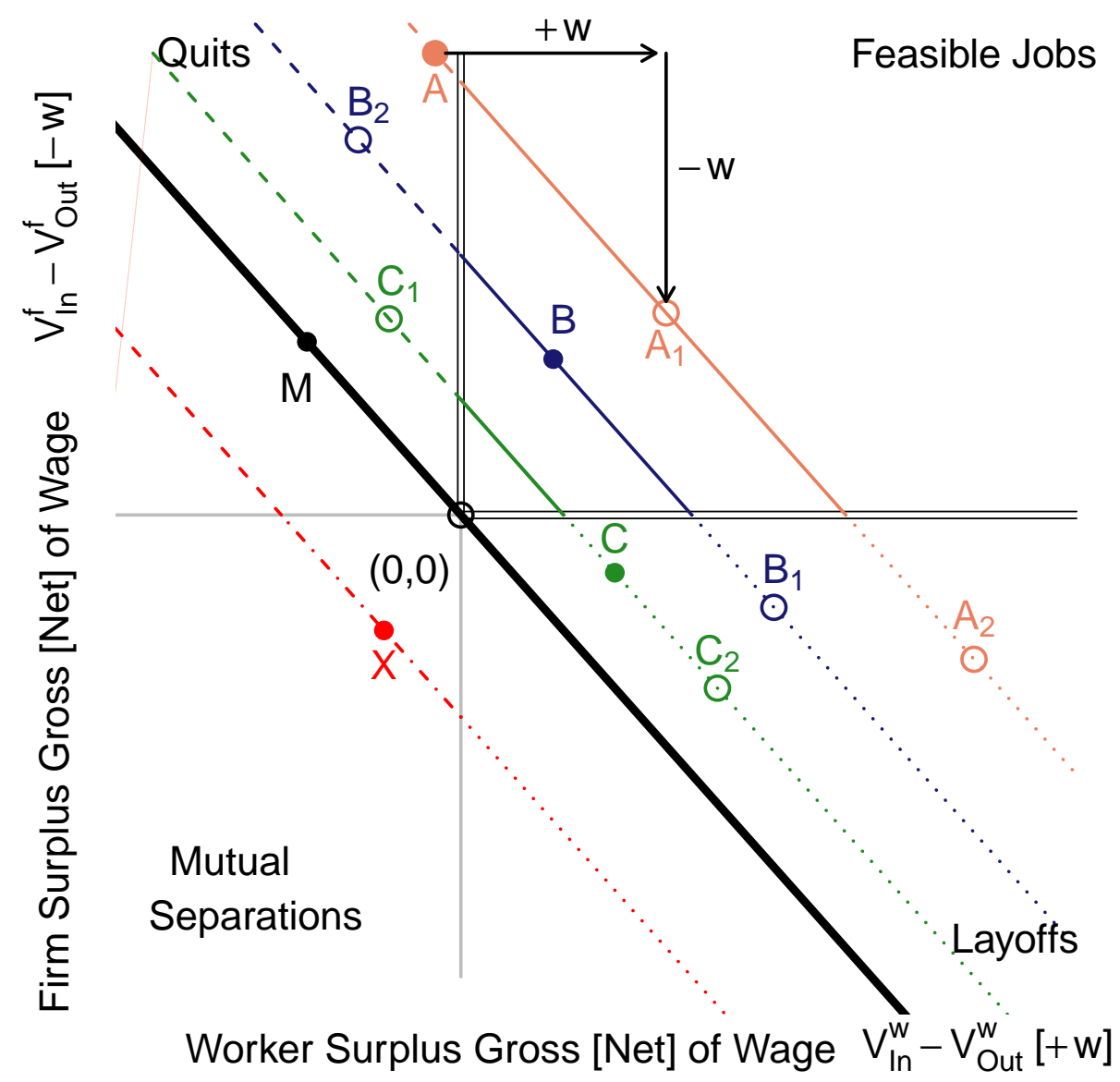

Note: The figure plots job case studies in the two-dimensional space of worker and firm job surplus. The solid circles $(\bullet)$ denote gross-of-wage surpluses, i.e. $V_{\text {In }}^{W}-V_{\text {Out }}^{W}$ for the worker and $V_{\text {In }}^{F}-V_{\text {Out }}^{F}$ for the firm. The empty circles (o) denote net-of-wage surpluses, i.e. $V_{\mathrm{In}}^{W}+w-V_{\text {Out }}^{W}$ for the worker and $V_{\mathrm{In}}^{F}-w-V_{\text {Out }}^{F}$ for the firm. The 135-degree lines are iso-joint-surplus lines, along which wages reallocate surplus between the firm and the worker. The empty lines ( ||$)$ at a right angle at the origin denote the participation constraints of the worker and the firm, namely positive net-of-wage surpluses. The bold diagonal line (I) represents the threshold for job viability on the basis of joint job surplus (which an appropriately set wage can in principle distribute to render each parties' surplus positive). 


\section{Coasean Model}
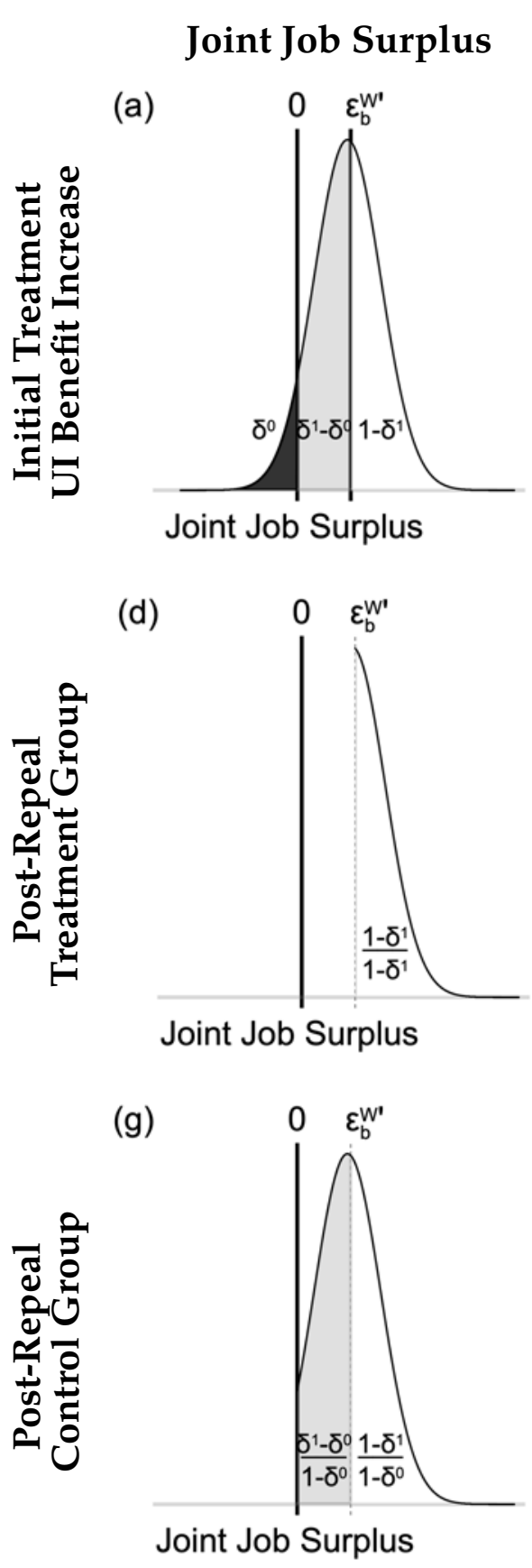

\section{Unilateral Surpluses}
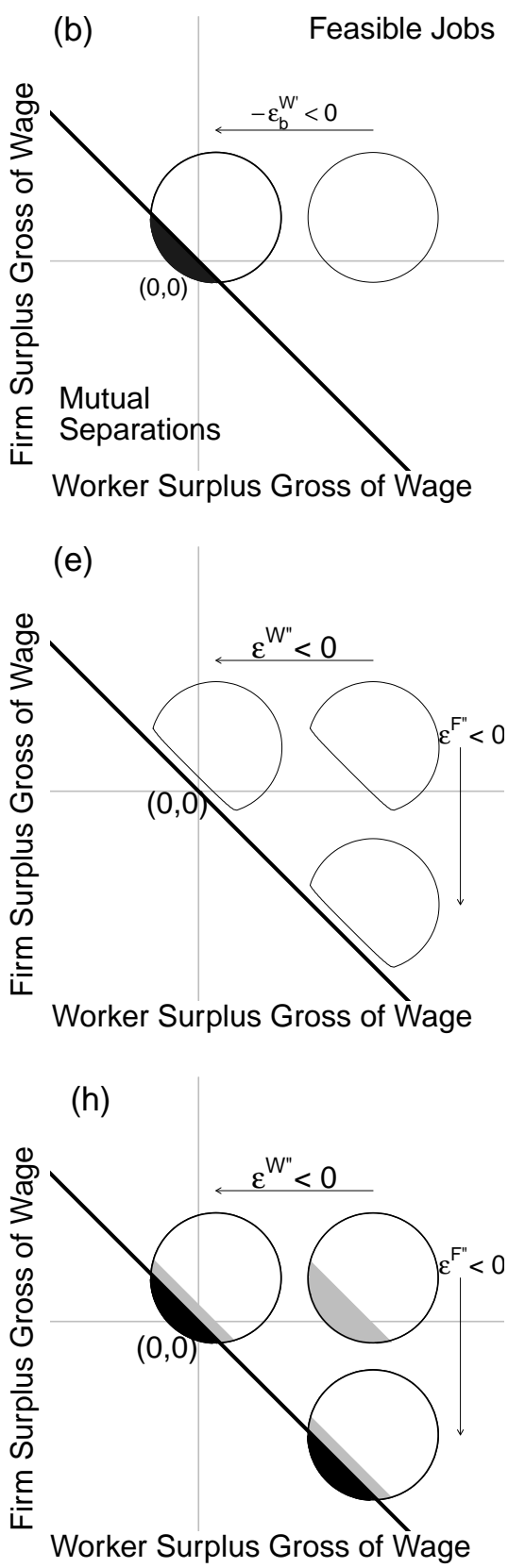

Non-Coasean Model With Wage Rigidity
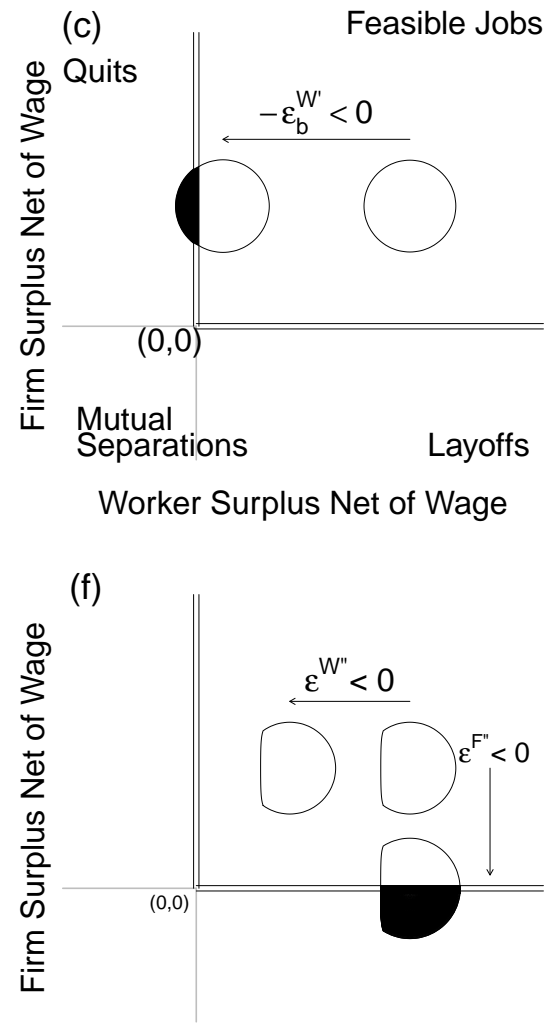

Worker Surplus Net of Wage

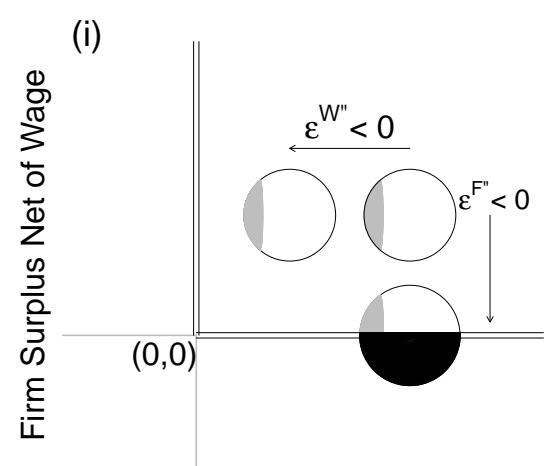

Worker Surplus Net of Wage

Note The figure illustrates surplus distributions underlying the separation dynamics. The left column shows a Coasean case in a joint-surplus representation; the middle column shows the model in a two-dimensional representation in terms of unilateral gross-of-wage surpluses building on Figure 2 The right column shows net-of-wage surpluses for a rigid-wage model. There, the empty lines (||) denote separation thresholds for net-of-wage unilateral surpluses. The bold diagonal line (I) does so for joint surplus in the middle column. The top row shows initial effects of REBP. The middle (bottom) row shows post-repeal surplus distributions among surviving matches in the former treatment (control) group. For the middle and right column, the two last rows also show responses to shocks. Panel (a) also includes separators unrelated to REBP but due to idiosyncratic shocks, indicated by the black mass of share $\delta^{0}$. Throughout, the marginal jobs are gray, making up share $\delta^{1}-\delta^{0}$. Inframarginal jobs surviving REBP are white and share $1-\delta^{1}$. At the point of repeal, among survivors in the control group $\left(\delta^{1}-\delta^{0}\right) /\left(1-\delta^{0}\right)$ are marginal, low surplus jobs. 


\section{Figure 4: Separations and Shocks in the Coasean and Non-Coasean Framework}

(a) Shocks to Joint Surplus in a Coasean Setting

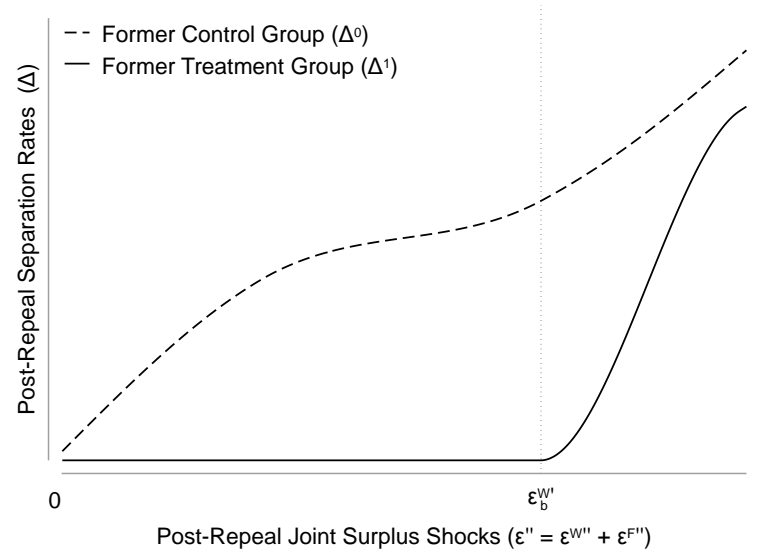

(c) Worker Shock in a Non-Coasean Setting

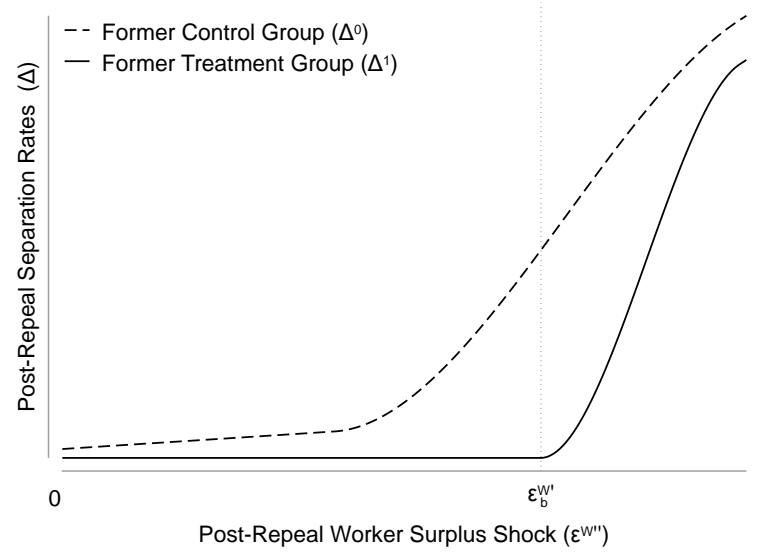

(b) Empirical Strategy: Observable Separation Rates

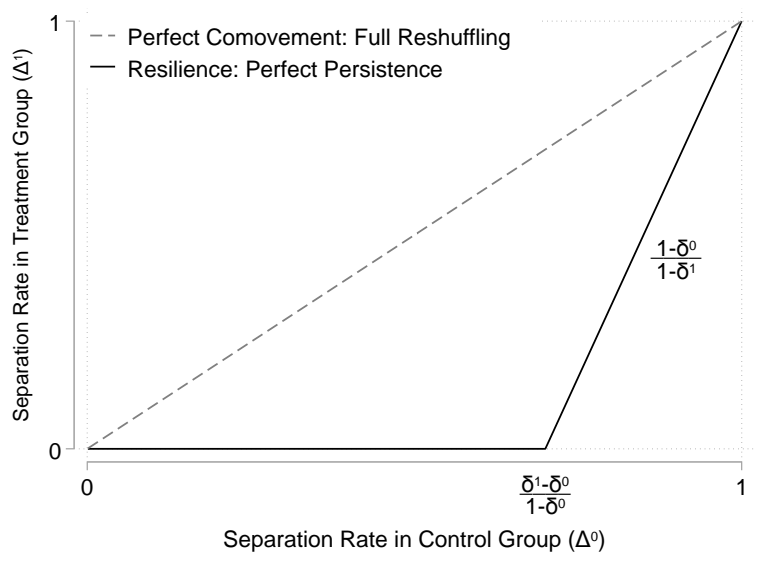

(d) Firm Shock in a Non-Coasean Setting

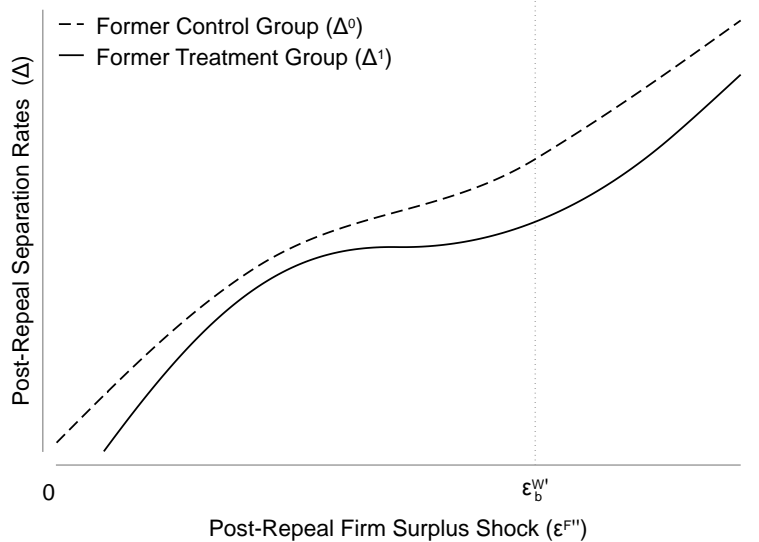

Note: The figures plot the dynamics of post-repeal job separations in the model, in the Coasean (efficient bargaining) and non-Coasean (fixed-wage) settings. Panel (a) plots the separations in the former treatment group $\left(\Delta^{1}\right)$ and former control group $\left(\Delta^{0}\right)$ in response to joint surplus shocks (i.e. either a worker or firm shock) in a Coasean setting. Panel (b) plots the relationship between treatment group and control group separation rates, after the treatment, for the Coasean setting, assuming perfect persistence and full reshuffling of job surplus. Panels (c) and (d) compare the separations of survivors in the former treatment and control groups, respectively, in response to post-repeal worker (c) and firm (d) surplus shocks for the non-Coasean settings. 
Figure 5: Initial Treatment Effect: Separations (1988-93) Among Pre-Reform Job Holders

(a) Levels

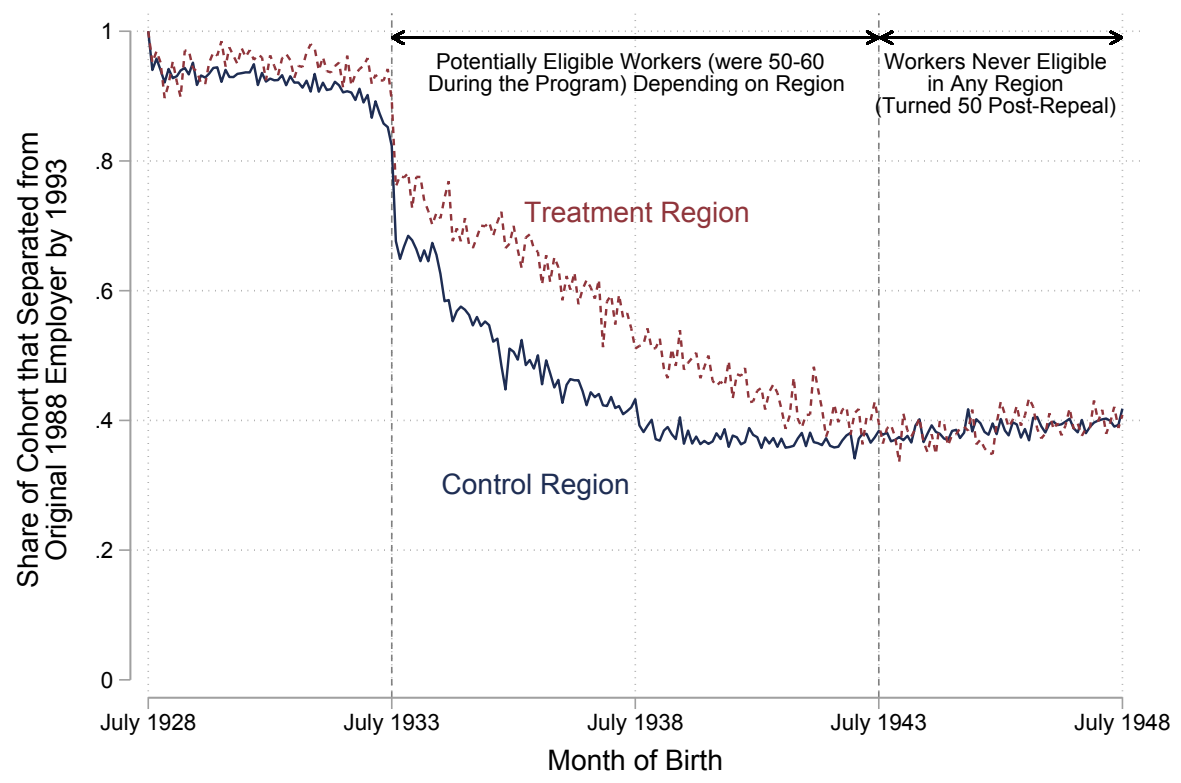

(b) Differences

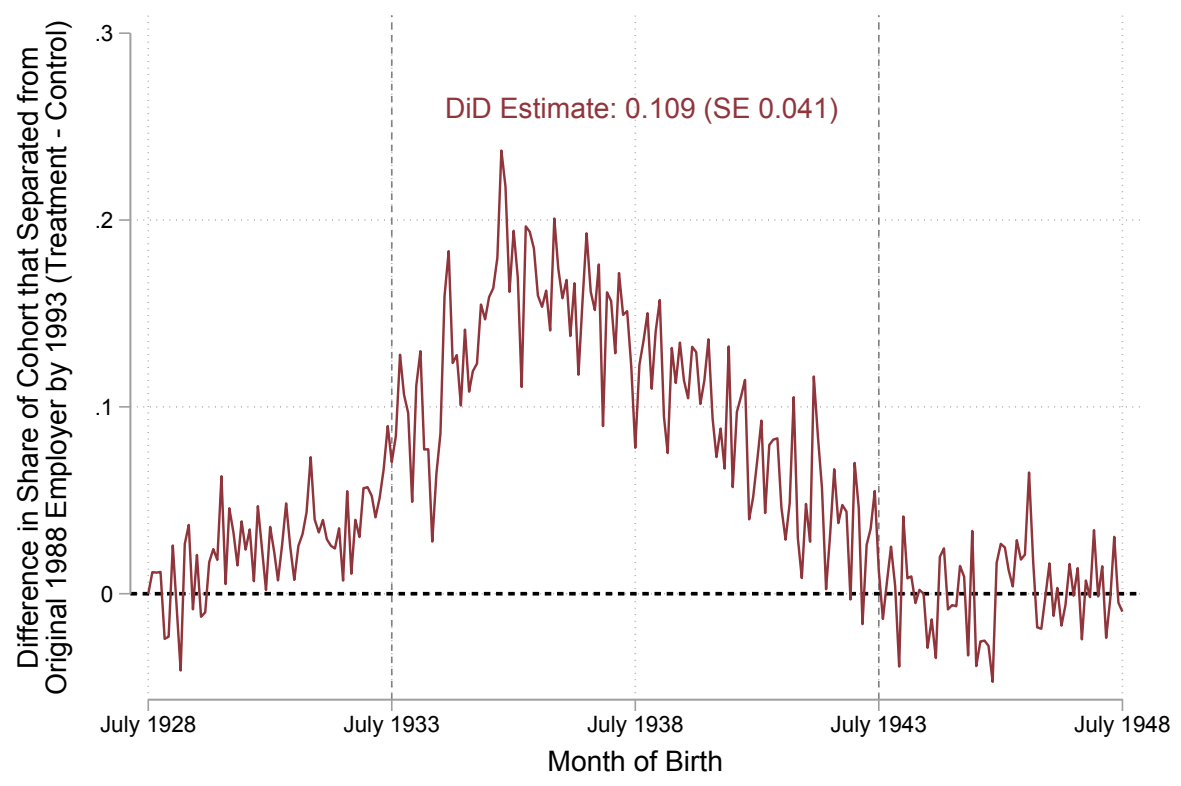

Note: Panel (a) shows the share of workers who separated from their 1988q2-employer (right before the reform) by 1993q3 (when reform had just ended). We plot rates by month of birth and within the treated (red, short dashes) and the control (blue, solid) regions. Panel (b) shows the difference between the treated and the control region by cohort. Cohorts born after 1943 were not covered by the policy as they turned 50 after the program was repealed 1993. Cohorts born before 1933 had all reached retirement age by 1993. 
Figure 6: Initial Treatment Effect: Additional Results

\section{Separations Between Ages 50 and 55}

(a) Levels

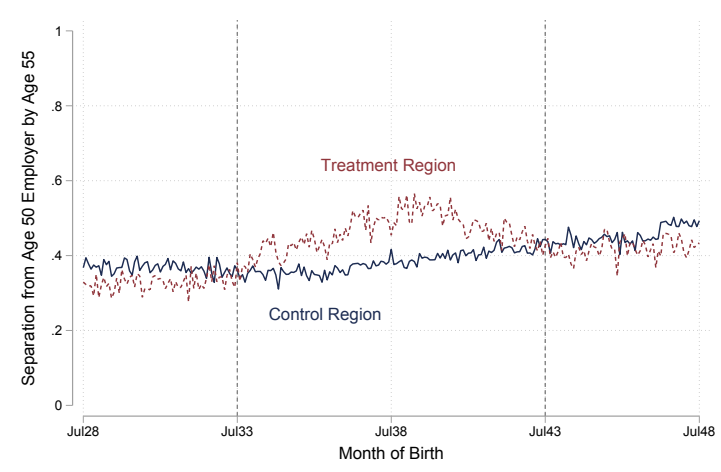

(b) Differences (Treatment - Control)

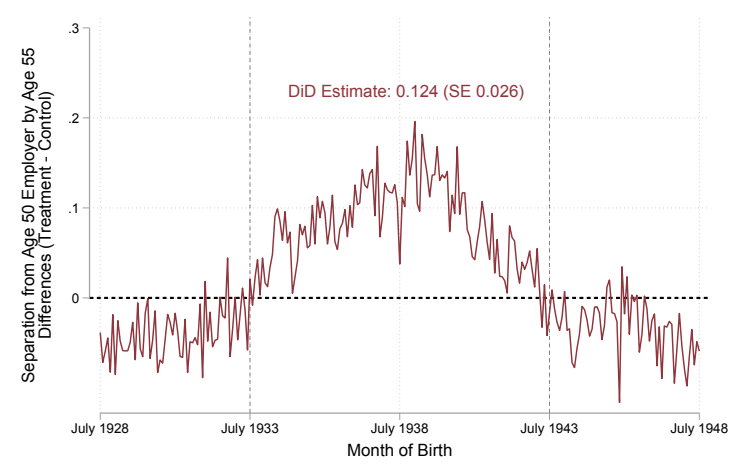

\section{Quarters Nonemployed (1988-93)}

(c) Levels

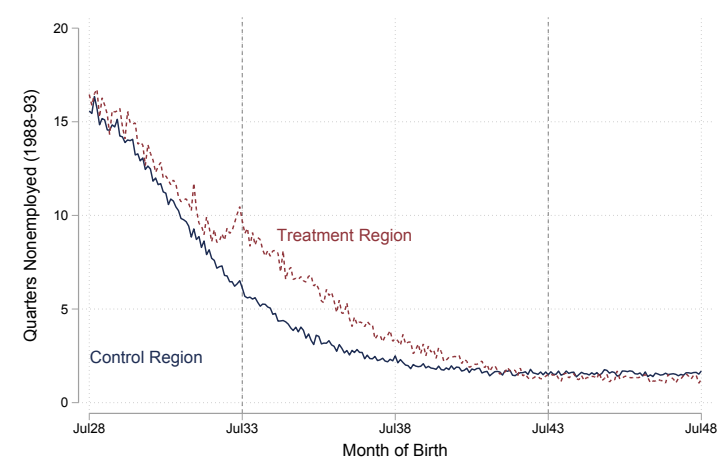

(d) Differences (Treatment - Control)

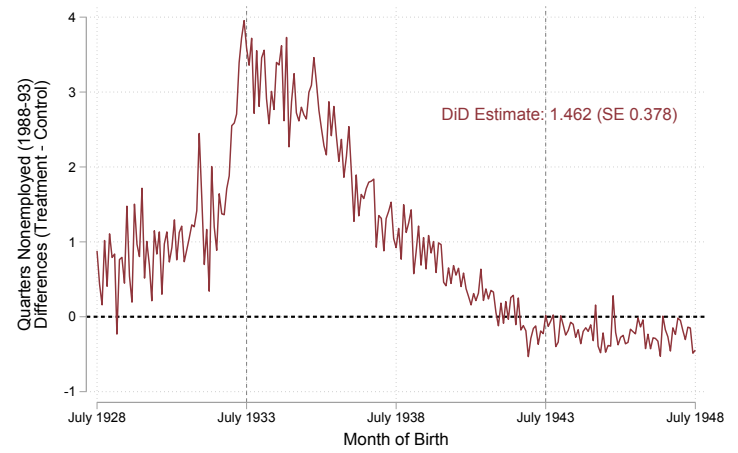

\section{Quarters Unemployed (Benefits) (1988-93)}

(e) Levels

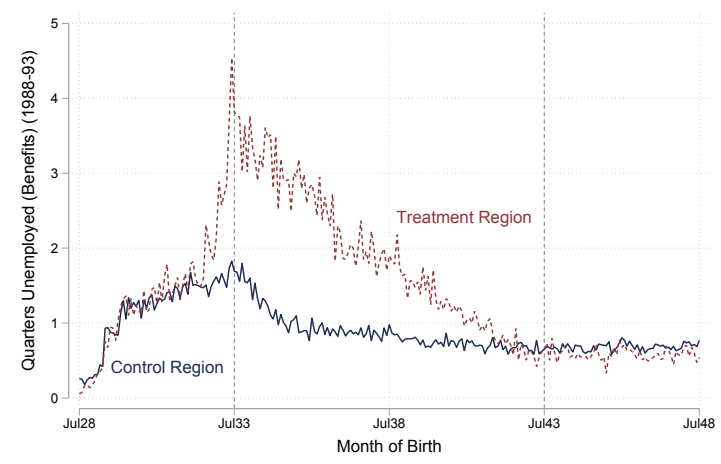

(f) Differences (Treatment - Control)

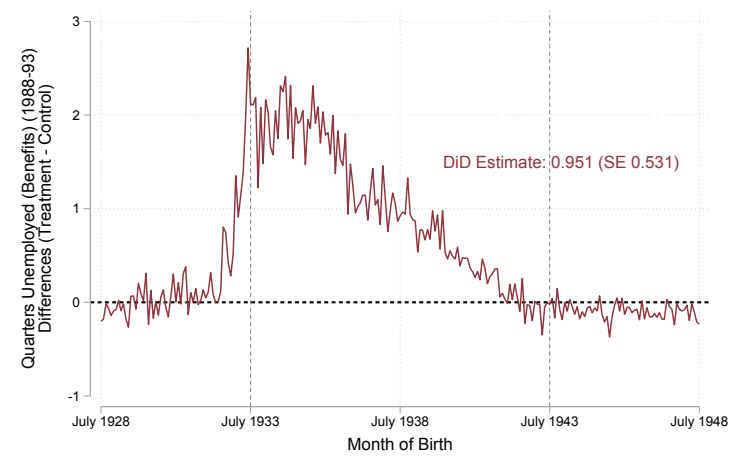

Note: Panel (a) shows the share of workers who separated from their initial employer (measured in quarter before turning 50) by the quarter before turning 55. Panels (c) and (e) show the average number of quarters that the workers are nonemployed and on unemployment benefits, respectively, during the REBP period, among those employed in the quarter before the start of REBP (1988q2). We plot rates by month of birth and within the REBP (treated) (red, short dashes) and control (blue, solid) regions. Panels (b), (d), and (f) show the differences between the treatment and the control regions by cohort. Cohorts born after 1943 were not covered by the policy as they turned 50 after the program was repealed in 1993. 
Figure 7: Resilience Test: Post-Repeal Separations (1994-96) Among Program Survivors

(a) Levels

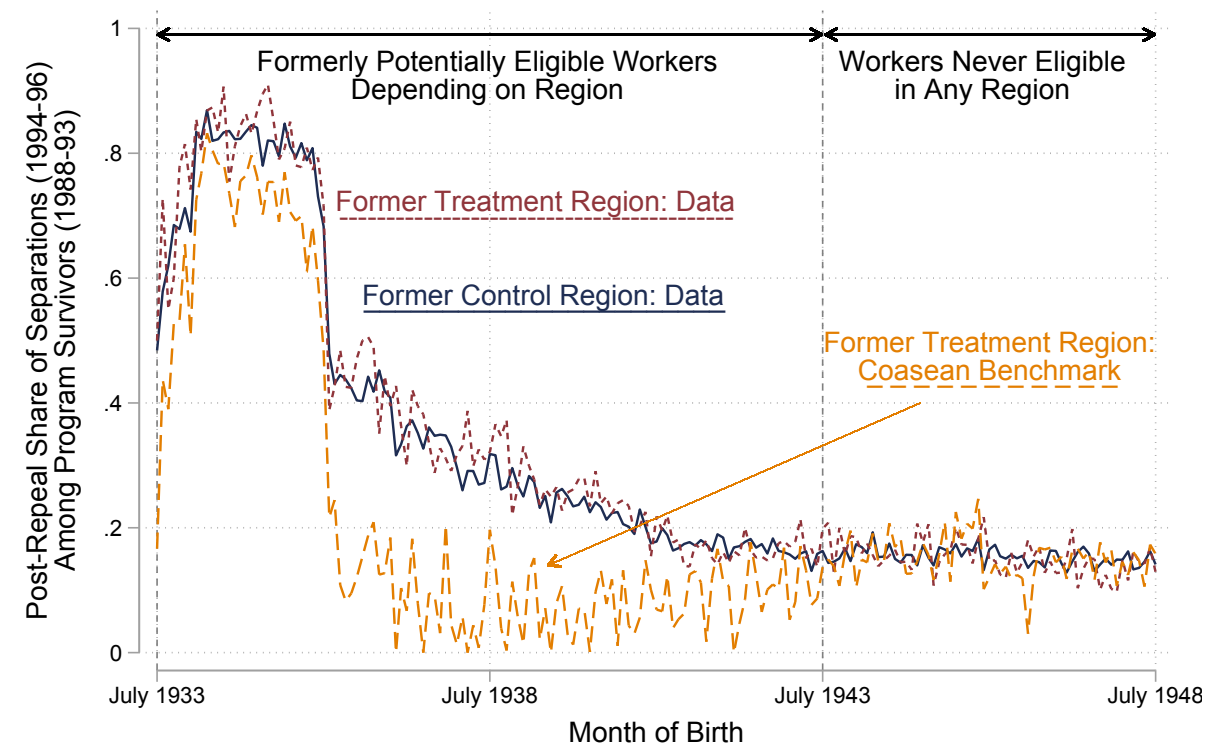

(b) Differences

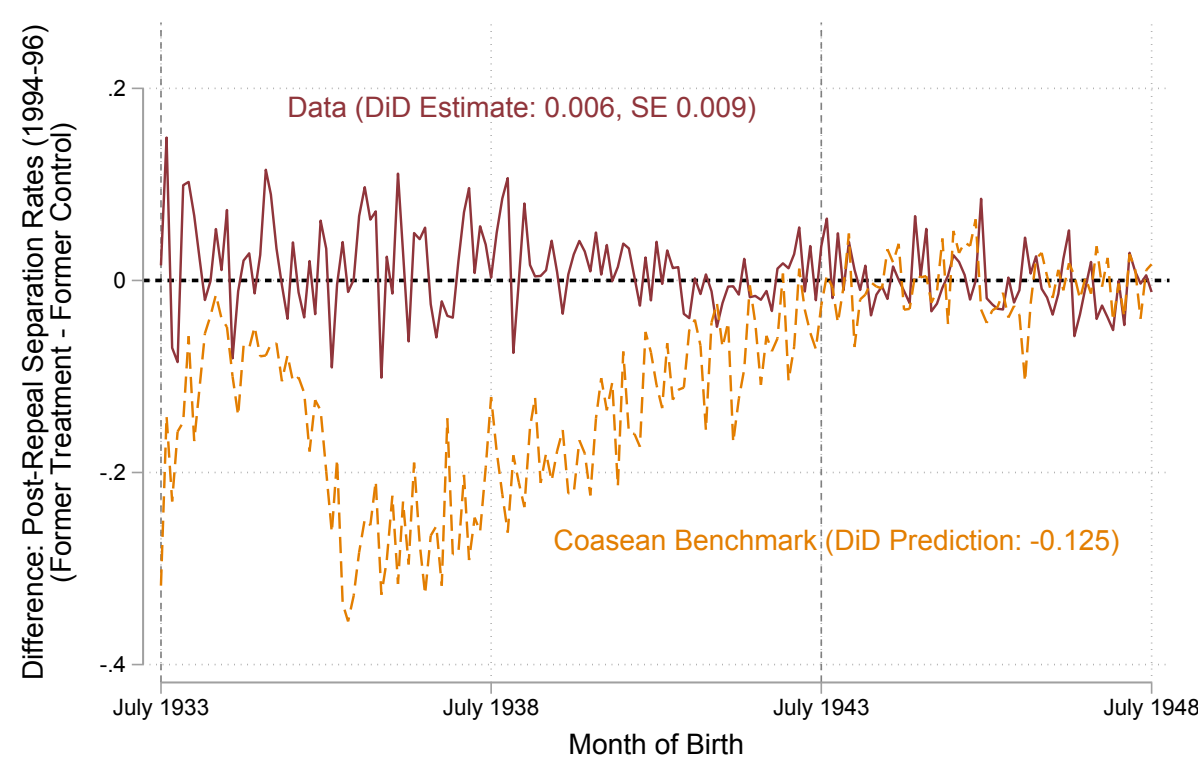

Note: Panel (a) shows, by month of birth, the share of workers observed in the same establishment between 1988q2 and 1994q1 who separate from that employer by 1996q1. The sample is split into treated (red, short dashes) and control (blue, solid) regions. The yellow dashed line plots the Coasean benchmark using Equation (7) (perfect persistence case). Panel (b) shows, by month of birth, the difference in separation rates from Panel (a) between the treated and control regions (red, solid), and between separations predicted based on the Coasean benchmark in treated regions and observed separations in control regions (yellow, dashed). The retirement age for Austrian men was 60 years old in this period, which explains the spike in separations among older cohorts. 
Figure 8: Resilience Test at Other Horizons: Post-Repeal Separations Among Program Survivors

Horizon: 1994-95

(a) Levels

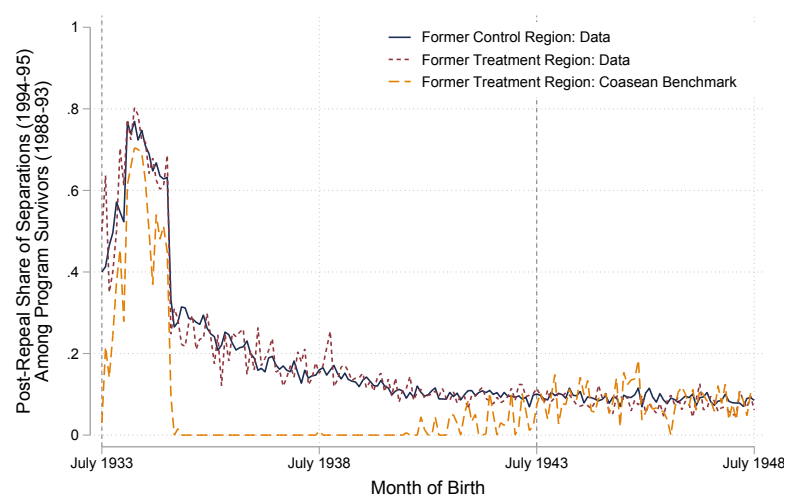

Horizon: 1994-97

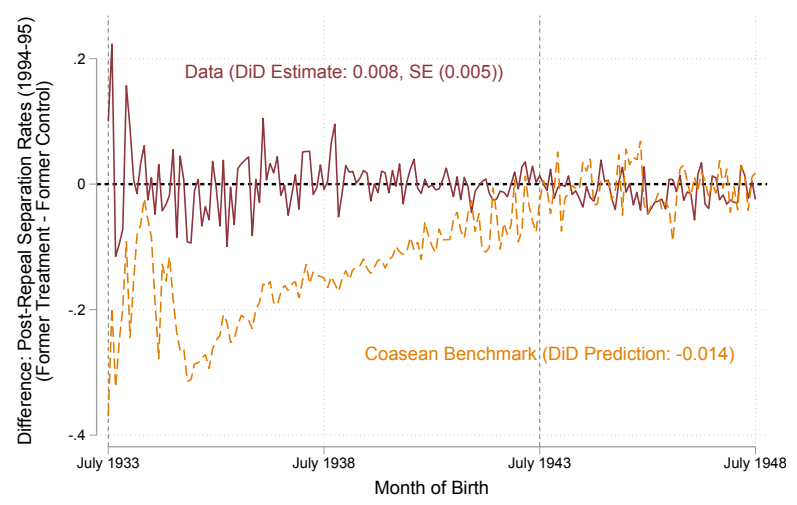

(c) Levels
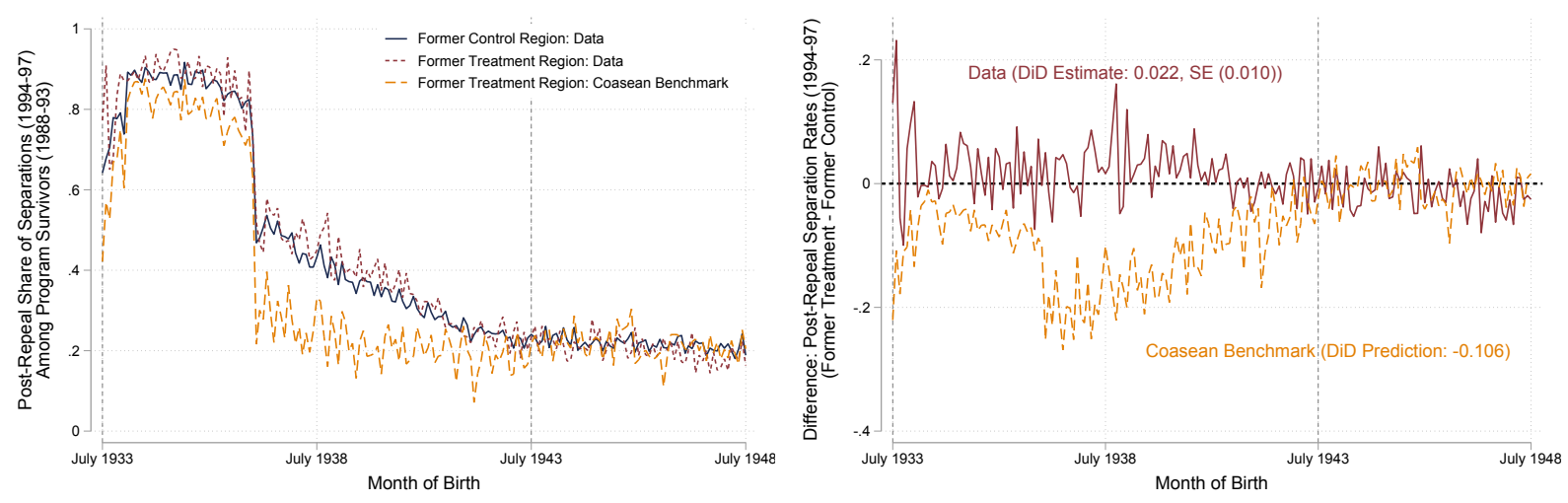

Horizon: 1994-98

(e) Levels

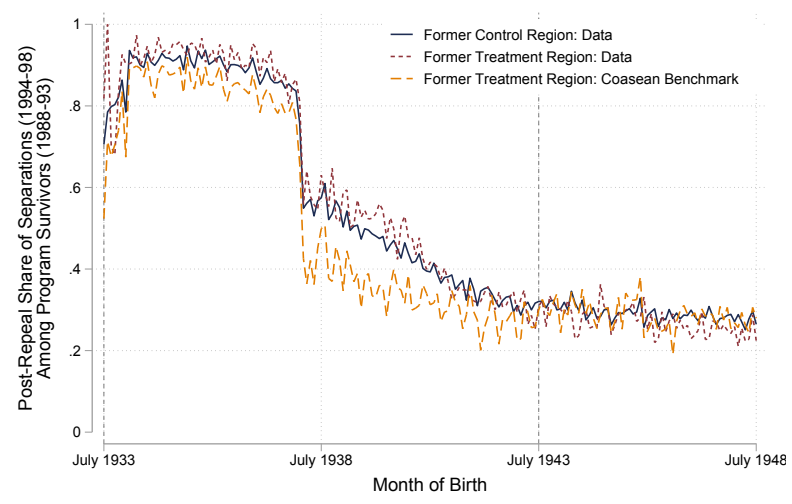

(b) Differences

(d) Differences

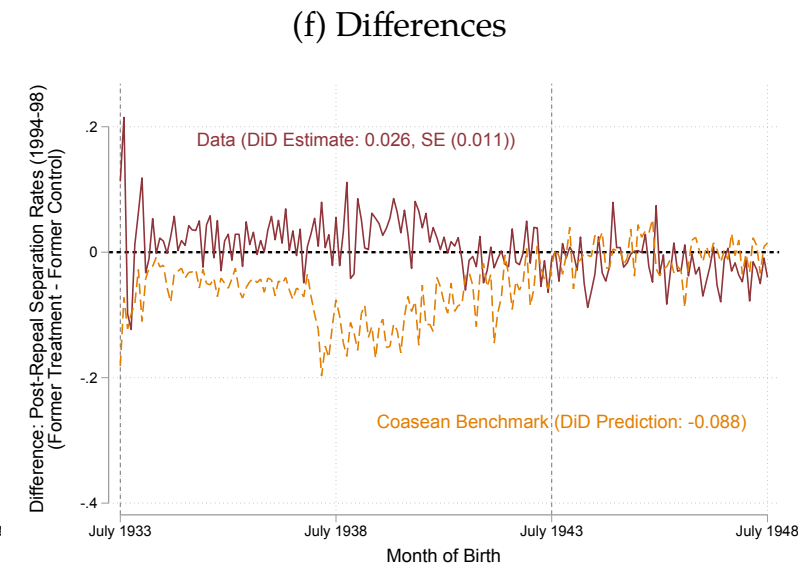

Note: Panels (a), (c), and (e) show variants of Figure 7Panel (a) for various post-repeal horizons. Panels (b), (d), and (f) show the observed and predicted differences in separation rates as in Figure7Panel (b). 
Figure 9: Resilience Tests: Post-Repeal Separation Responses to Negative Industry and Establishment-Level Growth Events (1994-96)

(a) Difference in Separation by Industry Growth

(b) Separations vs. Annual Establishment Growth
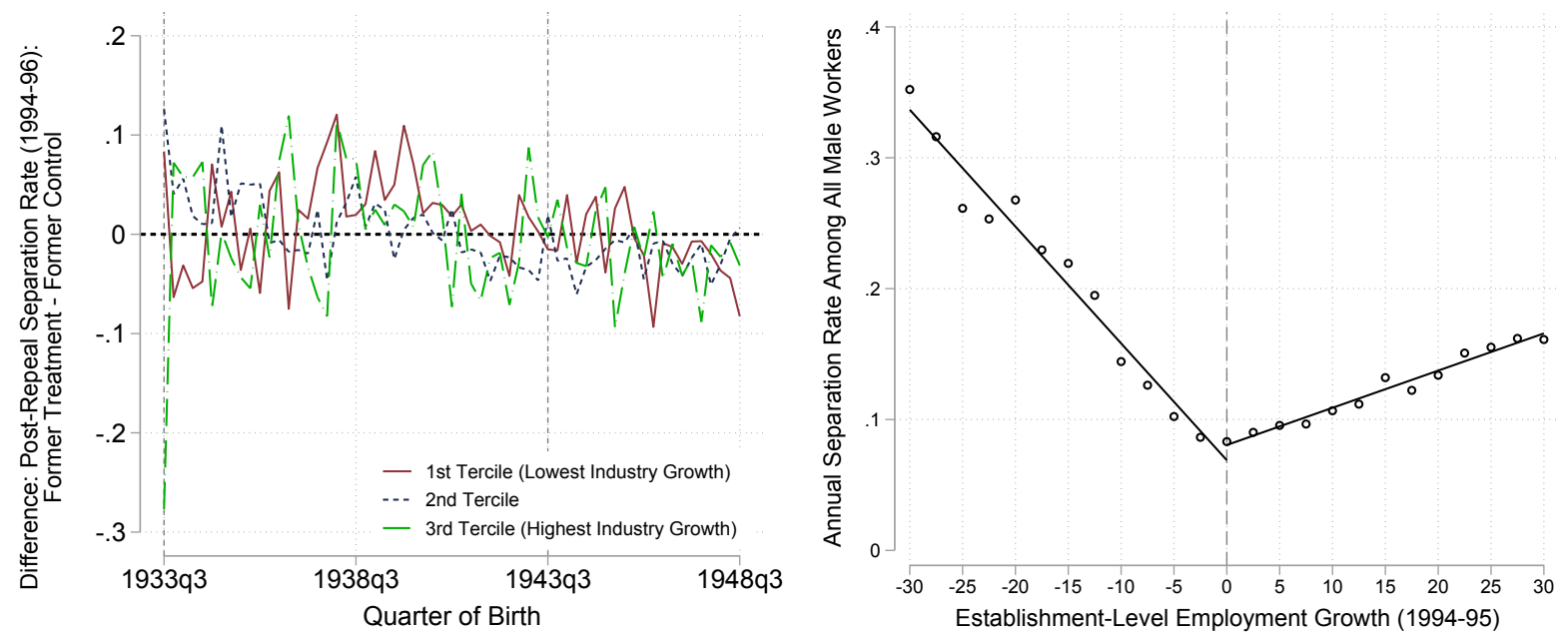

(c) Survivor Separations by Cohort and Region

(d) Birth Cohort-Specific Slopes
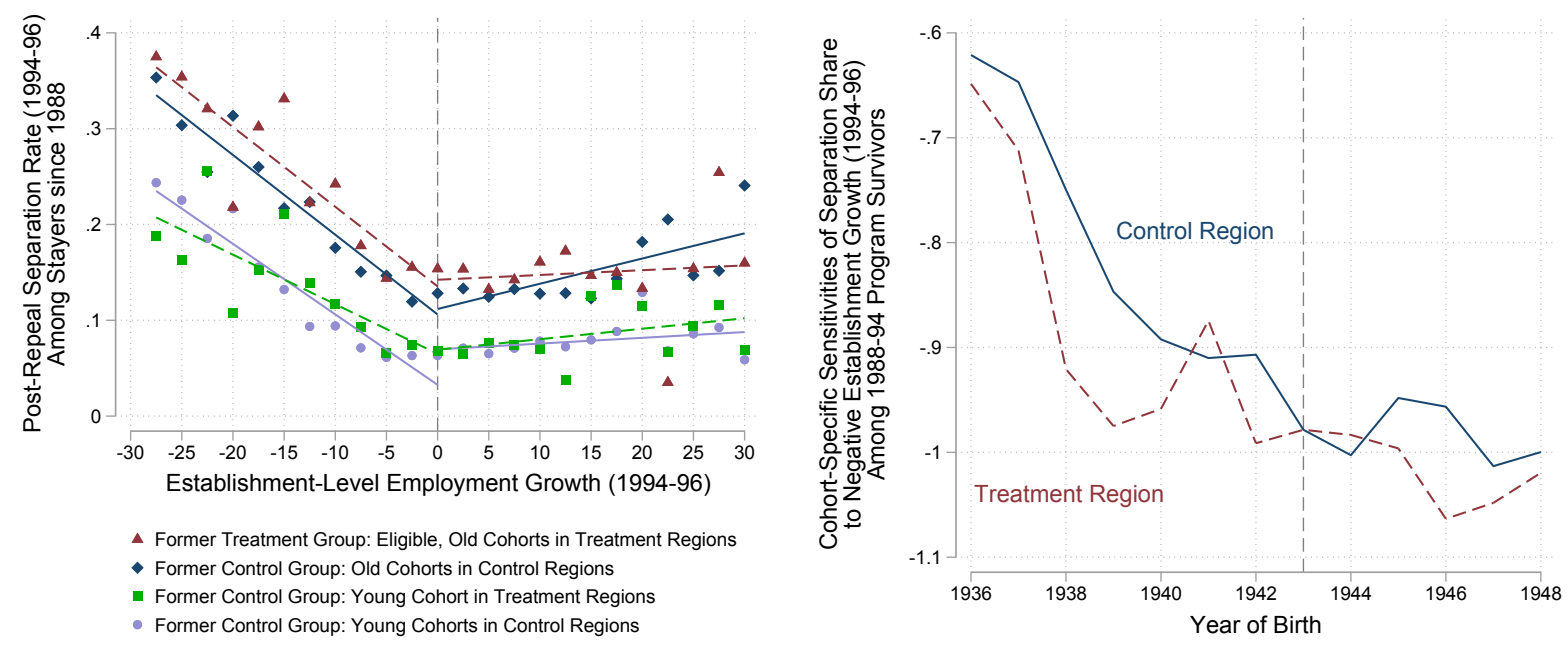

Note: Panel (a) splits the by-cohort regional difference from Figure7(b) into terciles of industry growth, with the first tercile denoting the lowest and the third tercile denoting the highest industry growth. Specifically, we calculate employment growth between 1994q1 and 1996q1 for each industry (two-digit NACE), among all workers (not just stayers) born after 1938. Panels (b), (c) and (d) plot the results of an analysis focusing on labor demand shifts within establishments. We confirm the "hockey-stick" relationship between separations and employment growth at the establishment level (Davis, Faberman, and Haltiwanger. 2013) in Panel (b). It plots annual separation rates for male workers employed in a given year by bins of 1994q1-95q1 establishment employment growth. Panel (c) focuses on separations among the four REBP groups: eligible and ineligible cohorts and regions, against total establishment employment growth. We ignore the cohorts born before 1936 since they have reached retirement age in 1996. Panel (d) plots the slope of the cohort-specific relationship between separations and establishment growth (1994-1996) among shrinking establishments by cohort and region. We adjust throughout for spurious layoffs due to mergers, take-overs, and administrative changes using the procedure in Fink et al. (2010). 


\section{Figure 10: Separations by Wage Rigidity Measures}

(a) By SD of Log Wage

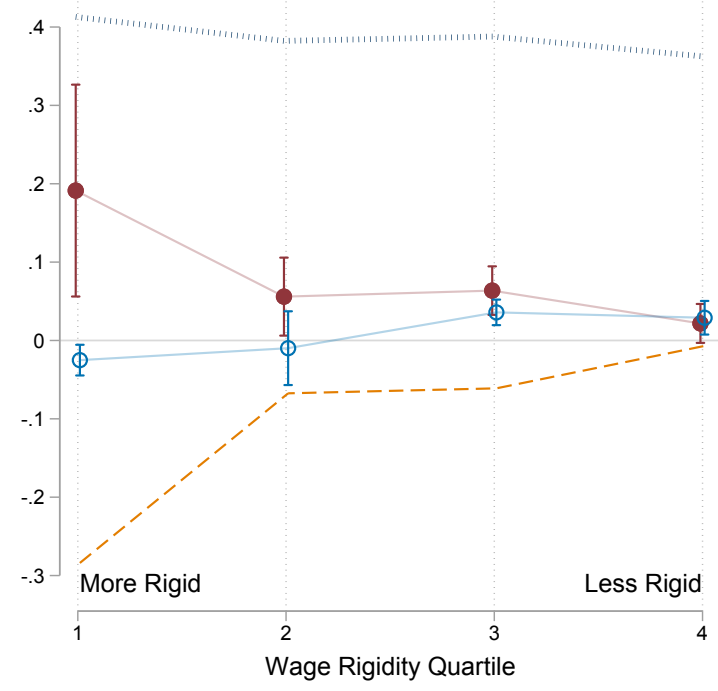

(c) By SD of $\Delta$ Log Wage

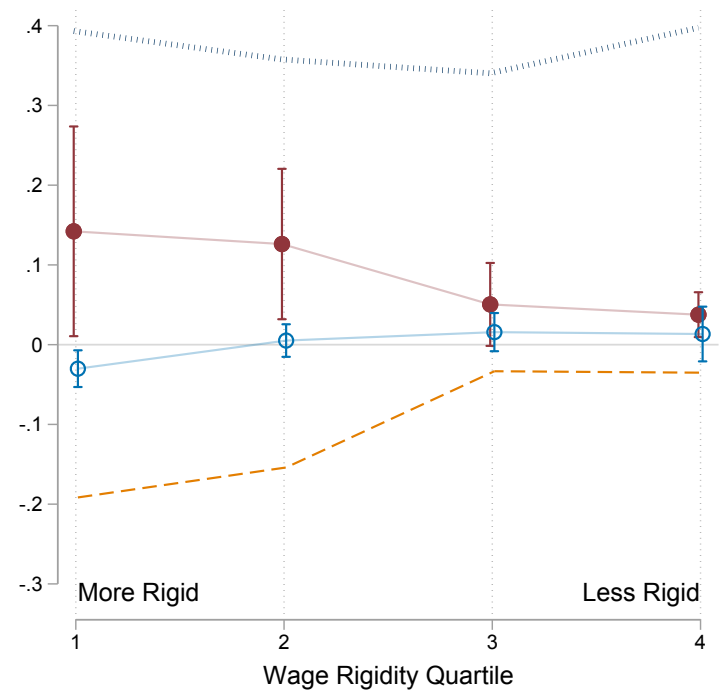

(b) By SD of Residuals of Log Wage

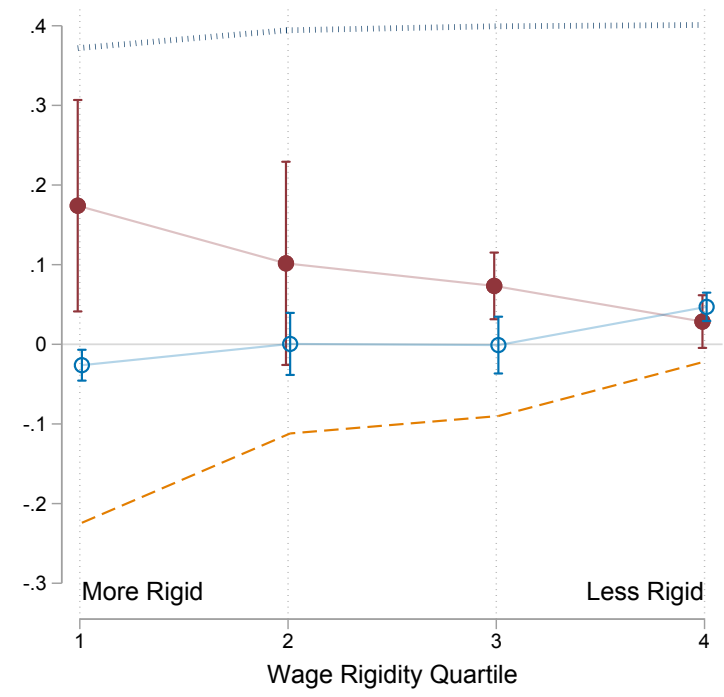

(d) By SD of Residuals of $\Delta$ Log Wage

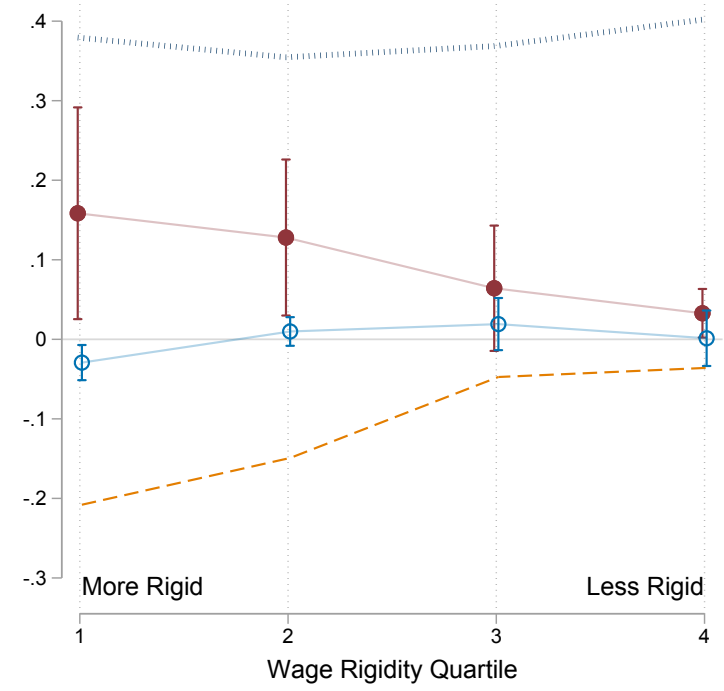

1.. Control Mean: Separation Level During Policy Period

- Initial Treatment DiD Effect on Separations During Policy Period

DiD Effect on Post-Repeal Separations: Data

- Coasean Benchmark for Post-Repeal Separations DiD Effect

(Or Non-Coasean Benchmark with Worker Shocks Only)

Note: The figure plots several coefficients by quartiles of the within-firm standard deviation of log wages (Panel (a)), the within-firm standard deviation of Mincer residuals from a regression of log earnings on tenure-experience-occupation-industry-year fixed effects (Panel (b)), and analogous measures for changes in log wages over a 5-year horizon (Panels (c) and (d)). We measure wage rigidity at the firm level in the pre-reform period. Cells further to the right exhibit more between-worker dispersion and thus less rigidity. The blue vertical dashes display the control group separation rate during REBP. The red circles plot the treatment effect of REBP on separations among the sample of workers who held a job in 1988 right before the onset of the program. The blue hollow circles plot the effect on separations in the post-repeal period (separation by 1996) in the sample of those workers who were employed in 1988 and whose job survived until 1994. Finally, the yellow dashed lines plot the predicted effect based on the Coasean benchmark. It also corresponds to the non-Coasean benchmark with worker shocks only. 


\title{
Appendix for Online Publication:
}

\author{
Marginal Jobs and Job Surplus: \\ A Test of the Efficiency of Separations
}

Simon Jäger, Benjamin Schoefer, and Josef Zweimüller

\section{Contents}

A Quantifying Worker's Value of the REBP UI Extension 54

\begin{tabular}{lll}
\hline B Theoretical Appendix: Full Coasean Model & 56
\end{tabular}

C Theoretical Appendix: Full Non-Coasean Model Featuring Wage Rigidity 62

\begin{tabular}{ll}
\hline D Variable Construction & 68
\end{tabular}

\begin{tabular}{|ll|}
\hline E & Estimation of the Mixed Model with Industry-by-Occupation Variation with \\
\hline Non-Linear Least Squares & 70
\end{tabular}

\begin{tabular}{|ll|l}
\hline F The Role of Severance Payments & 73
\end{tabular}

\begin{tabular}{lll}
\hline G Additional Tables & 82
\end{tabular}

\begin{tabular}{lll}
\hline $\mathrm{H}$ & Additional Figures & 90
\end{tabular}

\begin{tabular}{ll}
\hline Online Appendix References & 96
\end{tabular}

\section{List of Tables}

A.1 Structural Estimation of Share $\kappa$ of Separations within a Coasean Framework with Perfect Reshuffling of Job-Level Surplus: Industry-Occupation

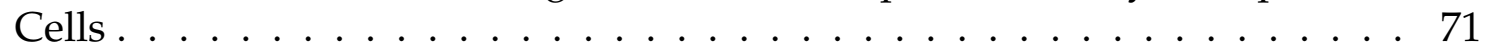

A.2 Tenure Quartiles and Underlying Years of Tenure, Monthly Salaries of Severance Pay, and Experience . . . . . . . . . . . . . . . . . . . . 79

A.3 Initial Treatment Effect: Difference-in-Differences Effects on Separations Between Age 50 and 55 Among Job Holders at Age 50 . . . . . . . . . . . 83

A.4 Resilience Test: Post-Repeal Separations (1994-95) Among Program Survivors 84

A.5 Resilience Test: Post-Repeal Separations (1994-97) Among Program Sur-

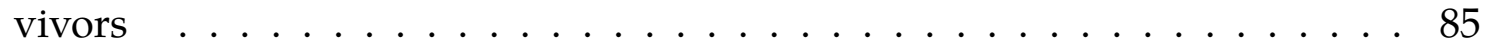

A.6 Resilience Test: Post-Repeal Separations (1994-98) Among Program Survivors 86 
A.7 Robustness to Retirement Dynamics (Dropping Cohorts Born Before 1938) for Resilience Test: Post-Repeal Separations (1994-96) Among Program Sur-

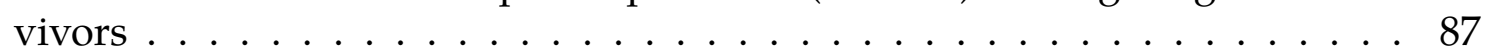

A.8 Complier Analysis by Predicted Separations $\ldots \ldots \ldots \ldots$

A.9 Summary Statistics of Wage Rigidity Proxies $\ldots \ldots$. . . . . . . . . . . . 89

\section{List of Figures}

A.1 Post-Repeal Separation Rates of REBP Survivors and non-REBP Survivors at the Industry-Occupation Level $\ldots \ldots \ldots \ldots$. . . . . . . . . . . . 72

A.2 Results by Quartiles of Tenure . . . . . . . . . . . . . . . . . . . . . . 80

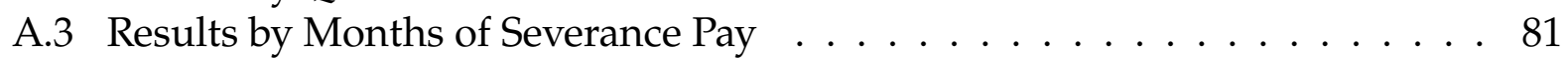

A.4 Industry Heterogeneity of Separation Behavior . . . . . . . . . . . . . . . . 90

A.5 No Evidence for Aggregate Spillovers: Separations during REBP and after REBP with Even Younger Control Cohorts . . . . . . . . . . . . . . . . . . 91

A.6 Initial Treatment Effect: Outcomes by Age . . . . . . . . . . . . . . . . . . . 92

A.7 Difference by Industry Growth and Establishment-Level "Hockey-Sticks" . 93

A.8 No Evidence for Employer-Level Spillovers: Differences in Post-Repeal Separations by Firm and Industry Exposure to REBP (Share of Program-Eligible (Old) Workers) $\ldots \ldots \ldots \ldots \ldots \ldots \ldots$. . . . . . . . . . . . . 94

A.9 $\quad$ Separations by Wage Rigidity Measures (Other Horizons) . . . . . . . . . . . 95 


\section{A Quantifying Worker's Value of the REBP UI Extension}

We calculate the cash value of extended benefits following the approach in Card, Chetty, and Weber (2007) and complement it with new data on unemployment assistance (UA, "Notstandshilfe" in German). Our estimate for the average cash value of the reform corresponds to about eight to nine months of pay or $71 \%$ of a worker's annual salary.

REBP changed potential UI benefit duration from 30 or 52 weeks to 209 weeks for older workers (see Figure 1 Panel (a)) ${ }_{27}^{27}$ To provide a conservative estimate of the value of the reform, we take 52 weeks as the alternative potential benefit duration. Under this assumption, REBP changed benefits by 157 weeks or 36.1315 months.

When benefits run out, many workers are eligible for lower UA benefits. UA benefits are means-tested and depend on other (spousal) sources of income as well as the number of dependents. They are capped at 0.92 of the worker's UI benefits, according to the formula

$$
\mathrm{UA}=\min \{0.92 \times \mathrm{UI}, \max \{0,0.95 \cdot \mathrm{UI}-\text { Spousal Earnings }+ \text { Dependent Allowances }\}\} .
$$

To impute counterfactual UA payments, we draw on data from the AMS, the Austrian employment agency, on unemployment benefit and UA receipt. This allows us to observe actually paid out UI and UA benefits. We draw on data from a period when both UI and UA payments are observed in the AMS data (2001-2009), and zoom in on workers whose UI benefits ran out and who did not take up employment in the subsequent 60 days. We then calculate the average ratio of UA to UI benefits. We assign everyone zero UA benefits if they do not receive UA benefits in the 60 days after UI benefits ran out, even though they may have been eligible for non-zero UA benefits but did not take them up. In our sample, we find that the average UA benefit corresponds to $50.5 \%$ of previous UI benefits.

The average replacement rate between 1988 and 1993 was 40.0\%. We calculate the average replacement rate for workers in eligible cohorts in the REBP region by simply assigning replacement rates to workers based on their earnings and averaging over workers from 1988 to 1993.

As a final input into our calculation, we account for the fact that benefits are not taxed. The average tax rate for personal income in Austria was $11.2 \%$ after a 1989 tax reform OECD (1990). In addition, employee-borne payroll taxes of about $18 \%$ were levied on wages ${ }^{28} \mathrm{We}$ thus scale up UI and UA benefits relative to gross income by $1 /\left(\left(1-\tau_{\text {average }}\right)\left(1-\tau_{\text {average }}^{\text {Soc. Sec. }}\right)\right)$ to account for non-taxation of benefits.

We can then calculate the cash value of the reform to the average worker according to

${ }^{27}$ For most of the treatment period, since 1989, the potential benefit duration for older workers was 52 weeks. Until 1989, the potential benefit duration was 30 weeks.

${ }^{28}$ Specifically, the total payroll taxes contribution rates for workers and firms were, in sum, $34.5 \%$ for blueand $38.6 \%$ for white-collar workers OECD (1990). In our sample, about $35.4 \%$ of workers among 1988 job holders were white-collar workers so that the average social security contribution rate is $0.345 \cdot(1-0.354)+$ $0.386 \cdot 0.354 \simeq 0.36$, leading to a worker contribution rate of $18 \%$. 
the formula:

$$
\underbrace{31.1315}_{\text {Additional UI months }} \times \underbrace{0.400}_{\text {UI RR }} \times \underbrace{(1-0.505)}_{\left(\frac{\text { UI RR - UA RR }}{\text { UI RR }}\right)} \times \underbrace{((1-0.115)(1-0.18))^{-1}}_{\left(\left(1-\tau_{\text {average }}\right)\left(1-\tau_{\text {average }}^{\text {Soc. Sec }}\right)\right)^{-1}} \times w=8.494 \cdot w,
$$

where $w$ denotes the average worker's monthly gross wage and RR denotes replacement rates. According to this calculation, the average cash value of the REBP reform to workers was about eight to nine months of salary or $71 \%$ of an annual salary. ${ }^{29}$

\footnotetext{
${ }^{29}$ Wages in Austria are paid based in 14, rather than 12, installments. The additional two installments are incorporated in the calculation of UI benefits. The monthly wage we mention above corresponds to an average wage corresponding to the annual salary divided by 12 .
} 


\section{B Theoretical Appendix: Full Coasean Model}

The full model below formalizes the effect of REBP and its repeal within the general Coasean model of jobs.

During-REBP Separation Behavior Separations (during [after] REBP denoted by $\delta[\Delta]$ ) occur if joint surplus were to turn negative, either due to aggregate shocks denoted by $\varepsilon$ (e.g., $\varepsilon_{b}^{W \prime}$ from the shift in UI benefits) or idiosyncratic shocks (health, productivity, amenities,...). Denote by $k\left(\mathbf{V}^{\prime} \mid \mathbf{V}\right)$ the Markov process governing the transition of job values into REBP and by $K\left(\mathbf{V}^{\prime \prime} \mid \mathbf{V}^{\prime}\right)$ the Markovian transition out of REBP, into the post-repeal period. We define $\widetilde{S}\left(\mathbf{V}^{\prime}\right)$ as the short-hand for the surplus level gross of a given aggregate surplus shifter, such that, for an aggregate shock $-\varepsilon^{\prime}<0, \widetilde{S}\left(\mathbf{V}^{\prime}, \varepsilon^{\prime}=0\right)=S\left(\mathbf{V}^{\prime}, \varepsilon^{\prime}\right)-\varepsilon^{\prime}$. For $\operatorname{REBP}, \varepsilon^{\prime}=\varepsilon_{b}^{W \prime}$, and hence separations in the treatment [control] group $Z=1[=0$ ] are:

$$
\delta^{Z}=\int_{\mathbf{V}} \underbrace{\int_{\mathbf{V}^{\prime}} \mathbb{1}\left(\widetilde{S}\left(\mathbf{V}^{\prime}\right)<Z \times \varepsilon_{b}^{W \prime}\right) k\left(\mathbf{V}^{\prime} \mid \mathbf{V}\right) d \mathbf{V}^{\prime}}_{\equiv \widetilde{\mathbb{d}}\left(\mathbf{V}, \mathrm{Z} \times \varepsilon_{b}^{W \prime}\right)} f^{Z}(\mathbf{V}) d \mathbf{V} .
$$

where $\widetilde{d}$ is a slight modification of $\mathbb{d}$ to a gross-surplus concept with separate aggregate shocks, and $f^{Z}($.) denotes the distribution prevailing at the onset of REBP, where we will assume that initial distributions are the same across groups $f^{0}()=.f^{1}($.). By contrast, $f_{\text {post }}^{Z}($.$) will denote post-REBP distributions that will naturally diverge due to REBP, not$ only in terms of surplus, but also in terms of some direct observables.

In this framework, the treatment effect of REBP corresponds to:

$$
\begin{aligned}
\delta^{1}-\delta^{0} & =\int_{\mathbf{V}} \int_{\mathbf{V}^{\prime}} \mathbb{1}\left(0 \leq \widetilde{S}\left(\mathbf{V}^{\prime}\right)<\varepsilon_{b}^{W \prime}\right) k\left(\mathbf{V}^{\prime} \mid \mathbf{V}\right) d \mathbf{V}^{\prime} f^{0}(\mathbf{V}) d \mathbf{V}=\int_{\mathbf{V}} \int_{\mathbf{V}^{\prime} \in M^{\prime}} k\left(\mathbf{V}^{\prime} \mid \mathbf{V}\right) d \mathbf{V}^{\prime} f^{0}(\mathbf{V}) d \mathbf{V} \\
& =\int_{\mathbf{V}}\left[\widetilde{\mathbb{d}}\left(\mathbf{V}, \varepsilon_{b}^{W \prime}\right)-\widetilde{\mathbb{d}}(\mathbf{V}, 0)\right] f^{0}(\mathbf{V}) d \mathbf{V},
\end{aligned}
$$

where the last line clarifies that the difference in separation rates comes from different thresholds (the gross-of-REBP surplus in the treated regions needs to meet a higher bar) and not from different pre-REBP distributions between the treated and the control regions (which instead we assume to be the same). The marginal jobs extracted by REBP make up set $M^{\prime}=\left\{\mathbf{V}^{\prime}: 0 \leq \widetilde{S}\left(\mathbf{V}^{\prime}\right)<\varepsilon_{b}^{W \prime}\right\}$. Our model makes no assumption on the origin of the surplus-relevant factors' distributions through surplus evolution $k\left(\mathbf{V}^{\prime} \mid \mathbf{V}\right)$. The surplus distribution can be partitioned into: (i) jobs that separate even in the control group fraction $\delta^{0}$ of the total mass at the onset of REBP; (ii) marginal jobs that separate due to REBP - fraction $\delta^{1}-\delta^{0}$; and (iii) infra-marginal jobs that don't separate even with REBP fraction $1-\delta^{1}$. 
REBP-Induced Truncation of the Surplus Distribution After the repeal of REBP, the program has truncated the treatment group's joint-surplus distribution below $\varepsilon_{b}^{W \prime}$. Hence, while the wider set of surviving jobs in the control group is $J^{\prime}=\left\{\mathbf{V}^{\prime}: \widetilde{S}\left(\mathbf{V}^{\prime}\right) \geq 0\right\}$, in the treatment group, the entire mass of survivors is concentrated in the inframarginal jobs, $\mathbf{V}^{\prime} \in\left(J^{\prime} \backslash M^{\prime}\right)$. ${ }^{30}$

Post-Repeal Separation Behavior We denote post-repeal-of-REBP functions with capital letters, namely $\Delta$ for $\delta, \mathbb{D}$ for $\mathbb{d}$, and $K$ for $k$. Post-repeal aggregate shocks and job value factors are denoted by " rather than'. The post-repeal separation behavior of the formerly treated and control groups can be formalized by considering aggregate (common to both groups) worker and firm surplus shocks $\varepsilon^{W^{\prime \prime}}$ and $\varepsilon^{F^{\prime \prime}}$, which we combine into a jointsurplus shock $\varepsilon^{\prime \prime}=\varepsilon^{W^{\prime \prime}}+\varepsilon^{F^{\prime \prime}}$. Post-repeal, these shocks lead to the following separation rates in the treatment [control] group $Z=1[=0]$ :

$$
\Delta^{Z}=\int_{\mathbf{V}^{\prime}} \underbrace{\int_{\mathbf{V}^{\prime \prime}} \mathbb{1}\left(\widetilde{S}\left(\mathbf{V}^{\prime \prime}\right)<\varepsilon^{\prime \prime}\right) K\left(\mathbf{V}^{\prime \prime} \mid \mathbf{V}^{\prime}\right) d \mathbf{V}^{\prime \prime}}_{\equiv \widetilde{\mathbb{D}}\left(\mathbf{V}^{\prime}, \varepsilon^{\prime \prime}\right)} f_{\text {post }}^{Z}\left(\mathbf{V}^{\prime}\right) d \mathbf{V}^{\prime} .
$$

Post-repeal, differences in separation rates will arise from differences in $f_{\text {post }}^{Z}$, the densities of job qualities between the treatment and the control groups, due to the selective separations induced by REBP (rather than from differences in aggregate shocks and thresholds $\varepsilon^{W^{\prime \prime}}$ and $\varepsilon^{F^{\prime \prime}}$, which in turn we here assume to the same across the groups, hence unlike during REBP, which shifted thresholds $Z \times \varepsilon_{b}^{W \prime}$ ):

$$
\Delta^{1}-\Delta^{0}=\int_{\mathbf{V}^{\prime}} \widetilde{\mathbb{D}}\left(\mathbf{V}^{\prime}, \varepsilon^{\prime \prime}\right)\left[f_{\text {post }}^{1}\left(\mathbf{V}^{\prime}\right)-f_{\text {post }}^{0}\left(\mathbf{V}^{\prime}\right)\right] d \mathbf{V}^{\prime} .
$$

${ }^{30}$ The density $f_{\text {post }}^{1}\left(\mathbf{V}^{\prime}\right)$ is zero for the marginal jobs, while the inframarginal REBP survivors reflect the (conditional) distribution in the control group starting from truncation point $\varepsilon_{b}^{W \prime}$ :

$$
f_{\text {post }}^{1}\left(\mathbf{V}^{\prime}\right)=\left\{\begin{array}{lll}
0 & \text { if } \quad \mathbf{V}^{\prime} \notin\left(J^{\prime} \backslash M^{\prime}\right) \Leftrightarrow \widetilde{S}\left(\mathbf{V}^{\prime}\right)<\varepsilon_{b}^{W \prime} \\
\frac{f_{\text {post }}^{0}\left(\mathbf{V}^{\prime}\right)}{1-\int_{\mathbf{V} \in M^{\prime}} f_{\text {post }}^{0}\left(\mathbf{V}^{\prime}\right) d \mathbf{V}^{\prime}} & \text { if } & \mathbf{V}^{\prime} \in\left(J^{\prime} \backslash M^{\prime}\right) \Leftrightarrow \widetilde{S}\left(\mathbf{V}^{\prime}\right) \geq \varepsilon_{b}^{W \prime} .
\end{array}\right.
$$


We now derive the separation rate of the former treatment group by replacing its densities as truncated versions of the control group's, as following Equation (A5) 31

$$
\begin{aligned}
\Delta^{1} & =\int_{\mathbf{V}^{\prime}} \widetilde{\mathbb{D}}\left(\mathbf{V}^{\prime}, \varepsilon^{\prime \prime}\right) f_{\text {post }}^{1}\left(\mathbf{V}^{\prime}\right) d \mathbf{V}^{\prime} \\
& =\int_{\mathbf{V}^{\prime} \in M^{\prime}} \widetilde{\mathbb{D}}\left(\mathbf{V}^{\prime}, \varepsilon^{\prime \prime}\right) f_{\text {post }}^{1}\left(\mathbf{V}^{\prime}\right) d \mathbf{V}^{\prime}+\int_{\mathbf{V}^{\prime} \notin M^{\prime}} \widetilde{\mathbb{D}}\left(\mathbf{V}^{\prime}, \varepsilon^{\prime \prime}\right) f_{\text {post }}^{1}\left(\mathbf{V}^{\prime}\right) d \mathbf{V}^{\prime} \\
& =0+\int_{\mathbf{V}^{\prime} \notin M^{\prime}} \widetilde{\mathbb{D}}\left(\mathbf{V}^{\prime}, \varepsilon^{\prime \prime}\right)\left[f_{\text {post }}^{0}\left(\mathbf{V}^{\prime}\right) \frac{1-\delta^{0}}{1-\delta^{1}}\right] d \mathbf{V}^{\prime} \\
& =\frac{1-\delta^{0}}{1-\delta^{1}}\left[\int_{\mathbf{V}^{\prime} \notin M^{\prime}} \widetilde{\mathbb{D}}\left(\mathbf{V}^{\prime}, \varepsilon^{\prime \prime}\right) f_{\text {post }}^{0}\left(\mathbf{V}^{\prime}\right) d \mathbf{V}^{\prime} \pm \int_{\mathbf{V}^{\prime} \in M^{\prime}} \widetilde{\mathbb{D}}\left(\mathbf{V}^{\prime}, \varepsilon^{\prime \prime}\right) f_{\text {post }}^{0}\left(\mathbf{V}^{\prime}\right) d \mathbf{V}^{\prime}\right] \\
& =\frac{1-\delta^{0}}{1-\delta^{1}}\left[\Delta^{0}-\int_{\mathbf{V}^{\prime} \in M^{\prime}} \widetilde{\mathbb{D}}\left(\mathbf{V}^{\prime}, \varepsilon^{\prime \prime}\right) f_{\text {post }}^{0}\left(\mathbf{V}^{\prime}\right) d \mathbf{V}^{\prime}\right] .
\end{aligned}
$$

The intuition is straightforward: modulo re-scaling by $\frac{1-\delta^{0}}{1-\delta^{1}}$ (since, post-repeal, the fraction of original jobs that remain in the treatment and in the control group is different), the separation behavior of the treatment group $\left(\Delta^{1}\right)$ is the same as that of the control group $\left(\Delta^{0}\right)$ except for the contribution of marginal matches $\left(\mathbf{V}^{\prime} \in M^{\prime}\right)$ to the separation behavior of the control group, which the expression nets out.

In order to map Equation (A9) into an empirically tangible object, we now put some structure on $K\left(\mathbf{V}^{\prime \prime} \mid \mathbf{V}^{\prime}\right)$.

Post-Repeal Idiosyncratic Shocks $K\left(\mathbf{V}^{\prime \prime} \mid \mathbf{V}^{\prime}\right)$ Up until now we have not made any assumption on the processes underlying the evolution of job surplus, $k\left(\mathbf{V}^{\prime} \mid \mathbf{V}\right)$ and $K\left(\mathbf{V}^{\prime \prime} \mid \mathbf{V}^{\prime}\right)$ - neither during REBP, nor for separations after the repeal. Two extreme cases are now presented below: perfect persistence as well as immediate reshuffling of idiosyncratic surplus. Importantly, in both cases, the evolution of surplus during the five-year REBP period $k\left(V^{\prime} \mid \boldsymbol{V}\right)$ is left fully general. We only specify the Markov process for right after REBP is repealed in 1993, namely $K\left(V^{\prime \prime} \mid V^{\prime}\right)$, so that this assumption only covers a shorter time horizon than the original REBP period.

Case I: Perfect Persistence This case permits fully general pre-repeal evolution $k\left(\mathbf{V}^{\prime} \mid \mathbf{V}\right)$. But it assumes that right after the repeal of REBP, specifically between the repeal period and the next period, the underlying job surplus is persistent. The sensibility of this assumption naturally depends on the given time interval from the repeal to the time we measure separations in the data; our most conservative horizon is one single year

${ }^{31}$ Specifically, from Equation $\mathrm{A5}$, for $\mathbf{V}^{\prime} \notin M^{\prime}$ :

$$
f_{\text {post }}^{1}\left(\mathbf{V}^{\prime}\right)=\frac{f_{\text {post }}^{0}\left(\mathbf{V}^{\prime}\right)}{1-\int_{\mathbf{V}^{\prime} \in M^{\prime}} f_{\text {post }}^{0}\left(\mathbf{V}^{\prime}\right) d \mathbf{V}^{\prime}}=\frac{f_{\text {post }}^{0}\left(\mathbf{V}^{\prime}\right)}{1-\frac{\delta^{1}-\delta^{0}}{1-\delta^{0}}}=f_{\text {post }}^{0}\left(\mathbf{V}^{\prime}\right) \frac{1-\delta^{0}}{1-\delta^{1}},
$$

where the second equality follows from the fact that the mass of marginal jobs (i.e. $\mathbf{V}^{\prime} \in M^{\prime}$ ) in the control group is $\frac{\delta^{1}-\delta^{0}}{1-\delta^{0}}$. 
following the repeal. Formally, the post-repeal transition matrix is now the identity matrix: $K\left(\mathbf{V}^{\prime \prime} \mid \mathbf{V}^{\prime}\right)=1$ if $\mathbf{V}^{\prime \prime}=\mathbf{V}^{\prime}$ and 0 otherwise; as a result, $\widetilde{\mathbb{D}}\left(\mathbf{V}^{\prime}, \varepsilon^{\prime \prime}\right)=\int_{\mathbf{V}^{\prime \prime}} \mathbb{1}\left(\widetilde{S}\left(\mathbf{V}^{\prime \prime}\right)<\right.$ $\left.\varepsilon^{\prime \prime}\right) K\left(\mathbf{V}^{\prime \prime} \mid \mathbf{V}^{\prime}\right) d \mathbf{V}^{\prime \prime}=\mathbb{1}\left(\widetilde{S}\left(\mathbf{V}^{\prime}\right)<\varepsilon^{\prime \prime}\right)$.

It is useful to distinguish two cases: $\varepsilon^{\prime \prime} \leq \varepsilon_{b}^{W \prime}$, and $\varepsilon^{\prime \prime}>\varepsilon_{b}^{W \prime}$. In case $\varepsilon^{\prime \prime} \leq \varepsilon_{b}^{W \prime}$, it follows from the definition of $\Delta^{1}$ in Equation (A6) that only marginal matches separate i.e. $\Delta^{0}=\int_{\mathbf{V}^{\prime} \in M^{\prime}} \widetilde{\mathbb{D}}\left(\mathbf{V}^{\prime}, \varepsilon^{\prime \prime}\right) f_{\text {post }}^{0}\left(\mathbf{V}^{\prime}\right) d \mathbf{V}^{\prime}$, and therefore ${ }^{32}$

$$
\Delta_{\varepsilon^{\prime \prime} \leq \varepsilon_{b}^{W}}^{1}=0
$$

In case $\varepsilon^{\prime \prime}>\varepsilon_{b}^{W \prime}$, all marginal matches separate in the control group and more, and so $\widetilde{\mathbb{D}}\left(\mathbf{V}^{\prime}, \varepsilon^{\prime \prime}\right)=1 \quad \forall \mathbf{V}^{\prime} \in M^{\prime}$, and $\Delta^{0}>\int_{\mathbf{V}^{\prime} \in M^{\prime}} \widetilde{\mathbb{D}}\left(\mathbf{V}^{\prime}, \varepsilon^{\prime \prime}\right) f_{\text {post }}^{0}\left(\mathbf{V}^{\prime}\right) d \mathbf{V}^{\prime}$. Hence, for this case, Equation (A9) becomes:

$$
\begin{aligned}
\Delta_{\varepsilon^{\prime \prime}>\varepsilon_{b}^{W \prime}}^{1} & =\frac{1-\delta^{0}}{1-\delta^{1}}\left[\Delta^{0}-\int_{\mathbf{V}^{\prime} \in M^{\prime}} f_{\text {post }}^{0}\left(\mathbf{V}^{\prime}\right) d \mathbf{V}^{\prime}\right] \\
& =\frac{1-\delta^{0}}{1-\delta^{1}}\left[\Delta^{0}-\frac{\delta^{1}-\delta^{0}}{1-\delta^{0}}\right],
\end{aligned}
$$

where $\frac{\delta^{1}-\delta^{0}}{1-\delta^{0}}$ is the fraction of marginal jobs in the control group, as discussed above.

Putting the two cases together, for the full range of aggregate shocks $\varepsilon^{\prime \prime}$ - which are unobserved but sufficiently revealed through realized control group post-repeal separation rate $\Delta^{0}$ - we obtain the model-predicted $\Delta^{1}$ as a function of $\Delta^{0}$, piece-wise linear with slopes and kink positions given by $\left(\delta^{0}, \delta^{1}\right): \Delta^{1}\left(\Delta^{0}\left(\varepsilon^{\prime \prime}\right), \delta^{0}, \delta^{1}\right)=\max \left\{0, \frac{1-\delta^{0}}{1-\delta^{1}}\left[\Delta^{0}\left(\varepsilon^{\prime \prime}\right)-\frac{\delta^{1}-\delta^{0}}{1-\delta^{0}}\right]\right\}$. As long as control group post-repeal separation rate $\Delta^{0}$ is lower than the fraction of marginal matches $\frac{\delta^{1}-\delta^{0}}{1-\delta^{0}}$, no separations should occur in the treatment group, simply because these matches are missing. Once control group separations cross that threshold, separations commence, and with a slope steeper than one, $\frac{1-\delta^{0}}{1-\delta^{1}}$, because the incremental separator count is over a smaller count of survivors in the formerly treated group, and both groups will have separation rates of $100 \%$ if all control jobs dissolve. Similarly, if the initial REBP treatment effect was zero, the curve would trace out a 45 degree line $\Delta^{1}=\Delta^{0}$. In that sense, the design has power if the initial treatment effect during REBP was large shifting the kink far to the right away from zero on the $\mathrm{x}$-axis.

That is, the revealed-preference treatment/control group approach makes empirically and quantitatively tractable the Coasean benchmark (with persistence) by reformulating the empirically elusive surplus concepts in the form of observables $-\Delta^{1}, \Delta^{0}$ and $\left(\delta^{0}, \delta^{1}\right)$. These properties sufficiently encode the surplus concepts $S$ as well as shocks $\varepsilon_{b}^{W \prime}$ of REBP, and the post-repeal shocks $\left(\varepsilon^{W \prime \prime}, \varepsilon^{F \prime \prime}\right)$.

${ }^{32}$ To see this, note that under the assumption of perfect persistence, $\Delta^{0}=\int_{\mathbf{V}^{\prime}} \mathbb{1}\left(\widetilde{S}\left(\mathbf{V}^{\prime}\right)<\varepsilon^{\prime \prime}\right) f_{\text {post }}^{0}\left(\mathbf{V}^{\prime}\right) d \mathbf{V}^{\prime}$. If $\varepsilon^{\prime \prime} \leq \varepsilon_{b}^{W \prime}$, all the separations come from $\mathbf{V}^{\prime}$ such that $\mathbb{1}\left(\widetilde{S}\left(\mathbf{V}^{\prime}\right)<\varepsilon_{b}^{W \prime}\right)$, which are $\mathbf{V}^{\prime} \in M^{\prime}$; therefore $\Delta^{0}=\int_{\mathbf{V}^{\prime}} \mathbb{1}\left(\widetilde{S}\left(\mathbf{V}^{\prime}\right)<\varepsilon^{\prime \prime}\right) f_{\text {post }}^{0}\left(\mathbf{V}^{\prime}\right) d \mathbf{V}^{\prime}=\int_{\mathbf{V}^{\prime} \in M^{\prime}} \mathbb{1}\left(\widetilde{S}\left(\mathbf{V}^{\prime}\right)<\varepsilon^{\prime \prime}\right) f_{\text {post }}^{0}\left(\mathbf{V}^{\prime}\right) d \mathbf{V}^{\prime}=\int_{\mathbf{V}^{\prime} \in M^{\prime}} \widetilde{\mathbb{D}}\left(\mathbf{V}^{\prime}, \varepsilon^{\prime \prime}\right) f_{\text {post }}^{0}\left(\mathbf{V}^{\prime}\right) d \mathbf{V}^{\prime}$. 
Case II: Perfect Reshuffling Next, we clarify the conditions required for the Coasean framework to rationalize the observed pattern: $\Delta^{1}=\Delta^{0}$. Since we will compare $\Delta^{0}$ and $\Delta^{1}$ across cells (cohorts and for an even wider range across an industry-occupation cells), we look for the condition that is capable of delivering $\Delta^{1}\left(\varepsilon^{\prime \prime}\right)=\Delta^{0}\left(\varepsilon^{\prime \prime}\right)$ for the entire range of post-repeal aggregate shocks $\varepsilon^{\prime \prime}$ hence captured by any level of $\Delta^{0} \in[0,1]$, and for any $\left(\delta_{0}, \delta_{1}\right)$ arising from REBP determining the missing mass of low-surplus matches in the former control group. We show that this condition yields a particular assumption about the process governing idiosyncratic surplus evolution - which then renders inconsequential the extraction of marginal jobs during REBP, by reshuffling immediately and fully the surplus distribution, such that the former treatment and control groups reconverge despite the massive extraction of marginal, low-surplus jobs. This condition requires that individual jobs do not have any persistence in their job-level surplus and their ranking, such that even within just a year the "hole" left by REBP in the treatment group is fully filled again. Formally, the Coasean case requires the following condition for equality between the separation rates:

$$
\begin{aligned}
& \Delta^{1}\left(\varepsilon^{\prime \prime}, \delta_{0}, \delta_{1}\right)=\Delta^{0}\left(\varepsilon^{\prime \prime}, \delta_{0}, \delta_{1}\right) \\
& \Leftrightarrow \int_{\mathbf{V}^{\prime} \in M^{\prime}} \widetilde{\mathbb{D}}\left(\mathbf{V}^{\prime}, \varepsilon^{\prime \prime}\right) \underbrace{f_{\text {post }}^{1}\left(\mathbf{V}^{\prime}\right)}_{=0} d \mathbf{V}^{\prime}+\int_{\mathbf{V}^{\prime} \in\left(J^{\prime} \backslash M^{\prime}\right)} \widetilde{\mathbb{D}}\left(\mathbf{V}^{\prime}, \varepsilon^{\prime \prime}\right) \underbrace{f_{\text {post }}^{1}\left(\mathbf{V}^{\prime}\right)}_{\frac{1-\delta^{0}}{1-\delta^{1}}\left(\mathbf{V}^{\prime}\right)} d \mathbf{V}^{\prime}+\int_{\mathbf{V}^{\prime} \notin J^{\prime}} \widetilde{\mathbb{D}}\left(\mathbf{V}^{\prime}, \varepsilon^{\prime \prime}\right) \underbrace{f_{\text {post }}^{1}\left(\mathbf{V}^{\prime}\right)}_{0} d \mathbf{V}^{\prime}= \\
& \int_{\mathbf{V}^{\prime} \in M^{\prime}} \widetilde{\mathbb{D}}\left(\mathbf{V}^{\prime}, \varepsilon^{\prime \prime}\right) f_{\text {post }}^{0}\left(\mathbf{V}^{\prime}\right) d \mathbf{V}^{\prime}+\int_{\mathbf{V}^{\prime} \in\left(J^{\prime} \backslash M^{\prime}\right)} \widetilde{\mathbb{D}}\left(\mathbf{V}^{\prime}, \varepsilon^{\prime \prime}\right) f_{\text {post }}^{0}\left(\mathbf{V}^{\prime}\right) d \mathbf{V}^{\prime}+\int_{\mathbf{V}^{\prime} \notin J^{\prime}} \widetilde{\mathbb{D}}\left(\mathbf{V}^{\prime}, \varepsilon^{\prime \prime}\right) \underbrace{f_{\text {post }}^{0}\left(\mathbf{V}^{\prime}\right)}_{0} d \mathbf{V}^{\prime} \\
& \Leftrightarrow \int_{\mathbf{V}^{\prime} \in M^{\prime}} \widetilde{\mathbb{D}}\left(\mathbf{V}^{\prime}, \varepsilon^{\prime \prime}\right) f_{\text {post }}^{0}\left(\mathbf{V}^{\prime}\right)\left[\frac{1-\delta^{0}}{\delta^{1}-\delta^{0}}\right] d \mathbf{V}^{\prime}=\int_{\mathbf{V}^{\prime} \in\left(J^{\prime} \backslash M^{\prime}\right)} \widetilde{\mathbb{D}}\left(\mathbf{V}^{\prime}, \varepsilon^{\prime \prime}\right) f_{\text {post }}^{0}\left(\mathbf{V}^{\prime}\right)\left[\frac{1-\delta^{0}}{1-\delta^{1}}\right] d \mathbf{V}^{\prime} \\
& \Leftrightarrow \underbrace{\int_{\mathbf{V}^{\prime} \in M^{\prime}} \int_{\mathbf{V}^{\prime \prime}} \mathbf{1}\left\{\widetilde{S}\left(\mathbf{V}^{\prime \prime}\right)<\varepsilon^{\prime \prime}\right\} K\left(\mathbf{V}^{\prime \prime} \mid \mathbf{V}^{\prime}\right) d \mathbf{V}^{\prime \prime} \tilde{f}_{M}^{0}\left(\mathbf{V}^{\prime}\right) d \mathbf{V}^{\prime}}=\underbrace{\int_{\mathbf{V}^{\prime} \in\left(J^{\prime} \backslash M^{\prime}\right)} \int_{\mathbf{V}^{\prime \prime}} \mathbf{1}\left\{\widetilde{S}\left(\mathbf{V}^{\prime \prime}\right)<\varepsilon^{\prime \prime}\right\} K\left(\mathbf{V}^{\prime \prime} \mid \mathbf{V}^{\prime}\right) d \mathbf{V}^{\prime \prime} \tilde{f}_{I}^{0}\left(\mathbf{V}^{\prime}\right) d \mathbf{V}^{\prime},} \\
& \text { Avg. sep. rate for the marginal jobs }
\end{aligned}
$$$$
\text { Avg. sep. rate of inframarginal jobs }
$$

where $\tilde{f}_{M}=f_{\text {post }}^{0}\left(\mathbf{V}^{\prime}\right)\left[\frac{1-\delta^{0}}{\delta^{1}-\delta^{0}}\right]$ is the density of the marginal jobs in the control group and $\tilde{f}_{I}^{0}=f_{\text {post }}^{0}\left(\mathbf{V}^{\prime}\right)\left[\frac{1-\delta^{0}}{1-\delta^{1}}\right]$ is the density of the inframarginal jobs in the control group.

The derivation above shows that, to observe the same post-repeal separation rate in the treatment and the control group, the average post-repeal separation rate for the jobs in the marginal group $\left(\mathbf{V}^{\prime} \in M^{\prime}\right)$ must be the same as that for the jobs in the inframarginal group $\left(\mathbf{V}^{\prime} \in\left(J^{\prime} \backslash M^{\prime}\right)\right)$.

This condition is fulfilled if we have perfect reshuffling of job surpluses one period to the next (formally, a transition matrix with identical rows) 33 That is, perfect reshuffling

${ }^{33}$ Strictly speaking, for a given single surplus shock $\varepsilon^{\prime \prime}$ we do not need perfect reshuffling: the condition is that the average separation probabilities of marginal versus inframarginal jobs are the same. However, for the condition to hold globally i.e. for all $\varepsilon^{\prime \prime}$ surplus shocks and REBP treatment effects $\delta^{1}-\delta^{0}-$ a range we try to trace out with cohort cells but then also when splitting up the sample into industry-occupation cells 
of idiosyncratic job surplus can mask Coasean separations: if the economy featured no persistence in worker and firm surplus whatsoever (such that the idiosyncratic Markov process reshuffles the position of jobs into the same, stationary surplus distribution in each period), the economy would not actually feature a truncated distribution when REBP is repealed - despite the massive extraction of temporarily-marginal jobs from REBP. We quantify the weight the data put on this extreme interpretation in the mixed model estimation, and discuss this assumption and hence more broadly the capacity of the Coasean model to account for the empirical separation outcomes in the main text 34

with large variation in separation rates -, perfect reshuffling (i.e. identical rows in the transition matrix) becomes necessary.

${ }^{34}$ Another assumption fulfills the condition at a particular point, but cannot account for the full set of findings: if all jobs have the same separation probability (say, some large negative (e.g., health) shock that is independent of the current job surplus), then the condition holds. But while tractable and intriguing, this assumption would be inconsistent with differential separation in the treated regions in response to REBP (i.e. our treatment effect in the first place) or across cells after the repeal. 


\section{Theoretical Appendix: Full Non-Coasean Model Featur- ing Wage Rigidity}

Non-Coasean Bargaining and Inefficient Separations The strong Coasean result of efficient separations arises from the assumption of flexible (re-)bargaining of compensation, from which joint job surplus stems as the sole allocative concept. However, a variety of potential real-world frictions, e.g. wage rigidity, may preclude such wage setting. Such frictions prevent the parties from moving towards a wage in the feasible-jobs frontier even though the job carries positive joint surplus, thereby shrinking the set of feasible jobs. Then, the Coasean allocation is not necessarily attainable, and inefficient separations can emerge. In this non-Coasean setting, we therefore think of wage $w$ as one additional job attribute that can evolve or be fixed, such that jobs are now characterized by $(w, \mathbf{V})$, and unilateral worker and firm surpluses $S^{W}\left(w, \mathbf{V}^{W}\right)$ and $S^{F}\left(w, \mathbf{V}^{F}\right)$ are allocative.

In consequence, with non-Coasean bargaining, a separation occurs if at least one of worker surplus or firm surplus turns negative at the given wage. Hence, the job-level separation probability is given by

$$
\mathbb{d}(w, \mathbf{V})=\int_{\left(w^{\prime}, \mathbf{V}^{\prime}\right)} \mathbb{1}(\underbrace{S^{W}\left(w^{\prime}, \mathbf{V}^{W \prime}\right)<0}_{\text {Quit }} \overbrace{V^{\text {Mutual Sep.: }} \wedge}^{S^{F}\left(w^{\prime}, \mathbf{V}^{F \prime}\right)<0}) k\left(\left(w^{\prime}, \mathbf{V}^{\prime}\right) \mid(w, \mathbf{V})\right) d\left(w^{\prime}, \mathbf{V}^{\prime}\right),
$$

where separations can be labled as quits (negative worker surplus but positive firm surplus), layoffs (reversed), or mutual separations (both negative). The non-Coasean expression also formalizes that here the initial incidence of a shock matters for separations for lack of automatic Coasean rebargaining, such that worker and firm values are not "fungible."

Separation Effects from REBP REBP reduced worker surplus, as REBP directly shifted workers' (nonemployment) outside option. Any market-level effects that in turn affected firm outside options or inside values we net out with a control group in the data.

Formally, the two separation rates by treatment group $(Z=1)$ and control group $(Z=0)$ therefore occur to differential worker surplus cutoffs, albeit at the same firm cutoff (here again normalized to zero without loss of generality). Let $\widetilde{S}^{i}\left(w^{\prime}, \mathbf{V}^{\prime}\right)$ denote the surplus of party $i \in\{W, F\}$ gross of a given aggregate shock, e.g. during REBP again the REBP worker surplus shifter $\varepsilon_{b}^{W \prime}$. We thus have: where $\widetilde{d}$ is a slight modification of $\mathbb{d}$ defined in Equation (A11).

REBP therefore pushed the following mass of jobs initially viable in 1988 into quit or layoff (or both) territory of negative unilateral surpluses, where again $f^{Z}$ (.) denotes the pre-REBP initial surplus distribution: That is, the incremental jobs destroyed by REBP had low worker surplus, between 0 and $\varepsilon_{b}^{W^{\prime}}$, making up the set of marginal-to-REBP jobs $M^{\prime N C}=\left\{\left(w^{\prime}, \mathbf{V}^{\prime}\right): 0 \leq \widetilde{S}^{W}\left(w^{\prime}, \mathbf{V}^{W \prime}\right)<\varepsilon_{b}^{W \prime} \wedge \widetilde{S}^{F}\left(w^{\prime}, \mathbf{V}^{F \prime}\right) \geq 0\right\}$. By contrast, the firm surplus of these jobs were positive (and moreover need not have been low, unless the two are very correlated). 
REBP-Induced Truncation of the Surplus Distribution As a result of REBP, right after the repeal, the treatment group therefore features a missing mass of marginal matches between 0 and $\varepsilon_{b}^{W^{\prime}}$, making up the set of marginal-to-REBP jobs $M^{\prime N C}=\left\{\left(w^{\prime}, \mathbf{V}^{\prime}\right): 0 \leq\right.$ $\left.\widetilde{S}^{W}\left(w^{\prime}, \mathbf{V}^{W \prime}\right)<\varepsilon_{b}^{W \prime} \wedge \widetilde{S}^{F}\left(w^{\prime}, \mathbf{V}^{F \prime}\right) \geq 0\right\}$ with low worker but not necessarily low firm surplus. By contrast, the distribution of surpluses in the control group remains a larger set $J^{\prime N C}=\left\{\left(w^{\prime}, \mathbf{V}^{\prime}\right): \widetilde{S}^{W}\left(w^{\prime}, \mathbf{V}^{W \prime}\right) \geq 0 \wedge \widetilde{S}^{F}\left(w^{\prime}, \mathbf{V}^{F \prime}\right) \geq 0\right\}$, still containing the low workersurplus jobs $M^{\prime N C} 35$

Post-Repeal Separation Behavior We again define the post-repeal separation rate of treatment [control] group $Z=1[=0]$ as a function of common worker and firm shocks $\varepsilon^{W^{\prime \prime}}$ and $\varepsilon^{F^{\prime \prime}}$ (which we can now, in contrast to the Coasean model, no longer collapse into a joint surplus shock $\varepsilon^{\prime \prime}$ as shocks are no longer fungible):

$$
\begin{aligned}
\Delta^{Z}= & \int_{\left(w^{\prime}, \mathbf{V}^{\prime}\right)} \underbrace{\int_{\left(w^{\prime \prime}, \mathbf{V}^{\prime \prime}\right)} \mathbb{1}\left(\widetilde{S}^{W}\left(w^{\prime \prime}, \mathbf{V}^{\prime \prime}\right)<\varepsilon^{W \prime \prime} \vee \widetilde{S}^{F}\left(w^{\prime \prime}, \mathbf{V}^{\prime \prime}\right)<\varepsilon^{F \prime \prime}\right) K\left(\left(w^{\prime \prime}, \mathbf{V}^{\prime \prime}\right) \mid\left(w^{\prime}, \mathbf{V}^{\prime}\right)\right) d\left(w^{\prime \prime}, \mathbf{V}^{\prime \prime}\right)}_{\equiv \widetilde{\mathbb{D}}\left(w^{\prime}, \mathbf{V}^{\prime} ; \varepsilon^{W \prime}, \varepsilon^{F \prime \prime}\right)} \\
f_{\text {post }}^{Z}\left(w^{\prime}, \mathbf{V}^{\prime}\right) d\left(w^{\prime}, \mathbf{V}^{\prime}\right) . & \text { (A13) }
\end{aligned}
$$

The non-Coasean analogue of the Coasean predicted post-repeal separation rate (A9) is (from a closely analogous derivation):

$$
\Delta^{1}=\frac{1-\delta^{0}}{1-\delta^{1}}\left[\Delta^{0}-\int_{\left(w^{\prime}, \mathbf{V}^{\prime}\right) \in M^{\prime N C}} \widetilde{\mathbb{D}}\left(w^{\prime}, \mathbf{V}^{\prime} ; \varepsilon^{W \prime \prime}, \varepsilon^{F \prime \prime}\right) f_{\text {post }}^{0}\left(w^{\prime}, \mathbf{V}^{\prime}\right) d\left(w^{\prime}, \mathbf{V}^{\prime}\right)\right] .
$$

As in the Coasean case, the post-repeal separation behavior of the former treatment group tracks that of the former control group, except for the contribution of the marginal jobs $\left(\left(w^{\prime}, \mathbf{V}^{\prime}\right) \in M^{\prime N C}\right)$ to such separation behavior. Unlike in the Coasean setting, these missing matches are marginal with respect to worker surplus - the dimension along which REBP selects them into separation - but not necessarily with respect to a firm surplus shock.

The Incidence of Worker vs. Firm Surplus Shifts In fact, this non-Coasean model can rationalize the observed patterns of separations even if we assume perfect persistence in job surplus following the REBP repeal (an assumption perhaps particularly plausible within the one-year interval following the repeal to 1995). By contrast, the Coasean model was not able to explain the empirical post-repeal separation behavior, except if one were willing to assume full reshuffling in idiosyncratic surplus.

\footnotetext{
${ }^{35}$ Formally in terms of densities, after REBP is repealed, the former treatment group's post-repeal surplus distribution $f_{\text {post }}^{1}($.$) is now again truncated, but specifically with regards to worker rather than joint surplus:$$$
f_{\text {post }}^{1}\left(w^{\prime}, \mathbf{V}^{\prime}\right)= \begin{cases}0 & \text { if } \quad\left(w^{\prime}, \mathbf{V}^{\prime}\right) \notin\left(J^{\prime N C} \backslash M^{\prime N C}\right) \Leftrightarrow \widetilde{S}^{W}\left(w^{\prime}, \mathbf{V}^{W \prime}\right)<\varepsilon_{b}^{W \prime} \vee \widetilde{S}^{F}\left(w^{\prime}, \mathbf{V}^{F \prime}\right)<0 \\ \frac{f_{\text {post }}^{0}\left(w^{\prime}, \mathbf{V}^{\prime}\right)}{1-\int_{\left(w^{\prime}, \mathbf{V}^{\prime}\right) \in M^{\prime N C}} f_{\text {post }}^{0}\left(w^{\prime}, \mathbf{V}^{\prime}\right) d\left(w^{\prime}, \mathbf{V}^{\prime}\right)} & \text { if } \quad\left(w^{\prime}, \mathbf{V}^{\prime}\right) \in\left(J^{\prime N C} \backslash M^{\prime N C}\right) \Leftrightarrow \widetilde{S}^{W}\left(w^{\prime}, \mathbf{V}^{W \prime}\right) \geq \varepsilon_{b}^{W \prime} \wedge \widetilde{S}^{F}\left(w^{\prime}, \mathbf{V}^{F \prime}\right) \geq 0 .\end{cases}
$$ 
As in the Coasean case, our objective is to rewrite expression (A14) in an empirically tractable form of realized control group separation rates (and the original size of the REBP treatment effects). In order to do this, we first specify the model to feature persistence of idiosyncratic job surplus (while still permitting any structure on $k\left(\left(w^{\prime}, \mathbf{V}^{\prime}\right) \mid(w, \mathbf{V})\right)$ i.e. no restriction on idiosyncratic shocks during the five years REBP was active), such that $K\left(\left(w^{\prime \prime}, \mathbf{V}^{\prime \prime}\right) \mid\left(w^{\prime}, \mathbf{V}^{\prime}\right)\right)=1$ if $\left(w^{\prime \prime}, \mathbf{V}^{\prime \prime}\right)=\left(w^{\prime}, \mathbf{V}^{\prime}\right)$ and 0 otherwise, such that for $Z=0,1$, post-repeal separation rates given by (A13) are specified to:

$$
\Delta^{Z}=\int_{\left(w^{\prime}, \mathbf{V}^{\prime}\right)} \mathbb{1}\left(\widetilde{S}^{W}\left(w^{\prime}, \mathbf{V}^{W \prime}\right)<\varepsilon^{W^{\prime \prime}} \vee \widetilde{S}^{F}\left(w^{\prime}, \mathbf{V}^{F \prime}\right)<\varepsilon^{F^{\prime \prime}}\right) f_{\text {post }}^{Z}\left(w^{\prime}, \mathbf{V}^{\prime}\right) d\left(w^{\prime}, \mathbf{V}^{\prime}\right) .
$$

Then, the general relationship between treatment and control separations given by Equation (A14) is specified to:

$\Delta^{1}=\frac{1-\delta^{0}}{1-\delta^{1}}\left[\Delta^{0}-\int_{\left(w^{\prime}, \mathbf{V}^{\prime}\right) \in M^{\prime N C}} \mathbb{1}\left(\widetilde{S}^{W}\left(w^{\prime}, \mathbf{V}^{W \prime}\right)<\varepsilon^{W^{\prime \prime}} \vee \widetilde{S}^{F}\left(w^{\prime}, \mathbf{V}^{F \prime}\right)<\varepsilon^{F^{\prime \prime}}\right) f_{\text {post }}^{0}\left(w^{\prime}, \mathbf{V}^{\prime}\right) d\left(w^{\prime}, \mathbf{V}^{\prime}\right)\right]$

As a second and last step to obtaining empirically tractable expressions, we now distinguish two cases: only worker or only firm shocks driving separations.

Resilience: Post-Repeal Separations Driven by Worker Surplus First, suppose most (all) post-repeal separations arise from worker shocks. In this case, the formerly treated group again exhibits resilience in the form of a piece-wise linear comovement between treatment and control separations featuring a flat-at-zero region, mirroring the Coasean case. This analogue arises because the selection during REBP was with respect to the same allocative concept post-repeal. Accordingly, the resulting expression is analogous to Coasean Equation (B) $\sqrt{36}$

$$
\Delta^{1}\left(\Delta_{0}\left(\varepsilon^{W \prime \prime}\right), \delta_{0}, \delta_{1}\right)=\max \left\{0, \frac{1-\delta^{0}}{1-\delta^{1}}\left[\Delta^{0}\left(\varepsilon^{W \prime \prime}\right)-\frac{\delta^{1}-\delta^{0}}{1-\delta^{0}}\right]\right\} .
$$

${ }^{36}$ To see this, consider again the two cases, $\varepsilon^{W \prime \prime} \leq \varepsilon_{b}^{W \prime}$ and $\varepsilon^{W \prime \prime}>\varepsilon_{b}^{W \prime}$, in order to derive $\Delta_{\varepsilon^{W \prime \prime}>\varepsilon_{b}^{W}}^{1},\left(\varepsilon^{W \prime \prime}\right)$ and $\Delta_{\varepsilon^{W \prime \prime} \leq \varepsilon_{b}^{W}}^{1}\left(\varepsilon^{W \prime \prime}\right)$ similarly to the Coasean persistence case. For the case of $\varepsilon^{W \prime \prime} \leq \varepsilon_{b}^{W \prime}$, it holds that jobs for which $\widetilde{S}^{W}\left(w^{\prime}, \mathbf{V}^{W \prime}\right)<\varepsilon^{W^{\prime \prime}}$ also have $\widetilde{S}^{W}\left(w^{\prime}, \mathbf{V}^{W \prime}\right)<\varepsilon_{b}^{W^{\prime}}$ and hence these jobs were in the marginal set w.r.t. REBP $\left(w^{\prime}, \mathbf{V}^{\prime}\right) \in M^{\prime N C}$. Therefore, using Equation A15, we have for the case of $\varepsilon^{W^{\prime \prime}} \leq \varepsilon_{b}^{W^{\prime}}$ (i.e. now we can limiting the integral to $M^{\prime N C}$ ):

$$
\Delta^{0}\left(\varepsilon^{W \prime \prime}\right)=\int_{\left(w^{\prime}, \mathbf{V}^{\prime}\right) \in M^{\prime N C}} \mathbb{1}\left(\widetilde{S}^{W}\left(w^{\prime}, \mathbf{V}^{W \prime}\right)<\varepsilon^{W^{\prime \prime}} \vee \widetilde{S}^{F}\left(w^{\prime}, \mathbf{V}^{F \prime}\right)<0\right) f_{\text {post }}^{0}\left(w^{\prime}, \mathbf{V}^{\prime}\right) d\left(w^{\prime}, \mathbf{V}^{\prime}\right),
$$

which implies that $\left.\Delta_{\varepsilon^{W \prime \prime}>\varepsilon_{b}^{W}}^{1}, \varepsilon^{W \prime \prime}\right)=0$ by Equation A16. By contrast, for the case of $\varepsilon^{W \prime \prime}>\varepsilon_{b}^{W \prime}$, all marginal-to-REBP jobs $\left(w^{\prime}, \mathbf{V}^{\prime}\right) \in M^{\prime N C}$ satisfy the condition $\left(\widetilde{S}^{W}\left(w^{\prime}, \mathbf{V}^{W \prime}\right)<\varepsilon^{W^{\prime \prime}} \vee \widetilde{S}^{F}\left(w^{\prime}, \mathbf{V}^{F \prime}\right)<0\right)$, and 
Therefore, when there is perfect persistence and only worker shocks, the marginal jobs are those which separate first and hence the average separation rate of the inframarginal jobs is lower than that of the marginal jobs, resulting in $\Delta^{1}\left(\varepsilon^{W \prime \prime}\right) \leq \Delta^{0}\left(\varepsilon^{W \prime \prime}\right)$ as in Equation (A19).

Perfect Comovement: Post-Repeal Separations Driven by Firm Surplus We now ask which properties let the non-Coasean model rationalize the (empirically consistent) comovement between the groups post-repeal. Of course, making an assumption of perfect reshuffling right after the repeal could again generate the perfect comovement in the nonCoasean setting (which was the only way the Coasean setting could rationalize this pattern) ${ }^{37}$ Yet, additionally even with persistence in idiosyncratic surplus, the non-Coasean model can rationalize very similar separation sensitivities between the treatment and control group REBP survivors: if post-repeal separations are largely due to firm surplus shocks. More precisely and subtly, another ingredient is that worker and firm surplus are approximately independently distributed, since REBP extracted jobs that were marginal with respect to worker (rather than firm) surplus.

With firm shocks, again assuming persistence in job surplus right after REBP is repealed but permitting arbitrary surplus evolution during REBP, the empirical relationship between post-repeal separation rates in the treatment and in the control group is driven by the relative separation behavior of marginal and inframarginal matches with respect to firm shocks - which in turn is determined by the distribution of firm surplus in the marginal vs. inframarginal matches. To formally derive this result, we start from the general relationship between the separation rates in the non-Coasean setting (with two

therefore Equation (A16) becomes

$$
\begin{aligned}
\Delta_{\varepsilon^{W \prime \prime} \leq \varepsilon_{b}^{W}}^{1}\left(\varepsilon^{W \prime \prime}\right) & =\frac{1-\delta^{0}}{1-\delta^{1}}\left[\Delta^{0}\left(\varepsilon^{W \prime \prime}\right)-\int_{\left(w^{\prime}, \mathbf{V}^{\prime}\right) \in M^{\prime N C}} \mathbb{1}\left(\widetilde{S}^{W}\left(w^{\prime}, \mathbf{V}^{W \prime}\right)<\varepsilon^{W^{\prime \prime}} \vee \widetilde{S}^{F}\left(w^{\prime}, \mathbf{V}^{F \prime}\right)<0\right) f_{\text {post }}^{0}\left(w^{\prime}, \mathbf{V}^{\prime}\right) d\left(w^{\prime}, \mathbf{V}^{\prime}\right)\right] \\
& =\frac{1-\delta^{0}}{1-\delta^{1}}\left[\Delta^{0}\left(\varepsilon^{W \prime \prime}\right)-\int_{\left(w^{\prime}, \mathbf{V}^{\prime}\right) \in M^{\prime N C}} f_{\text {post }}^{0}\left(w^{\prime}, \mathbf{V}^{\prime}\right) d\left(w^{\prime}, \mathbf{V}^{\prime}\right)\right] \\
& =\frac{1-\delta^{0}}{1-\delta^{1}}\left[\Delta^{0}\left(\varepsilon^{W \prime \prime}\right)-\frac{\delta^{1}-\delta^{0}}{1-\delta^{0}}\right]
\end{aligned}
$$

where $\frac{\delta^{1}-\delta^{0}}{1-\delta^{0}}$ is the fraction of marginal jobs in the control group. Combining the two cases, we obtain Equation (A19).

${ }^{37}$ Perfect comovement requires that, in response to the shock being considered, the average separation rate of the marginal jobs is equal to the average separation rate of the inframarginal jobs. The same identical derivation as Coasean section in paragraph "Case II: Perfect Reshuffling" applies: simply replace $\mathbf{V}^{\prime}$ with $\left(w^{\prime}, \mathbf{V}^{\prime}\right), \widetilde{\mathbb{D}}\left(\mathbf{V}^{\prime}, \varepsilon^{\prime \prime}\right)$ with $\widetilde{\mathbb{D}}\left(w^{\prime}, \mathbf{V}^{\prime} ; \varepsilon^{W \prime}, \varepsilon^{F \prime}\right), M^{\prime}$ and $J^{\prime}$ with $M^{\prime N C}$ and $J^{\prime N C}$ respectively. This condition holds for any shock and any joint density $f_{\text {post }}^{0}\left(w^{\prime} ; \mathbf{V}^{W^{\prime}}, \mathbf{V}^{F^{\prime}}\right)$ when there is perfect reshuffling in surplus. Additionally, it holds for only-firm-shocks when there is perfect persistence and firm and worker surpluses are independently distributed, as discussed below. 
unilateral surpluses and participation constraints) $\sqrt[38]{38}$

$$
\begin{aligned}
& \quad \Delta^{1}\left(\varepsilon^{F \prime \prime}, \delta^{0}, \delta^{1}\right) \lesseqgtr \Delta^{0}\left(\varepsilon^{F \prime}, \delta^{0}, \delta^{1}\right) \\
& \Leftrightarrow \int_{\left(w^{\prime}, \mathbf{V}^{\prime}\right) \in\left(J^{\prime N C} \backslash M^{\prime N C}\right)} \mathbb{1}\left(\widetilde{S}^{W}\left(w^{\prime}, \mathbf{V}^{W \prime}\right)<0 \vee \widetilde{S}^{F}\left(w^{\prime}, \mathbf{V}^{F \prime}\right)<\varepsilon^{F^{\prime \prime}}\right) \tilde{f}_{I}^{0}\left(w^{\prime}, \mathbf{V}^{\prime}\right) d\left(w^{\prime}, \mathbf{V}^{\prime}\right) \\
& \vdots \int_{\left(w^{\prime}, \mathbf{V}^{\prime}\right) \in M^{\prime N C}} \mathbb{1}\left(\widetilde{S}^{W}\left(w^{\prime}, \mathbf{V}^{W \prime}\right)<0 \vee \widetilde{S}^{F}\left(w^{\prime}, \mathbf{V}^{F \prime}\right)<\varepsilon^{F^{\prime \prime}}\right) \tilde{f}_{M}^{0}\left(w^{\prime}, \mathbf{V}^{\prime}\right) d\left(w^{\prime}, \mathbf{V}^{\prime}\right) \\
& \Leftrightarrow \quad \int_{\left(w^{\prime}, \mathbf{V}^{\prime}\right) \in\left(J^{\prime N C} \backslash M^{\prime N C}\right)} \mathbb{1}\left(\widetilde{S}^{F}\left(w^{\prime}, \mathbf{V}^{F \prime}\right)<\varepsilon^{F^{\prime \prime}}\right) \tilde{f}_{I}^{0}\left(w^{\prime}, \mathbf{V}^{\prime}\right) d\left(w^{\prime}, \mathbf{V}^{\prime}\right) \\
& \vdots \int_{\left(w^{\prime}, \mathbf{V}^{\prime}\right) \in M^{\prime N C}} \mathbb{1}\left(\widetilde{S}^{F}\left(w^{\prime}, \mathbf{V}^{F \prime}\right)<\varepsilon^{F^{\prime \prime}}\right) \tilde{f}_{M}^{0}\left(w^{\prime}, \mathbf{V}^{\prime}\right) d\left(w^{\prime}, \mathbf{V}^{\prime}\right) \\
& \Leftrightarrow \operatorname{Prob}\left(0 \leq \widetilde{S}^{F}\left(w^{\prime}, \mathbf{V}^{F \prime}\right)<\varepsilon^{F^{\prime \prime}} \mid \widetilde{S}^{W}\left(w^{\prime}, \mathbf{V}^{W \prime}\right) \geq \varepsilon_{b}^{W \prime}\right) \\
& \lesseqgtr \operatorname{Prob}\left(0 \leq \widetilde{S}^{F}\left(w^{\prime}, \mathbf{V}^{F \prime}\right)<\varepsilon^{F^{\prime \prime}} \mid 0 \leq \widetilde{S}^{W}\left(w^{\prime}, \mathbf{V}^{W \prime}\right)<\varepsilon_{b}^{W \prime}\right),
\end{aligned}
$$

where $\tilde{f}_{I}^{0}\left(w^{\prime}, \mathbf{V}^{\prime}\right)=f_{\text {post }}^{0}\left(w^{\prime}, \mathbf{V}^{\prime}\right)\left[\frac{1-\delta^{0}}{1-\delta^{1}}\right]$ is the density of the inframarginal jobs in the control group and $\tilde{f}_{M}^{0}\left(w^{\prime}, \mathbf{V}^{\prime}\right)=f_{\text {post }}^{0}\left(w^{\prime}, \mathbf{V}^{\prime}\right)\left[\frac{1-\delta^{0}}{\delta^{1}-\delta^{0}}\right]$ is the density of the marginal jobs in the control group.

The second step recognizes that condition $\widetilde{S}^{W}\left(w^{\prime}, \mathbf{V}^{W \prime}\right)<0$ is slack without worker aggregate shocks and with persistence in idiosyncratic surplus (i.e. for these jobs, $\left.f_{\text {post }}^{0}\left(w^{\prime}, \mathbf{V}^{W \prime}, \mathbf{V}^{F \prime}\right)=0\right)$.

The third step clarifies that the conditions now compare two simple conditional cumulative distribution functions of firm surplus with threshold given by the firm surplus shock, for the range of worker surplus shocks partitioned by the REBP surplus cutoff.39

Our empirically interesting case is:

$$
\Delta^{1}\left(\varepsilon^{F \prime \prime}, \delta^{0}, \delta^{1}\right)=\Delta^{0}\left(\varepsilon^{F \prime \prime}, \delta^{0}, \delta^{1}\right),
$$

such that the two post-repeal separation rates are equal for all post-repeal firm shocks and

${ }^{38}$ This expression is derived by specializing Equation (A15) to the case of firm shocks only, and then, analogous to the Coasean derivation $\mathrm{A} 10$, combining the inframarginal jobs in the treatment and control groups on one side, using:

$$
\begin{aligned}
\Delta^{1}\left(\varepsilon^{F \prime \prime}\right) & =\int_{\left(w^{\prime}, \mathbf{V}^{\prime}\right)} \mathbb{1}\left(\widetilde{S}^{W}\left(w^{\prime}, \mathbf{V}^{W \prime}\right)<0 \vee \widetilde{S}^{F}\left(w^{\prime}, \mathbf{V}^{F \prime}\right)<\varepsilon^{F^{\prime \prime}}\right) f_{\text {post }}^{1}\left(w^{\prime}, \mathbf{V}^{\prime}\right) d\left(w^{\prime}, \mathbf{V}^{\prime}\right) \\
& =\int_{\left(w^{\prime}, \mathbf{V}^{\prime}\right) \in\left(J^{\prime N C} \backslash M^{\prime N C}\right)} \mathbb{1}\left(\widetilde{S}^{W}\left(w^{\prime}, \mathbf{V}^{W \prime}\right)<0 \vee \widetilde{S}^{F}\left(w^{\prime}, \mathbf{V}^{F \prime}\right)<\varepsilon^{F^{\prime \prime}}\right) f_{\text {post }}^{0}\left(w^{\prime}, \mathbf{V}^{\prime}\right)\left[\frac{1-\delta^{0}}{1-\delta^{1}}\right] d\left(w^{\prime}, \mathbf{V}^{\prime}\right),
\end{aligned}
$$

where the second equality follows from Equation (A12) (after reformulating the densities there into $1-\delta^{0}$ and $\left.1-\delta^{1}\right)$.

${ }^{39} \mathrm{To}$ see this formally, note that the property of joint densities implies that $f_{\text {post }}^{0}\left(w^{\prime}, \mathbf{V}^{W \prime}, \mathbf{V}^{F \prime}\right)=$ 
moreover for any size of the set of marginal jobs REBP extracted $\left(\delta^{1}-\delta^{0}\right)$. This "global" condition is fulfilled if worker and firm surpluses are independently distributed.40 The nonCoasean setting can then rationalize our findings of no post-repeal resilience whatsoever even with perfect persistence in idiosyncratic job surplus.

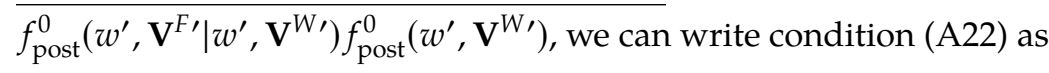

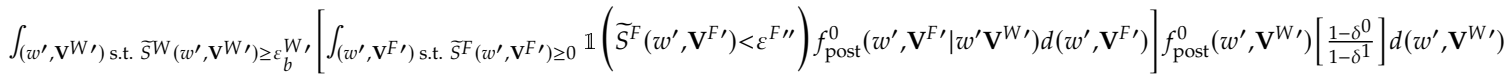

$$
\begin{aligned}
& \lesseqgtr \int_{\left.\left(w^{\prime}, \mathbf{V}^{W^{\prime}}\right) \text { s.t. } 0 \leq \tilde{S}_{\left(w^{\prime}\right.}, \mathbf{V}^{W^{\prime}}\right)<\varepsilon_{b}^{W^{\prime}}}\left[\int_{\left(w^{\prime}, \mathbf{V}^{F^{\prime}}\right) \text { s.t. } \widetilde{s}^{F}\left(w^{\prime}, \mathbf{V}^{F^{\prime}}\right) \geq 0} \mathbb{1}\left(\widetilde{S}^{F}\left(w^{\prime}, \mathbf{V}^{F \prime}\right)<\varepsilon^{F \prime \prime}\right) f_{\text {post }}^{0}\left(w^{\prime}, \mathbf{V}^{F \prime} \mid w^{\prime}, \mathbf{V}^{W^{\prime}}\right) d\left(w^{\prime}, \mathbf{V}^{F \prime}\right)\right] f_{\text {post }}^{0}\left(w^{\prime}, \mathbf{V}^{W^{\prime}}\right)\left[\frac{1-\delta^{0}}{\delta^{1}-\delta^{0}}\right] d\left(w^{\prime}, \mathbf{V}^{W^{\prime}}\right) \text {, }
\end{aligned}
$$

which we can rewrite in terms of surpluses directly, defining densities of surpluses $h($.$) rather than of$ job/wage attributes $f_{\text {post }}($.$) :$

$$
\begin{aligned}
& \int_{\widetilde{S}^{W \prime} \geq \varepsilon_{b}^{W \prime}}\left[\int_{\widetilde{S}^{F^{\prime}} \geq 0} \mathbb{1}\left(\widetilde{S}^{F}<\varepsilon^{F \prime \prime}\right) h_{\text {post }}^{0}\left(\widetilde{S}^{F^{\prime}} \mid \widetilde{S}^{W \prime}\right) d \widetilde{S}^{F \prime}\right] h_{\text {post }}^{0}\left(\widetilde{S}^{W \prime}\right)\left[\frac{1-\delta^{0}}{1-\delta^{1}}\right] \widetilde{S}^{W \prime} \\
\lesseqgtr & \int_{0 \leq \widetilde{S}^{W^{\prime}}<\varepsilon_{b}^{W,}}\left[\int_{\widetilde{S}^{F^{\prime}} \geq 0} \mathbb{1}\left(\widetilde{S}^{F^{\prime}}<\varepsilon^{F \prime \prime}\right) h_{\text {post }}^{0}\left(\widetilde{S}^{F^{\prime}} \mid \widetilde{S}^{W \prime}\right) d \widetilde{S}^{F \prime}\right] h_{\text {post }}^{0}\left(\widetilde{S}^{W \prime}\right)\left[\frac{1-\delta^{0}}{\delta^{1}-\delta^{0}}\right] d \widetilde{S}^{W \prime} .
\end{aligned}
$$

Up until now we rewrote condition A22. Now assume that worker surplus and firm surpluses are independent: $h_{\text {post }}^{0}\left(\widetilde{S}^{F \prime} \mid \widetilde{S}^{W \prime}\right)=h_{\text {post }}^{0}\left(\widetilde{S}^{F \prime}\right)$. Then condition A22) collapses to equality. That is, if worker and firm surpluses are independently distributed, $\Delta^{1}\left(\varepsilon^{F \prime \prime}, \delta^{0}, \delta^{1}\right)=\Delta^{0}\left(\varepsilon^{F \prime}, \delta^{0}, \delta^{1}\right)$, i.e. post-repeal separation rates co-move perfectly in response to a firm shock even if there is perfect persistence of surplus for one period to the next.

${ }^{40}$ Of course, in practice, the shocks may be percent shifters of the given job surplus, so that the condition would not literally need to apply in levels. 


\section{Variable Construction}

Outcome Variables We describe the construction of the outcome variables presented in the paper. In the descriptions below, status refers to a variable in the ASSD aggregating hundreds of administrative designations into 12 labor market statuses Zweimüller et al. (2009). We classify self-employment (status $==6$ ) and mini-jobs (status $==10$ ) as employment.

\section{Separation}

- Create an indicator if equal to one, between two periods (e.g., 1988q2 and 1993q3), the worker is observed in the same establishment.

- If not, the worker is separated

\section{Separation into Nonemployment}

- Create an indicator equal to one if the worker separated as defined above and had no other employer between 1988q2 and 1993q3.

\section{Unemployment (Quarters)}

- Between two periods (e.g., 1988q2 and 1993q3), count the number of quarters where the worker is observed on UI or UA (status $=1$ ).

- Multiply the quarter count by 3 to get a monthly count for tractability.

\section{Continuous Employment (Quarters)}

- Between two periods (e.g., 1988q2 and 1993q3), count the number of quarters where the worker is employed in the same establishment as the quarter before.

- Stop counting when the worker is observed either employed in a new establishment or with another labor market status.

Wage Rigidity Measures We consider active male workers within the ASSD earnings caps in the five-year period before REBP (1982-87) ${ }^{41}$ The four indices of wage rigidity are standard deviations at the firm level of the following underlying variables, which are all nominal and winsorized at the $1 \%$ level by year:

1. Log wage: the natural logarithm of annual earnings in 2018 euros.

2. The residuals of log wage regressed on tenure-experience-occupation-industry-year fixed effects. Tenure is made up of 5 three-year categories and a category for those with more than 15 years of tenure. Experience is made up of 5 five-year categories and a category for those with more than 25 years experience. Occupation refers to white- vs. blue-collar, for which there are often separate collective bargaining agreements. Industry refers to four-digit industries per the NACE 2008 (Rev. 2) classification.

${ }^{41}$ We consider full-time jobs, mini-jobs, and self-employment. We only keep the last quarter for each year, and drop workers at the yearly earnings caps. 
3. Five-year wage growth for stayers: we compute wage growth for all workers between 1982 and 1987, and only keep workers who stayed with the same firm in 1982 and 1987.

4. The residuals of five-year wage growth for stayers based on the same regressors as in 2. above.

We next merge onto the 1988 job holders sample using firm identifiers, compute quartiles weighing by 1988 job holders, and carry forward by worker to subsequent periods. 


\section{E Estimation of the Mixed Model with Industry-by-Occupation Variation with Non-Linear Least Squares}

We now present a formal structural estimation of our model to estimate $\kappa$, by estimating Equation (9) with (i) richer variation at the industry-by-occupation level, (ii) providing a single estimate and confidence interval for $\kappa$ in each specification, and (iii) accounting for the nonlinear nature of the specification (due to the max operator in Equation (7)). This estimation again reveals point estimates $\hat{\kappa}$ that are close to or even above 1 . Even in our most conservative specification, the lower limit of the $95 \%$ confidence interval for $\mathcal{K}$ is 0.890 , indicating that at least $89 \%$ of separations had to come from full reshuffling of job surplus for the data to be consistent with a Coasean setting. With such a high share of reshuffling-consistent (or persistence-inconsistent) separations, the estimation of the structural model thus delivers parameters estimates that directly mirror the reducedform evidence in Section 5, which - at odds with perfect persistence within a Coasean framework - had shown that post-repeal behavior did not differ between treated and untreated matches.

Formally, we estimate $\kappa$ using non-linear least squares/GMM based on the moment condition $E\left[v_{i} \mid \Delta_{i}^{0}\right]=0$ in Equation (9). Intuitively, the parameter $\mathcal{K}$ is identified through the non-linearity in the relationship between $\Delta_{i}^{1}$ and $\Delta_{i}^{0}$ induced by the resilience to nonlarge shocks to surplus predicted by the Coasean model with persistence.

To proxy for $\Delta_{i}^{0}$, we use post-repeal separation rates among workers in the non-REBP region in the same industry-occupation cell who were not treated by the program and who thus still contain marginal jobs but are exposed to plausibly similar industry-level surplus shocks. We use observed separation rates during REBP in the REBP and non-REBP regions to measure $\delta_{i}^{1}$ and $\delta_{i}^{0}$ in each industry-occupation cell.

Reduced-Form Evidence on Comovement of Separation Rates Before providing results of the structural estimation, we plot the reduced-form relationship between $\Delta_{i}^{1}$ and $\Delta_{i}^{0}$ at the industry-by-occupation level in binned scatter plots in Appendix Figure A.1. The figure shows the relationship between post-repeal separation rates (at horizons ranging from 1995 to 1998) at the industry-by-occupation cell level in formerly treated cohorts (born between 1938 and 1943) in the REBP regions against separations rates in the same cohorts in non-REBP regions who did not experience the treatment. The relationship appears strong, positive, and linear. As a placebo benchmark, we also plot as outcome variable the separation rate in slightly younger, ineligible cohorts (born between 1943 and 1948). The relationship is just as strong and positive, thus providing evidence that the industry-by-occupation cells in the different regions were affected by similar shocks to surplus. As Appendix Figure A.1 reveals, there is no discernible difference between the slope of the relationship of separation behavior of formerly treated cohorts to their same-aged peers in the non-REBP region and the relationship in slightly younger cohorts. In particular, we do not observe evidence for resilience, i.e. lower separation rates, at low post-repeal separation rates in the non-REBP regions (which our structural model will then formally also link with variation in the cell-specific kink position). 
Results of Estimation Appendix Table A.1 reports estimates of $\kappa$ based on estimation of Equation (9) with non-linear least squares. Across specifications, we find estimates of $\kappa$ that are always above 1 in the non-linear least squares model. The smallest point estimate is 1.027 with variation at the four-digit level and considering post-repeal separations by 1995. Even the most conservative i.e. lowest $95 \%$ confidence interval for $\hat{\kappa}$ rules out $\hat{\kappa} \leq 0.89$, that fewer than $89 \%$ of cells in the Austrian labor market in our sample would need to be of the perfect-shuffling type to rationalize the data through the Coasean lens.

The table further reveals even larger estimates at longer horizons, e.g., with the confidence intervals excluding one when considering separations by 1998, according with intuition that full reshuffling becomes less implausible at multi-year horizons. However, even at the shortest horizon, considering separations by 1995 as outcome variable, we find that $100 \%$ (lower $95 \%$ confidence interval: $89 \%$ ) of the cells would need to be of the perfect reshuffling kind, ${ }^{42}$

Table A.1: Structural Estimation of Share $\mathcal{\kappa}$ of Separations within a Coasean Framework with Perfect Reshuffling of Job-Level Surplus: Industry-Occupation Cells

\begin{tabular}{|c|c|c|c|c|c|c|c|c|}
\hline & \multicolumn{4}{|c|}{ 2-Digit Industry $\times$ Occupation Cells } & \multicolumn{4}{|c|}{ 4-Digit Industry $\times$ Occupation Cells } \\
\hline & 1995 & 1996 & 1997 & 1998 & 1995 & 1996 & 1997 & 1998 \\
\hline$\kappa$ (Reshuffling) & $\begin{array}{c}1.046 \\
(0.054)\end{array}$ & $\begin{array}{c}1.077 \\
(0.067)\end{array}$ & $\begin{array}{c}1.053 \\
(0.080)\end{array}$ & $\begin{array}{c}1.158 \\
(0.099)\end{array}$ & $\begin{array}{c}1.027 \\
(0.070)\end{array}$ & $\begin{array}{c}1.077 \\
(0.066)\end{array}$ & $\begin{array}{c}1.119 \\
(0.076)\end{array}$ & $\begin{array}{c}1.169 \\
(0.074)\end{array}$ \\
\hline $\begin{array}{c}95 \% \text { CI } \\
\text { (Lower Limit) }\end{array}$ & 0.939 & 0.943 & 0.894 & 0.962 & 0.890 & 0.947 & 0.968 & 1.023 \\
\hline$R^{2}$ & 0.426 & 0.531 & 0.588 & 0.528 & 0.174 & 0.278 & 0.273 & 0.275 \\
\hline$N$ & 95 & 95 & 95 & 95 & 262 & 262 & 262 & 262 \\
\hline
\end{tabular}

Note: The table reports estimates of $\kappa$ based on estimation of Equation (9) with non-linear least squares allowing for an intercept shift. We collapse the data at the industry by occupation (blue/white collar) level and weight each observation by the number of workers in the cell, dropping cells with fewer than ten workers who survived REBP and those cells with a smaller separation rate in the REBP compared to the non-REBP region during the program (27.8 and $38.6 \%$ of cells for 2-digit and 4-digit industry cuts, respectively). The outcome variable is the separation rate from February 1994 to February of each year among REBP survivors in the REBP region. The model includes the corresponding separation rate among control workers (cohorts born between 1933 and 1943 but ineligible due to location in the control regions) as the main regressor along with its transformations according to Equation 9 .

${ }^{42}$ We have also explored strategies to account for measurement error using methodology for nonlinear models developed in Li and Vuong (1998), Li (2002) and Schennach (2004), surveyed in Schennach (2012). These lead to qualitatively and quantitatively similar results. 


\section{Figure A.1: Post-Repeal Separation Rates of REBP Survivors and non-REBP Survivors at the Industry-Occupation Level}

(a) Separations by 1995

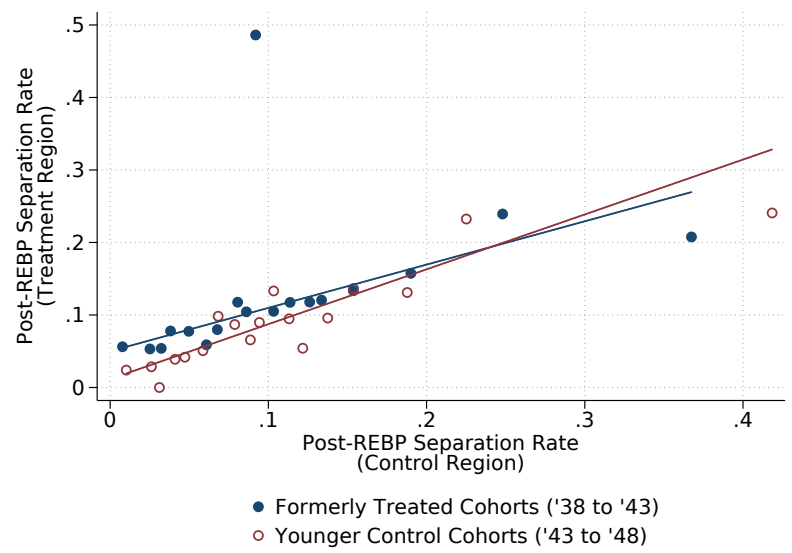

(c) Separations by 1997

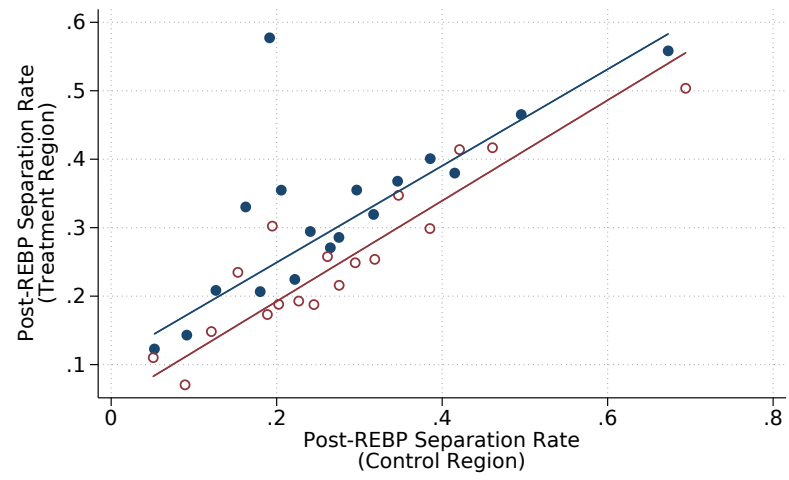

- Formerly Treated Cohorts ('38 to '43)

- Younger Control Cohorts ('43 to '48) (b) Separations by 1996

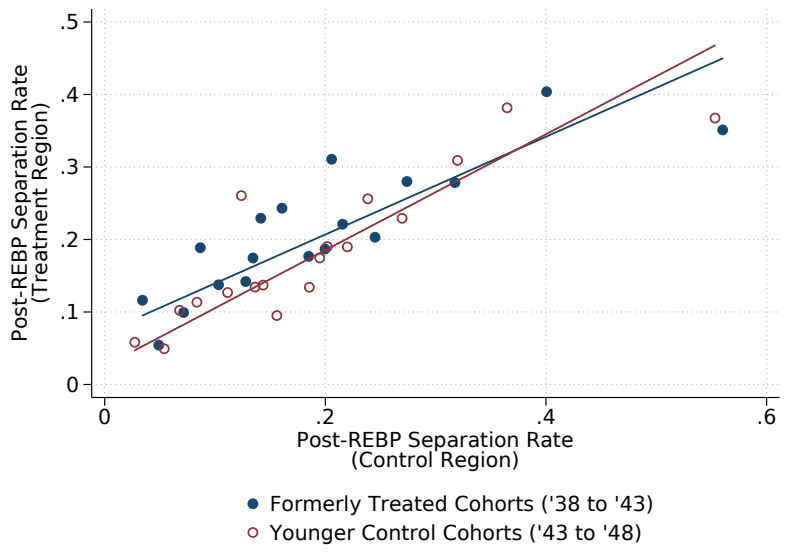

(d) Separations by 1998

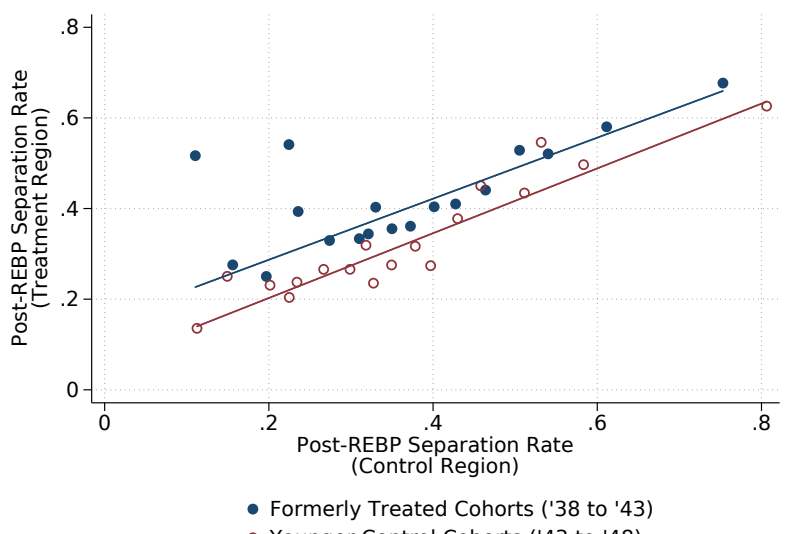

Note: The figures plot binned scatter plots of the post-repeal separation rates at the industry-by-occupation cell level among survivors in the REBP regions against those in the same cell in the non-REBP regions. The blue dots indicate the relationship for cohorts born between 1938 and 1943, i.e. those who were eligible for REBP before its repeal. As a placebo, we also show the relationship for slightly younger cohorts, born between 1943 and 1948 and thus never eligible for REBP. Observations are weighted by the number of survivors in the respective control-region cell. Industries are categorized at the four-digit level. 


\section{F The Role of Severance Payments}

Here, we assess the role of severance pay in our analysis. We first analyze the case of flexible wages. With flexible wages, we show that our original takeaway for the Coasean case remains completely unchanged, following the neutrality results in Lazear (1986, 1990). We then reiterate that severance payment is no longer neutral with wage rigidity, as in Garibaldi and Violante (2005). Here, we clarify that the incremental consequence of severance pay over our non-Coasean model in Section 7 is simply to shift the baseline unilateral surplus distributions, but the intuitions of the fixed-wage setting (and hence its empirical implications) remain analogous.

\section{F.1 Theoretical Assessment}

We modify our basic setup in (1) and (2) to include severance pay $s$ paid upon any separation, regardless of whether this is a quit or a layoff.

The severance payment affects the outside value. The neutrality of the severance payment emerges already in the formulation of joint job surplus. To see this, we add the severance payment $s$ into the definition of the values analogously to the wage payment $w$, whereby the values are defined gross of wages and severance payment now:

$$
\begin{aligned}
S^{W} & =V_{I n}^{W}+w-\left[V_{\text {Out }}^{W}+s\right] \\
S^{F} & =V_{I n}^{F}-w-\left[V_{\text {Out }}^{F}-s\right]
\end{aligned}
$$

Joint surplus $S=V_{I n}^{W}+V_{I n}^{F}-V_{O u t}^{W}-V_{O u t}^{F}$ is independent of severance payment $s$. Hence, separation decisions in bilaterally efficient bargaining settings remain efficient, and specifically neutralize the severance payments. That is, separations in a setting with and without severance pay mandates are identical. This neutrality result is well-known (see, e.g., Lazear, 1986, 1990). We do not discuss dynamic or specific frictions that break the neutrality here (except for fixed wages below, which is our leading friction in the main part of the paper). We also do not derive strategic forms of the bargaining game, and do not differentiate quits and layoffs here, exactly because in this benchmark setting there is no notion of a one-sided separation.

Fixed Wages We now introduce wage rigidity in the form of fixed wages, as in Section 7 . Here, severance payment will have an effect on separations, as in Garibaldi and Violante (2005).

We consider two variants. First, severance is paid no matter who initiates the separation. The participation constraints then become:

$$
\begin{aligned}
& V_{I n}^{W}+w \geq V_{\text {Out }}^{W}+s \\
& V_{\text {In }}^{F}-w \geq V_{\text {Out }}^{F}-s
\end{aligned}
$$

As the fixed-wage setting accommodates distinctions between quits and layoffs, we now model also a setting in which severance payments are due only upon a layoff, but not 
upon a quit (in Austria, severance payments are also due upon mutual separations, but this case does not have a clear mapping into our non-Coasean setting):

$$
\begin{aligned}
& V_{\text {In }}^{W}+w \geq V_{\text {Out }}^{W} \\
& V_{\text {In }}^{F}-w \geq V_{\text {Out }}^{F}-s
\end{aligned}
$$

In both cases, the presence of a severance payment mandate therefore leaves the intuitions of our non-Coasean model in Section 7 intact, except that the severance payment may shift the surplus distributions. That is, one could redefine the firms' outside option as $\tilde{V}_{\mathrm{O} u t}^{F}=V_{\mathrm{Out}}^{F}-s$ and apply the subsequent logic of our model with rigid wages. Importantly, the formation of matches could be affected if wages are completely rigid. However, our analysis takes a given cross-section of existing employment relationship and takes the initial formation process as given in the past.

\section{Dynamics: Increasing Severance Payment by Staying, and Unconditional Severance} Payment Upon Retirement We close with two important institutional features of Austrian severance pay. First, severance payments are an increasing step function of tenure. Second, and particularly relevant for our sample, severance payment is due upon retirement irrespective of the type of separation.

To assess the potential dynamic effects within a Coasean framework, it is useful to ask: how would the step function of severance payments affect the path of flexible (Coasean) wages? This perspective provides a tangible assessment of the severance payments in employment relationships. But also gives a useful benchmark whether Austrian wage setting institutions can plausibly be flexible. In practice, basic bargaining theory implies that the required wage path need not be tilted noticeably.

We now think of the severance pay $s=s_{B}-s_{A}$ as the incremental one when crossing the next tenure step. We have pre-step workers in group $A$ and those across the step in group $B$. The bargaining and surplus implications for the $B$ workers are described above already: $s$ does not affect the joint surplus (and hence not (efficient) separations either), and only boosts workers' outside option (at the expense of that of the firm).

To now understand how this feature affects wage setting in group $A$, we must assume a wage setting protocol within the class of bilaterally efficient models. We also must explicitly introduce dynamics with continuation values. Throughout, we will choose those assumptions that are most extreme in that they yield the maximal reduction of $A$ wages from $s$.

First, we assume that there is no separation risk between $A$ and $B$, and moreover workers do not discount the future. This assumption maximizes the effect of the continuation value onto $w_{A}$, the wage of group $A$. It also allows us to think of a simple two-period model, consisting of the duration as worker type $A$ as the first period and thereafter starting as type $B$.

Second, we assume Nash bargaining with worker bargaining power $\phi$. As will become clear below, this assumption will lead to a one-to-one effect of the severance payment onto the (present value of) wages paid out to $A$ workers, $w_{A}$.

We start by defining the value of employment for the $A$ worker (so the index is $W A$ for 
worker of type $A$ ):

$$
V_{\mathrm{In}}^{W A}+w_{A}=\widetilde{V}_{I n}^{W A}+\widetilde{w}_{A}+\left[V_{\mathrm{In}}^{W B}+w_{B}\right],
$$

where $\tilde{x}$ denotes a present value minus the continuation value after upgrading from $A$ to $B$. That is, $\widetilde{V}_{I n}^{W A}$ now denotes the value of the worker, gross of the wage, while of type $A$, for that period, and similarly $\widetilde{w}_{A}$ now denoting the present value of wages paid over the course of this tenure window (recall the absence of separations and discounting).

Assuming Nash wage bargaining in jobs of type $A$ with worker bargaining power $\phi^{A}$, the wage rule is:

$$
\begin{aligned}
\widetilde{w}_{A} & =\phi^{A} S_{A}+\left[V_{\text {Out }}^{W A}-V_{\text {In }}^{W A}\right] \\
& =\phi^{A} S_{A}+\left[V_{\text {Out }}^{W A}-\left[\widetilde{V}_{I n}^{W A}+\left[V_{\text {In }}^{W B}+w_{B}\right]\right],\right.
\end{aligned}
$$

where $S_{A}$ is the joint surplus in jobs of type $A$.

The expression reveals two insights. First, $s$ does not affect joint surplus at step $A$ nor $B$ (as we have shown above). Second, the expression makes clear that severance pay $s$ affects wages of the pre-step worker $A$ by affecting the continuation value $V_{\text {In }}^{W B}$. Through this channel, it can affect wage setting while in $A$. The effect is maximal as we assumed away discounting and separations.

Second, to quantify the effect of the severance payment on the job value and hence wages $w_{A}$, we specify the bargaining protocol for period $B$. We again assume Nash bargaining, which we show yields the maximal, i.e. one-to-one, wage effect, irrespectively of the bargaining power.

That is, in period $B$, Nash wages are set such that

$$
V_{\text {In }}^{W B}+w_{B}=\phi^{B} S_{B}+\left[V_{\text {Out }}^{W B}+s\right] .
$$

Here, the joint surplus $S_{B}$ is not affected by the severance payment, as discussed above. Yet, the worker's outside option is affected. Since Nash bargaining has the net-of-wage inside value equal the outside option plus a share of the joint surplus, and since the joint surplus pie size is unaffected, this particular bargaining protocol implies the largest increase in the worker's continuation value from $A$ into $B$ : a one-to-one pass-through. Importantly, there are many other bilaterally efficient bargaining assumptions that can feature smaller passthrough or nearly full neutrality, such as alternating offer bargaining (Hall and Milgrom, 2008) or fixed wages with renegotiation only if a participation constraint is hit (MacLeod and Malcomson, 1993). Hence, our Nash assumption for wages $w_{B}$ yields the largest, i.e. one-to-one, effect of the severance payment into the continuation value.

Using backward induction, we now replace the continuation value of $A$ workers in Equation (A33):

$$
\widetilde{w}_{A}=\phi^{A} S_{A}+\left[V_{\text {Out }}^{W A}-\left[\widetilde{V}_{I n}^{W A}+\phi^{B} S_{B}+\left[V_{\text {Out }}^{W B}+s\right]\right],\right.
$$

That is, pre-step wages $\widetilde{w}_{A}$ fall in $s$ one to one. Hence, in this case of the upper bound of the effect magnitude, in period $A$ the worker and firm bargain away the boost from 
the severance payment, having the worker pay for it in advance. They anticipate that $s$ will lead the worker to extract higher wages tomorrow (in period $B$ ), but since she can do so only upon continuing, this boost is part of her inside value today (in period $A$ ). It therefore gets neutralized in period- $A$ wages entirely. This result is simply a variant of the neutrality result in Lazear (1986, 1990); Garibaldi and Violante (2005) adapted to our setting.

Calibrating the Upper Bound on Wage Effects Recall that $\widetilde{w}_{A}$ represents the present value of period $A$ wages. A realistic jump of $s$ in our sample is of 3 months when the worker adds 5 years of tenure, the usual step size for higher-tenured workers. Here, we would therefore amortize the 3 month wages over $5 \times 12=60$ monthly wage payments, for example with a decrease of monthly wages by $3 / 60=5 \%$ - compared to a benchmark of a counterfactual economy without that tenure step. Such wage effects can be smoothed out or alternatively be implemented with a tilt in the tenure gradient, as any presentvalue-preserving schedule implementing this wage adjustment would do. Institutionally, collective bargaining (typically occurring between employers and unions in industryby-occupation-by-region cells and setting wages for experience and tenure groups) may incorporate such severance payment offsets as the severance pay-tenure schedule is widely known in advance.

Therefore, the reality of severance payments in Austrian setting is far from subject to the bonding critique of Lazear (1986, 1990), whereby wages would have to be dramatically lower, even turn negative, to neutralize the institution.

We close by reiterating two statements. First, wage gradients separately would not be indicative of Coasean and non-Coasean bilateral interactions, as the aforementioned alternative protocols (MacLeod and Malcomson, 1993; Hall and Milgrom, 2008) achieve bilateral efficiency despite wages being largely neutral to the kind of outside option boosts severance payments provides. Second, the ballparked wage adjustment are overestimates as we assume (i) no discounting, (ii) no separations between $A$ and $B$, and (iii) implement the Nash wage protocol, whereby the outside option boost adds one to one into the continuation value in $B$ as well as into the wage in $A$. Other bargaining protocols will yield smaller pass-through.

Extensions: Separations and Retirement Payouts Importantly, s could in principle affect the continuation value from $A$ into $B$ either through the improved payoff while employed, but also through the higher payoff in case of a separation from $B$. One way to think about this setup is that, e.g., due to Markov process $k(. \mid$.$) in the job characteristics, separations$ may occur (or simply due to an ad-hoc "exogenous" separation). In case of separation while in $B$, the $B$ worker's actual continuation value, i.e. the same the outside option in Nash bargaining, will be augmented by the severance payment $s$. Therefore, in the separation states of the continuation term from $A$ to such a "risky" $B$, the continuation value continues to be affected one to one. In the other states without a separation, while in $B$, the worker obtains the employment value of $B$ through bargaining, which in our setting also yields a one to one boost from $s$ due to bargaining. Therefore, permitting separations while in $B$ turns out to leave the one-to-one effect on the contination value 
intact. Hence, the bargaining of period- $A$ wages inherits the same unit pass-through. (And again, separation before entering $B$ will lead to attenuation.)

Interestingly, incorporating the institutional feature that $s$ gets paid unconditionally at retirement, does not change the insights. Yet, different mechanisms are at work, namely solely through the direct effect of increased inside continuation value (rather than increase in outside option which leads to increased wages). This consideration may be particularly relevant to our sample of older workers. For example, Manoli and Weber (2016) present compelling intertemporal substitution evidence for retirement delays across the next step of tenure categories, which however operate at very short time windows. This evidence for the dynamic non-neutrality of severance payments is consistent with, for example, wage rigidity (by which workers for whom retiring right above the severance payment step could simply bargain for higher wages and retire at the otherwise optimal date). The authors interpret the evidence as Frischian labor supply behavior, due to the (reasonable) assumption that wages are unlikely to move at such narrow windows. However, the evidence is also consistent with the expected lump-sum payment being smoothed out over the tenure steps before the increase.

\section{F.2 Empirical Evaluation}

Empirical Tenure and Severance Pay Distribution in our Sample Appendix Table A.2 presents summary statistics (mean and range) of tenure and tenure-implied severance payment in monthly salaries of our sample of 1988 job holders, as well as the share meeting the experience requirement. We compute these values both for 1988 -our lower bound and the number relevant for REBP separations - and extrapolating tenure to 1993 assuming no separation - which is the baseline for the post-repeal context and the upper bound for the REBP sample. These baseline values are our references because we cannot credibly condition on tenure at the point of separation, which is endogenous to the treatment. Finally, note that in 1988, tenure is left-censored at about 16 years since the ASSD begins in 1972. (The maximum tenure is 16.38 as the ASSD begins on January 1, 1972, and our pre-REBP 1988 cutoff date is May 15.) Foreshadowing our empirical analysis, we have split up the 1988 job holders into four quartiles by tenure.

The table clarifies that our sample has wide dispersion in tenure and implied severance payments, permitting us to study how the effects of REBP and its aftermath may be mediated by severance payments.

Strategy: Heterogeneity Analysis Our method splits up the sample into quartiles by tenure and estimates REBP treatment effects and post-repeal separation rates (and also constructs baseline control group separation rates), as in our heterogeneity analysis by wage rigidity in Section 8 . Appendix Figure A.2 presents these results by tenure quartile and the various post-repeal horizons. Appendix Figure A.3 does so for the respective severance payments, where instead of sorting workers by quartiles, we sort workers into bins by the discrete set of policy-mandated severance steps. Again, we do so along baseline 1988 levels and extrapolated 1993 tenure, following the measures summarized in Appendix Table A.2. 
Results We find that the REBP treatment effect is present in all categories. Interestingly, the effect is larger among higher-tenure workers, and, hence, those with more months of severance payment. This pattern supports the causal effect of REBP on separations for the workers that even upon unilateral quits may be at risk of losing severance payments (although the separations may well be mutual in practice). Hence, the degree of severance pay does not appear to play a dominant role in mediating the incremental separation dynamics. The fact that the gradient slopes upward suggests that other factors, such as age composition and, relatedly, the ease of transitioning into retirement post-repeal, may dominate the sorting (although we do not dissect these possibilities here). 
Table A.2: Tenure Quartiles and Underlying Years of Tenure, Monthly Salaries of Severance Pay, and Experience

\begin{tabular}{|c|c|c|c|c|c|c|c|c|}
\hline $\begin{array}{l}\text { Tenure } \\
\text { Quartile }\end{array}$ & $\begin{array}{l}\text { Mean Years } \\
\text { of Tenure }\end{array}$ & \multicolumn{2}{|c|}{$\begin{array}{c}\text { Range of Years } \\
\text { of Tenure }\end{array}$} & $\begin{array}{c}\text { Mean } \\
\text { Severance Pay }\end{array}$ & \multicolumn{2}{|c|}{$\begin{array}{c}\text { Range of } \\
\text { Severance Pay }\end{array}$} & $\begin{array}{c}\text { Mean } \\
\text { Experience }\end{array}$ & $\begin{array}{c}\text { Share Meeting } \\
\text { Experience Requirement }\end{array}$ \\
\hline \multicolumn{9}{|c|}{1988 (actual) } \\
\hline 1 & 1.60 & 0.003 & 4.01 & 0.34 & 0 & 2 & 19.10 & $90 \%$ \\
\hline 2 & 7.30 & 4.01 & 10.79 & 2.95 & 2 & 4 & 20.93 & $97 \%$ \\
\hline 3 & 14.11 & 10.79 & 16.36 & 4.76 & 4 & 6 & 22.37 & $100 \%$ \\
\hline 4 & 16.37 & 16.36 & 16.38 & 6 & 6 & 6 & 24.21 & $100 \%$ \\
\hline \multicolumn{9}{|c|}{1993 (extrapolated if no separation) } \\
\hline 1 & 6.85 & 5.25 & 9.26 & 3 & 3 & 3 & 24.35 & $96 \%$ \\
\hline 2 & 12.55 & 9.26 & 16.04 & 4.14 & 3 & 6 & 26.19 & $100 \%$ \\
\hline 3 & 19.36 & 16.04 & 21.61 & 7.24 & 6 & 9 & 27.62 & $100 \%$ \\
\hline 4 & 21.63 & 21.61 & 21.63 & 9 & 9 & 9 & 29.46 & $100 \%$ \\
\hline
\end{tabular}

ป $\quad$ Note: The table reports two calculations of years of tenure, monthly salaries of severance pay, and experience for job holders in 1988. In the first panel, we compute the mean and range of each variable for job holders in 1988. In the second panel, we compute the mean and range of years of tenure and months of severance pay assuming each job holder in 1988 remains in their job until August 1993. We also show the mean experience (in years) and the share of workers in each quartile that satisfy the REBP experience requirement (at least 9 years during the past 15 years). Years of tenure are left-censored since the ASSD database begins on 1972. Thus, monthly salaries of severance pay for quartile 4 should be interpreted as lower bounds of actual monthly salaries of severance payment for both panels. All numbers expressed with no decimals reflect integers. 


\section{Figure A.2: Results by Quartiles of Tenure}

(a) Post-Repeal Resilience Through 1995

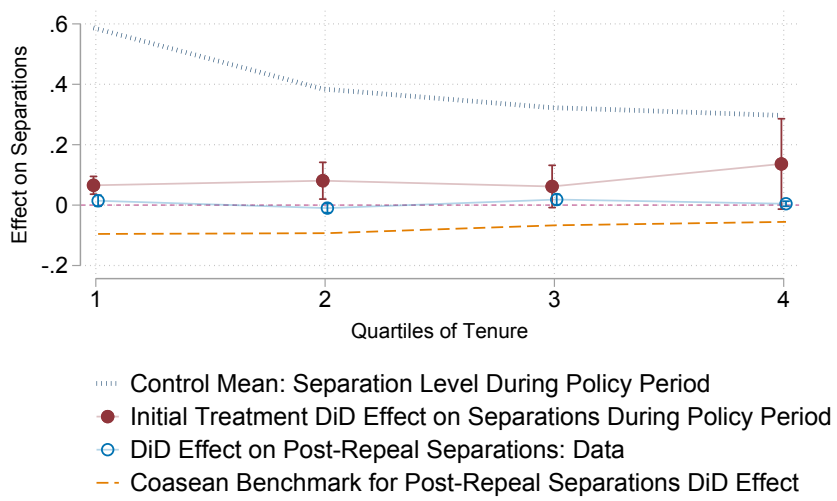

(c) Post-Repeal Resilience Through 1997

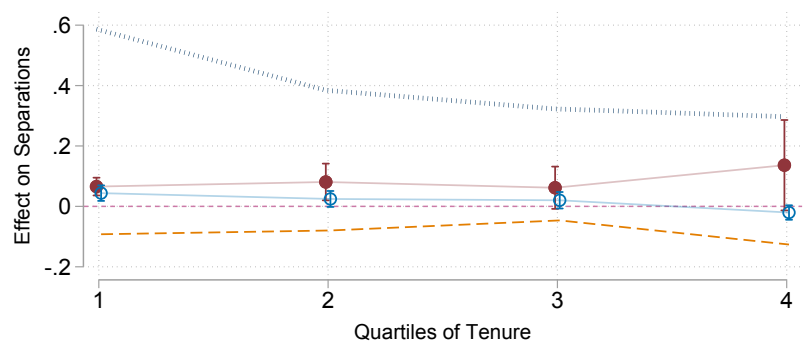

"I." Control Mean: Separation Level During Policy Period

- Initial Treatment DiD Effect on Separations During Policy Period

o DiD Effect on Post-Repeal Separations: Data

- - Coasean Benchmark for Post-Repeal Separations DiD Effect (b) Post-Repeal Resilience Through 1996

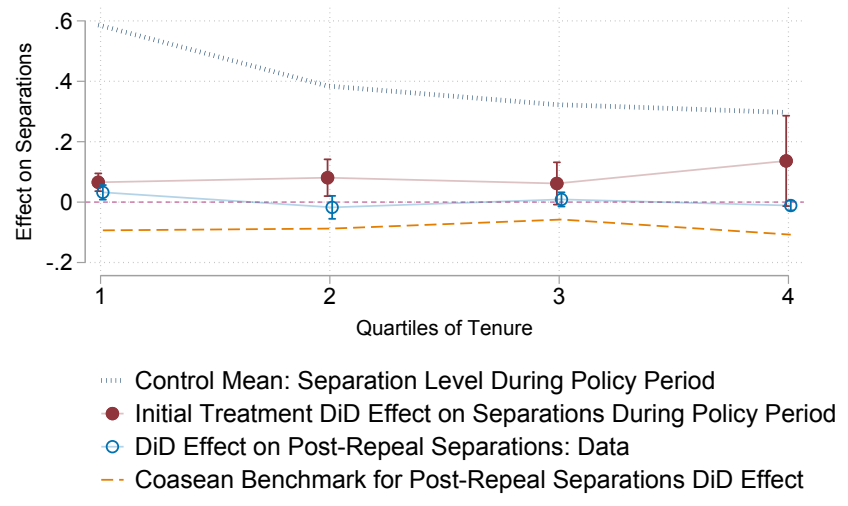

(d) Post-Repeal Resilience Through 1998

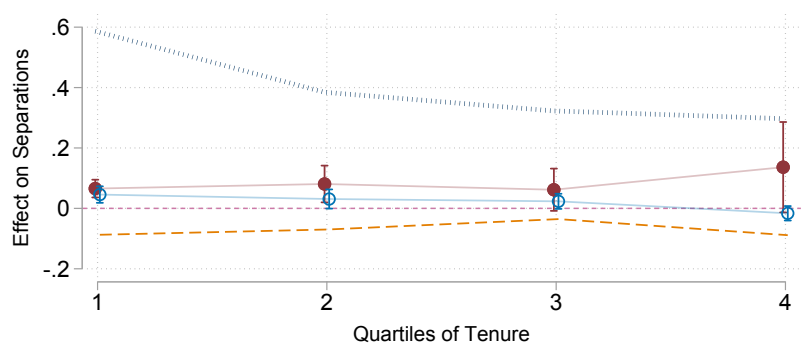

"'" Control Mean: Separation Level During Policy Period

- Initial Treatment DiD Effect on Separations During Policy Period

- DiD Effect on Post-Repeal Separations: Data

- - Coasean Benchmark for Post-Repeal Separations DiD Effect 
Figure A.3: Results by Months of Severance Pay

(a) Calcuation Based on 1988 Tenure

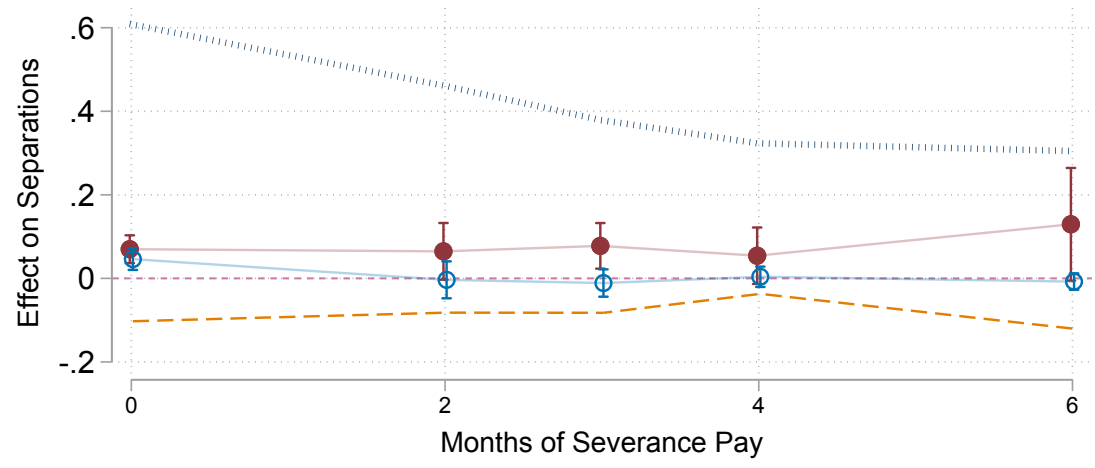

"'w. Control Mean: Separation Level During Policy Period

- Initial Treatment DiD Effect on Separations During Policy Period

- DiD Effect on Post-Repeal Separations: Data

- Coasean Benchmark for Post-Repeal Separations DiD Effect

(b) Calcuation Based on 1988 Tenure Extrapolated to 1993

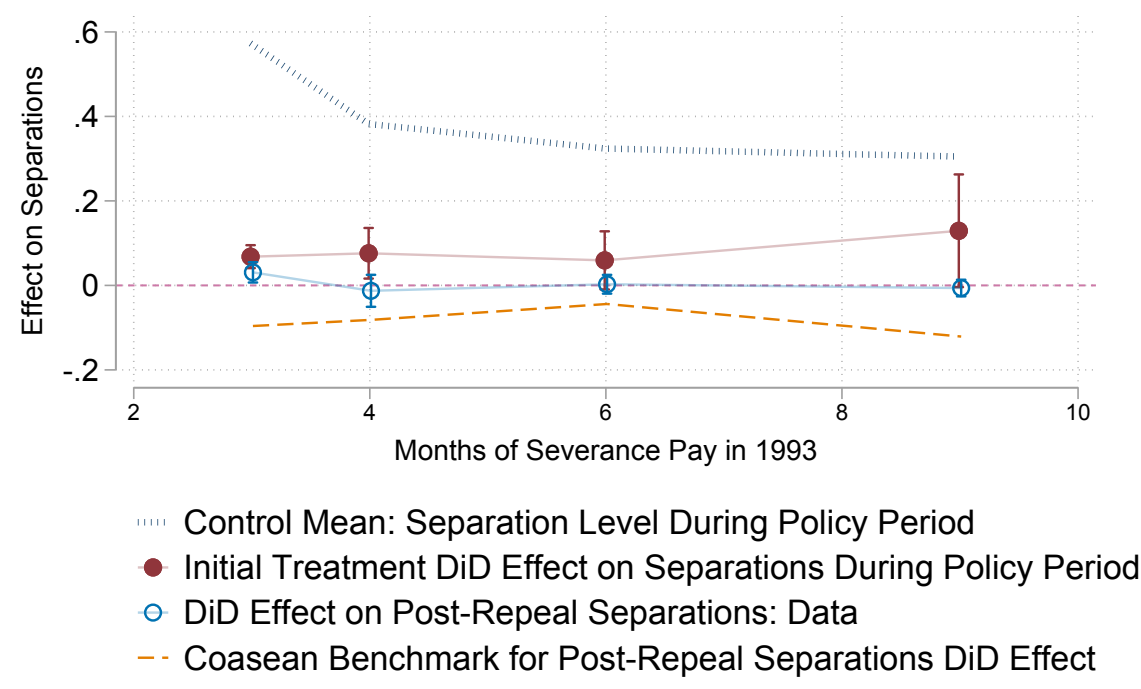




\section{G Additional Tables}


Table A.3: Initial Treatment Effect: Difference-in-Differences Effects on Separations Between Age 50 and 55 Among Job Holders at Age 50

\begin{tabular}{|c|c|c|c|c|c|}
\hline & $\begin{array}{c}(1) \\
\text { Separation }\end{array}$ & $\begin{array}{c}(2) \\
\text { Separation } \\
\text { Into Nonemployment }\end{array}$ & $\begin{array}{c}\text { (3) } \\
\text { Nonemployment } \\
\text { (Quarters) }\end{array}$ & $\begin{array}{c}\text { (4) } \\
\text { Unemp. (Benefits) } \\
\text { (Quarters) }\end{array}$ & $\begin{array}{c}\text { (5) } \\
\text { Cont. Empl. } \\
\text { (Quarters) }\end{array}$ \\
\hline REBP Region $\times$ Treated Cohort & $\begin{array}{c}0.124^{* * *} \\
(0.026)\end{array}$ & $\begin{array}{l}0.098^{* *} \\
(0.040)\end{array}$ & $\begin{array}{l}1.027^{* *} \\
(0.506)\end{array}$ & $\begin{array}{c}0.745 \\
(0.560)\end{array}$ & $\begin{array}{c}-1.147^{* * *} \\
(0.328)\end{array}$ \\
\hline REBP Region & $\begin{array}{l}-0.035 \\
(0.031)\end{array}$ & $\begin{array}{l}0.022^{* *} \\
(0.010)\end{array}$ & $\begin{array}{c}0.129 \\
(0.302)\end{array}$ & $\begin{array}{c}0.129 \\
(0.238)\end{array}$ & $\begin{array}{c}0.559 \\
(0.527)\end{array}$ \\
\hline Treated Cohort & $\begin{array}{c}-0.070^{* * *} \\
(0.015)\end{array}$ & $\begin{array}{c}-0.006^{* *} \\
(0.002)\end{array}$ & $\begin{array}{l}-0.381 \\
(0.312)\end{array}$ & $\begin{array}{l}-0.249 \\
(0.181)\end{array}$ & $\begin{array}{l}1.174^{* *} \\
(0.581)\end{array}$ \\
\hline Constant & $\begin{array}{c}0.424^{* * *} \\
(0.080)\end{array}$ & $\begin{array}{c}0.130 * * * \\
(0.021)\end{array}$ & $\begin{array}{c}2.299 * * * \\
(0.822)\end{array}$ & $\begin{array}{l}1.117^{*} \\
(0.603)\end{array}$ & $\begin{array}{c}14.605^{* * *} \\
(1.638)\end{array}$ \\
\hline $\begin{array}{l}\text { Observations } \\
\text { Adjusted } R^{2} \\
\text { No of Clusters }\end{array}$ & $\begin{array}{c}378,693 \\
0.006 \\
100\end{array}$ & $\begin{array}{c}378,693 \\
0.014 \\
100\end{array}$ & $\begin{array}{c}378,693 \\
0.008 \\
100\end{array}$ & $\begin{array}{c}378,693 \\
0.011 \\
100\end{array}$ & $\begin{array}{c}378,693 \\
0.005 \\
100\end{array}$ \\
\hline
\end{tabular}

Note: The table reports results of the econometric specification in (8). REBP captures the effect of REBP-eligibility on the outcomes listed in columns (1) through (5) on a sample of workers employed in the quarter before turning 50. Separation denotes an indicator function that is 1 if a worker is not employed by their employer at age 49.75 by the quarter before they turn 55. Separation into Nonemployment denotes an indicator for Separation from the initial employer interacted with an indicator for not taking up employment with another employer by the quarter before turning 55. Nonemployment (Quarters), Unemployment (Benefits) (Quarters), and Continuous Employment (Quarters) denote the quarters of nonemployment, unemployment benefits, and continuous employment with the initial employer between age 50 and age 55 . Standard errors clustered at the administrative region level are reported in parentheses. Levels of significance: ${ }^{*} 10 \%$, ${ }^{*} 5 \%$, and ${ }^{* * *} 1 \%$. 
Table A.4: Resilience Test: Post-Repeal Separations (1994-95) Among Program Survivors

\begin{tabular}{|c|c|c|c|c|c|}
\hline & $\begin{array}{c}(1) \\
\text { Separation }\end{array}$ & $\begin{array}{c}(2) \\
\text { Separation } \\
\text { Into Nonemployment }\end{array}$ & $\begin{array}{c}(3) \\
\text { Nonemployment } \\
\text { (Quarters) }\end{array}$ & $\begin{array}{c}\text { (4) } \\
\text { Unemp. (Benefits) } \\
\text { (Quarters) }\end{array}$ & $\begin{array}{c}\text { (5) } \\
\text { Cont. Empl. } \\
\text { (Quarters) }\end{array}$ \\
\hline REBP Region $\times$ Treated Cohort & $\begin{array}{l}0.008^{*} \\
(0.005)\end{array}$ & $\begin{array}{c}0.004 \\
(0.002)\end{array}$ & $\begin{array}{c}0.002 \\
(0.008)\end{array}$ & $\begin{array}{l}-0.022 \\
(0.014)\end{array}$ & $\begin{array}{c}-0.016 \\
(0.010)\end{array}$ \\
\hline REBP Region & $\begin{array}{l}-0.012 \\
(0.011)\end{array}$ & $\begin{array}{l}-0.001 \\
(0.007)\end{array}$ & $\begin{array}{l}-0.008 \\
(0.018)\end{array}$ & $\begin{array}{c}0.002 \\
(0.013)\end{array}$ & $\begin{array}{l}0.058^{* *} \\
(0.026)\end{array}$ \\
\hline Treated Cohort & $\begin{array}{c}0.072^{* * * *} \\
(0.005)\end{array}$ & $\begin{array}{c}0.083^{* * *} \\
(0.001)\end{array}$ & $\begin{array}{c}0.198^{* * *} \\
(0.006)\end{array}$ & $\begin{array}{l}0.048^{* *} \\
(0.021)\end{array}$ & $\begin{array}{c}-0.181^{* * *} \\
(0.018)\end{array}$ \\
\hline Constant & $\begin{array}{c}0.093^{* * * *} \\
(0.029)\end{array}$ & $\begin{array}{l}0.044^{* *} \\
(0.019)\end{array}$ & $\begin{array}{l}0.113^{* *} \\
(0.047)\end{array}$ & $\begin{array}{c}0.044 \\
(0.036)\end{array}$ & $\begin{array}{l}4.744^{* * * *} \\
(0.069)\end{array}$ \\
\hline Observations & 207,785 & 207,785 & 207,785 & 207,785 & 207,785 \\
\hline Adjusted $R^{2}$ & 0.011 & 0.020 & 0.017 & 0.003 & 0.009 \\
\hline No of Clusters & 99 & 99 & 99 & 99 & 99 \\
\hline
\end{tabular}

Note: The table replicates Table 3 for the 1994-95 horizon. 
Table A.5: Resilience Test: Post-Repeal Separations (1994-97) Among Program Survivors

\begin{tabular}{lccccc}
\hline \hline & $\begin{array}{c}(1) \\
\text { Separation }\end{array}$ & $\begin{array}{c}(2) \\
\text { Separation } \\
\text { Into Nonemployment }\end{array}$ & $\begin{array}{c}(3) \\
\text { Nonemployment } \\
\text { (Quarters) }\end{array}$ & $\begin{array}{c}(4) \\
\text { Unemp. (Benefits) } \\
\text { (Quarters) }\end{array}$ & $\begin{array}{c}\text { Cont. Empl. } \\
\text { (Quarters) }\end{array}$ \\
\hline REBP Region $\times$ Treated Cohort & $0.022^{* *}$ & $0.019^{* * *}$ & 0.076 & -0.122 & $-0.120^{*}$ \\
& $(0.010)$ & $(0.007)$ & $(0.055)$ & $(0.082)$ & $(0.069)$ \\
REBP Region & -0.015 & 0.005 & -0.005 & 0.010 & 0.172 \\
& $(0.026)$ & $(0.013)$ & $(0.113)$ & $(0.083)$ & $(0.184)$ \\
Treated Cohort & $0.200^{* * *}$ & $0.240^{* * *}$ & $1.555^{* * *}$ & $0.227^{*}$ & $-1.319^{* * *}$ \\
& $(0.014)$ & $(0.005)$ & $(0.014)$ & $(0.123)$ & $(0.119)$ \\
Constant & $0.220^{* * *}$ & $0.090^{* *}$ & $0.638^{* *}$ & 0.269 & $11.297^{* * * *}$ \\
& $(0.069)$ & $(0.036)$ & $(0.284)$ & $(0.209)$ & $(0.509)$ \\
Observations & & & & & \\
Adjusted $R^{2}$ & 207,785 & 207,785 & 207,785 & 207,785 & 207,785 \\
No of Clusters & 0.045 & 0.079 & 0.062 & 0.006 & 0.029 \\
\hline \hline
\end{tabular}

Note: The table replicates Table 3 for the 1994-97 horizon. 
Table A.6: Resilience Test: Post-Repeal Separations (1994-98) Among Program Survivors

\begin{tabular}{|c|c|c|c|c|c|}
\hline & $\begin{array}{c}(1) \\
\text { Separation }\end{array}$ & $\begin{array}{c}(2) \\
\text { Separation } \\
\text { Into Nonemployment }\end{array}$ & $\begin{array}{c}\text { (3) } \\
\text { Nonemployment } \\
\text { (Quarters) }\end{array}$ & $\begin{array}{c}(4) \\
\text { Unemp. (Benefits) } \\
\text { (Quarters) }\end{array}$ & $\begin{array}{c}\text { (5) } \\
\text { Cont. Empl. } \\
\text { (Quarters) }\end{array}$ \\
\hline REBP Region $\times$ Treated Cohort & $\begin{array}{l}0.026^{* *} \\
(0.011)\end{array}$ & $\begin{array}{l}0.018^{*} \\
(0.009)\end{array}$ & $\begin{array}{c}0.145 \\
(0.096)\end{array}$ & $\begin{array}{l}-0.170 \\
(0.114)\end{array}$ & $\begin{array}{l}-0.224^{* *} \\
(0.110)\end{array}$ \\
\hline REBP Region & $\begin{array}{c}-0.022 \\
(0.029)\end{array}$ & $\begin{array}{c}0.008 \\
(0.014)\end{array}$ & $\begin{array}{c}-0.001 \\
(0.184)\end{array}$ & $\begin{array}{c}0.015 \\
(0.133)\end{array}$ & $\begin{array}{c}0.262 \\
(0.299)\end{array}$ \\
\hline Treated Cohort & $\begin{array}{c}0.241^{* * *} \\
(0.015)\end{array}$ & $\begin{array}{c}0.299 * * * \\
(0.011)\end{array}$ & $\begin{array}{c}2.651^{* * *} \\
(0.039)\end{array}$ & $\begin{array}{l}0.282^{*} \\
(0.169)\end{array}$ & $\begin{array}{c}-2.187^{* * *} \\
(0.194)\end{array}$ \\
\hline Constant & $\begin{array}{c}0.293^{* * *} \\
(0.080)\end{array}$ & $\begin{array}{c}0.122^{* * *} \\
(0.038)\end{array}$ & $\begin{array}{l}1.053^{* *} \\
(0.461)\end{array}$ & $\begin{array}{c}0.434 \\
(0.334)\end{array}$ & $\begin{array}{c}14.154^{* * *} \\
(0.837)\end{array}$ \\
\hline $\begin{array}{l}\text { Observations } \\
\text { Adjusted } R^{2} \\
\text { No of Clusters }\end{array}$ & $\begin{array}{c}207,785 \\
0.059 \\
99\end{array}$ & $\begin{array}{c}207,785 \\
0.104 \\
99\end{array}$ & $\begin{array}{c}207,785 \\
0.085 \\
99\end{array}$ & $\begin{array}{c}207,785 \\
0.005 \\
99\end{array}$ & $\begin{array}{c}207,785 \\
0.040 \\
99\end{array}$ \\
\hline
\end{tabular}

Note: The table replicates Table 3 for the 1994-98 horizon. 
Table A.7: Robustness to Retirement Dynamics (Dropping Cohorts Born Before 1938) for Resilience Test: Post-Repeal Separations (1994-96) Among Program Survivors

\begin{tabular}{|c|c|c|c|c|c|}
\hline & $\begin{array}{c}(1) \\
\text { Separation }\end{array}$ & $\begin{array}{c}(2) \\
\text { Separation } \\
\text { Into Nonemployment }\end{array}$ & $\begin{array}{c}\text { (3) } \\
\text { Nonemployment } \\
\text { (Quarters) }\end{array}$ & $\begin{array}{c}(4) \\
\text { Unemp. (Benefits) } \\
\text { (Quarters) }\end{array}$ & $\begin{array}{c}\text { (5) } \\
\text { Cont. Empl. } \\
\text { (Quarters) }\end{array}$ \\
\hline REBP Region $\times$ Treated Cohort & $\begin{array}{l}0.011^{*} \\
(0.006)\end{array}$ & $\begin{array}{l}0.012^{* *} \\
(0.005)\end{array}$ & $\begin{array}{c}0.062^{* * *} \\
(0.015)\end{array}$ & $\begin{array}{l}-0.018 \\
(0.019)\end{array}$ & $\begin{array}{c}-0.089^{* * *} \\
(0.025)\end{array}$ \\
\hline REBP Region & $\begin{array}{l}-0.003 \\
(0.019)\end{array}$ & $\begin{array}{c}0.008 \\
(0.011)\end{array}$ & $\begin{array}{l}-0.007 \\
(0.056)\end{array}$ & $\begin{array}{c}0.005 \\
(0.041)\end{array}$ & $\begin{array}{c}0.116 \\
(0.088)\end{array}$ \\
\hline Treated Cohort & $\begin{array}{c}0.056^{* * *} \\
(0.004)\end{array}$ & $\begin{array}{c}0.073^{* * *} \\
(0.005)\end{array}$ & $\begin{array}{c}0.288^{* * *} \\
(0.006)\end{array}$ & $\begin{array}{l}0.065^{*} \\
(0.034)\end{array}$ & $\begin{array}{c}-0.227^{* * *} \\
(0.037)\end{array}$ \\
\hline Constant & $\begin{array}{c}0.157^{* * *} \\
(0.051)\end{array}$ & $\begin{array}{l}0.068^{* *} \\
(0.030)\end{array}$ & $\begin{array}{l}0.324^{* *} \\
(0.142)\end{array}$ & $\begin{array}{c}0.136 \\
(0.107)\end{array}$ & $\begin{array}{l}8.166^{* * *} \\
(0.241)\end{array}$ \\
\hline $\begin{array}{l}\text { Observations } \\
\text { Adjusted } R^{2} \\
\text { No of Clusters }\end{array}$ & $\begin{array}{c}178,590 \\
0.006 \\
99\end{array}$ & $\begin{array}{c}178,590 \\
0.015 \\
99\end{array}$ & $\begin{array}{c}178,590 \\
0.011 \\
99\end{array}$ & $\begin{array}{c}178,590 \\
0.002 \\
99\end{array}$ & $\begin{array}{c}178,590 \\
0.003 \\
99\end{array}$ \\
\hline
\end{tabular}

Note: The table reports results of the specification in $[8]$ while dropping all workers who reached retirement age by 1998 . The coefficient on REBP Region $\times$ Treated Cohort captures the effect of REBP-eligeibility on the outcomes listed in columns (1) through (5) on a sample of workers employed at the same establishment in May 1988 and February 1994. The regression specification includes region and cohort effects. Separation denotes an indicator function that is 1 if a worker is not employed by their employer from February 1994 (and May 1988) in February 1996. Separation into Nonemployment denotes an indicator for Separation from the initial employer interacted with an indicator for not being employed in February 1996. Employment Indicator denotes whether a worker is employed in February 1996. Employment (Quarters), Unemployment (Quarters) and Continuous Employment (Quarters) denote the quarters of employment, unemployment insurance/assistance receipt, and continuous employment with the initial employer between February 1994 and 1996. Standard errors clustered at the administrative region level are reported in parentheses. Levels of significance: ${ }^{*} 10 \%,{ }^{* *} 5 \%$, and ${ }^{* * *} 1 \%$. 
Table A.8: Complier Analysis by Predicted Separations

\begin{tabular}{lccc}
\hline \hline Type & Mean & SE & CI \\
\hline Compliers & 0.67 & 0.098 & {$[0.48,0.87]$} \\
Always-Separators & 0.49 & 0.038 & {$[0.41,0.56]$} \\
Non-Separators & 0.33 & 0.078 & {$[0.17,0.48]$} \\
Control Group = Compliers + Non-Separators & 0.37 & 0.080 & {$[0.22,0.53]$} \\
All & 0.44 & 0.056 & {$[0.33,0.55]$} \\
\hline \hline
\end{tabular}

Note: This table reports characteristics of compliers, always-separators, and non-separators using predicted separations as complier attributes. The prediction is estimated as follows: for all workers employed in 1982, we regress an indicator for separating from the 1982 job by 1987 on a rich set of covariates measured in 1982: age, industry-occupation fixed effects interacted third degree polynomials in tenure and experience, indicators for deciles for income and local unemployment rates, and indicators for nonemployment or nonemployment with UI spells between 1972 and 1982. Compliers are those workers who are employed in 1988 and whose job would have survived in the absence of the REBP reform, always-separators are those matches that separate even in the control group (i.e. absent REBP), and non-separators are the matches that survive even in the treatment group (i.e. despite REBP). For each of the variables and groups, the table reports means as well as standard errors (in parentheses) based on 100 bootstrap replications blocked at the administrative region level. 
Table A.9: Summary Statistics of Wage Rigidity Proxies

\begin{tabular}{|c|c|c|c|c|}
\hline Within-Firm SD of ... & Log Wage & $\begin{array}{l}\text { Residuals of } \\
\text { Log Wage }\end{array}$ & $\Delta$ Log Wage & $\begin{array}{l}\text { Residuals of } \\
\Delta \text { Log Wage }\end{array}$ \\
\hline \multicolumn{5}{|l|}{ Q1 } \\
\hline Mean & 0.13 & 0.11 & 11.53 & 10.18 \\
\hline Range & $0,0.17$ & $0,0.14$ & $0,16.32$ & $0,14.21$ \\
\hline \multicolumn{5}{|l|}{ Q2 } \\
\hline Mean & 0.19 & 0.15 & 19.28 & 16.40 \\
\hline Range & $0.17,0.21$ & $0.14,0.17$ & $16.32,22.04$ & $14.21,18.38$ \\
\hline \multicolumn{5}{|l|}{ Q3 } \\
\hline Mean & 0.24 & 0.18 & 25.02 & 20.80 \\
\hline Range & $0.21,0.28$ & $0.17,0.20$ & $22.04,27.79$ & $18.38,23.66$ \\
\hline \multicolumn{5}{|l|}{ Q4 } \\
\hline Mean & 0.42 & 0.27 & 40.09 & 31.50 \\
\hline Range & $0.28,2.30$ & $0.20,1.33$ & $27.79,126.92$ & $23.67,135.74$ \\
\hline \multicolumn{5}{|c|}{ Correlation [Rank Correlation] Between Within-Firm SD of ... } \\
\hline Log Wage & 1 & $0.88[0.77]$ & $0.34[0.33]$ & $0.35[0.35]$ \\
\hline Residuals of Log Wage & & 1 & $0.40[0.39]$ & $0.43[0.43]$ \\
\hline$\Delta$ Log Wage & & & 1 & $0.92[0.85]$ \\
\hline Residuals of $\Delta$ Log Wage & & & & 1 \\
\hline
\end{tabular}




\section{H Additional Figures}

Figure A.4: Industry Heterogeneity of Separation Behavior

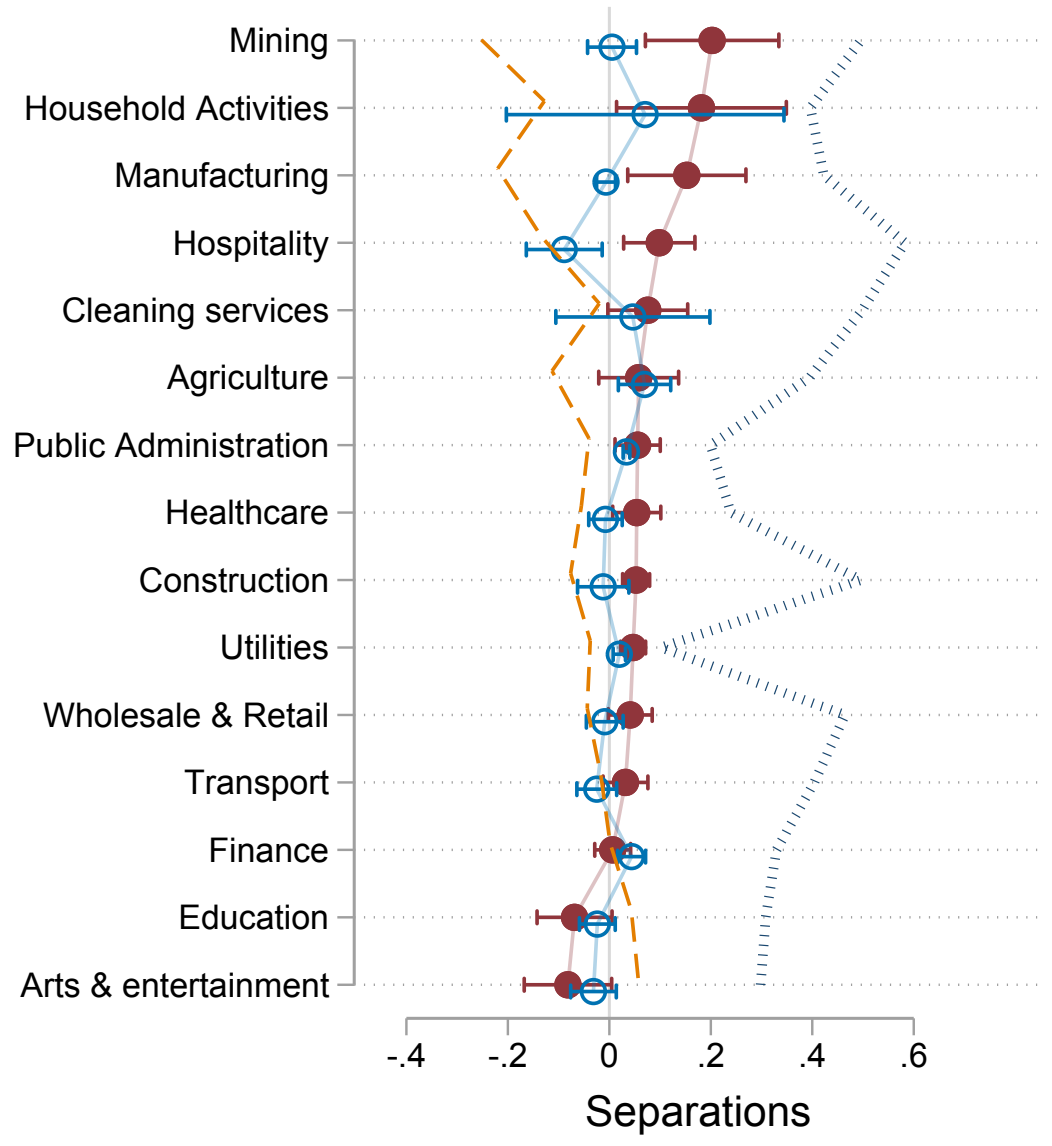

111. Control Mean: Separation Level During Policy Period

- Initial Treatment DiD Effect on Separations During Policy Period

O DiD Effect on Post-Repeal Separations: Data

- Coasean Benchmark for Post-Repeal Separations DiD Effect

(Or Non-Coasean Benchmark with Worker Shocks Only)

Note: The figure reports several separation outcomes, repeating our analysis within each industry cell. The coefficients in blue show the separation behavior for survivors between 1994 and 1996. 
Figure A.5: No Evidence for Aggregate Spillovers: Separations during REBP and after REBP with Even Younger Control Cohorts

(a) Separations During REBP (1988 to 1993)

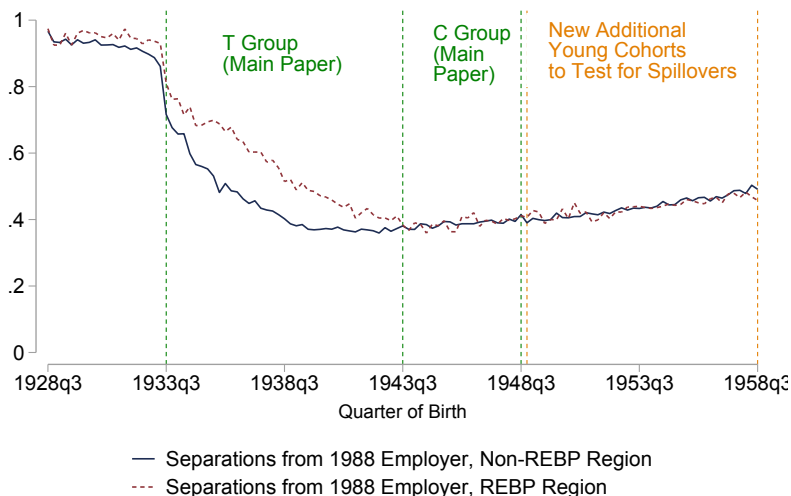

(c) Post-Repeal Separations (1994 to 1996)

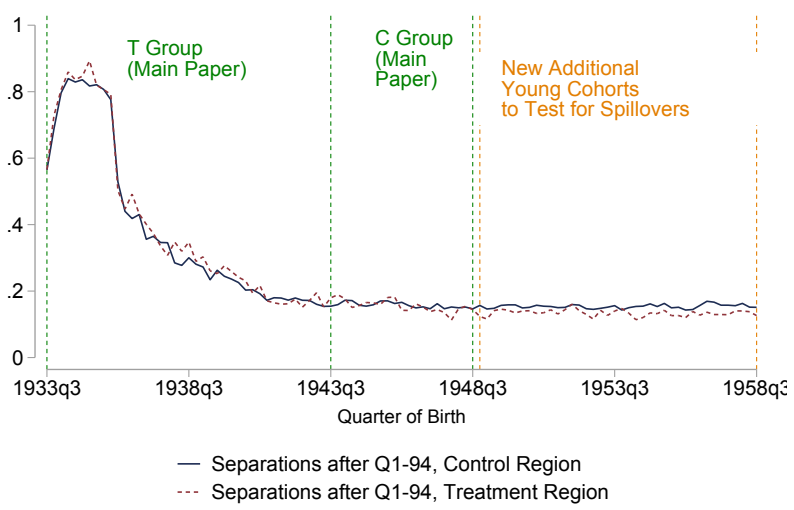

(b) During REBP: Difference T vs. C

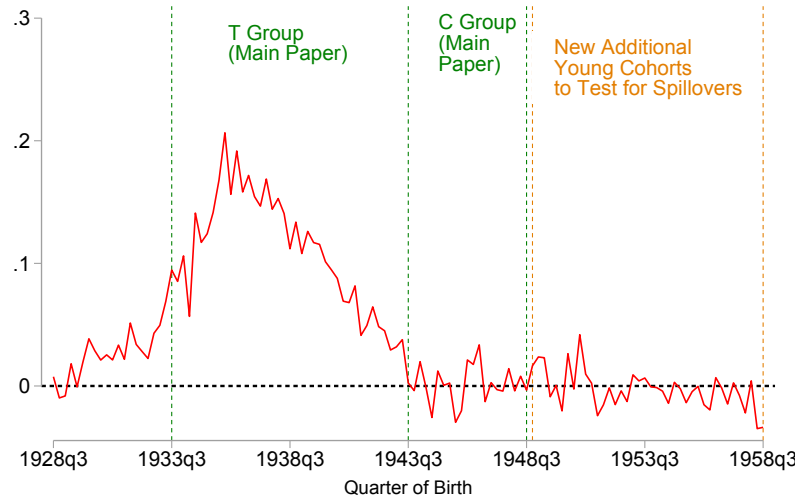

(d) Post-Repeal: Difference T vs. C

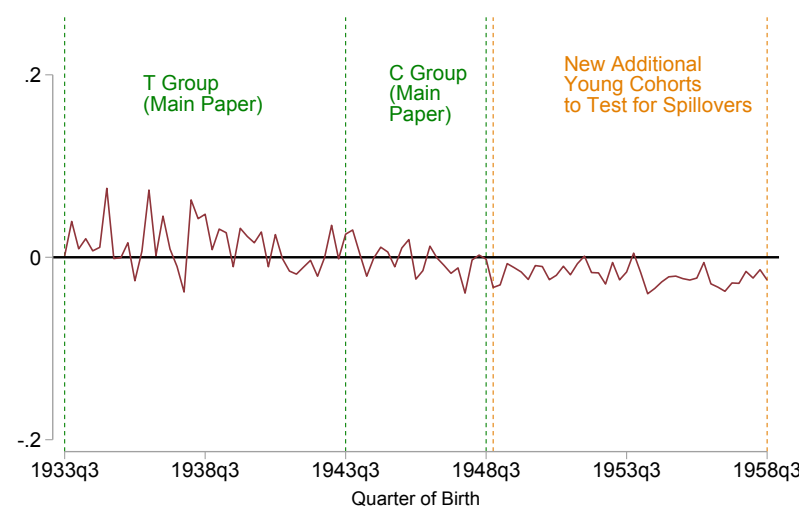

Note: Panel (a) shows the share of workers who separated from their 1988q2-employer (right before the reform) by 1993q3 (when reform had just ended) for all workers born between 1928 and 1958. It plots rates by month of birth and within the REBP (red, short dashes) and non-REBP (blue, solid) regions. Panel (b) shows the difference between the REBP and the control region by cohort. Panels (c) and (d) are based on workers whose matches with their 1988q2-employer survived until 1994q1. Among these survivors, Panel (a) shows the share of workers who separated from their initial employer by 1996 for all workers born between 1933 and 1958. Panel (c) plots rates by month of birth and within the REBP (red, short dashes) and non-REBP (blue, solid) regions. Panel (d) shows the difference between the REBP and the control region by cohort. 
Figure A.6: Initial Treatment Effect: Outcomes by Age

(a) Level

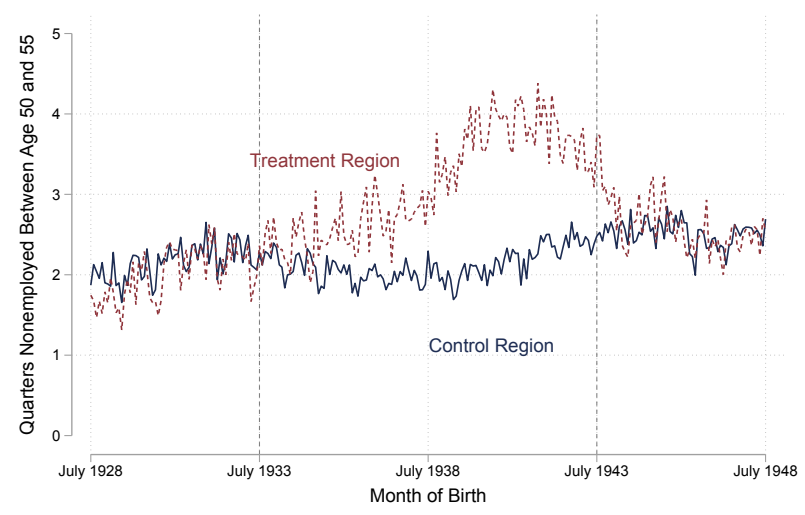

(c) Level

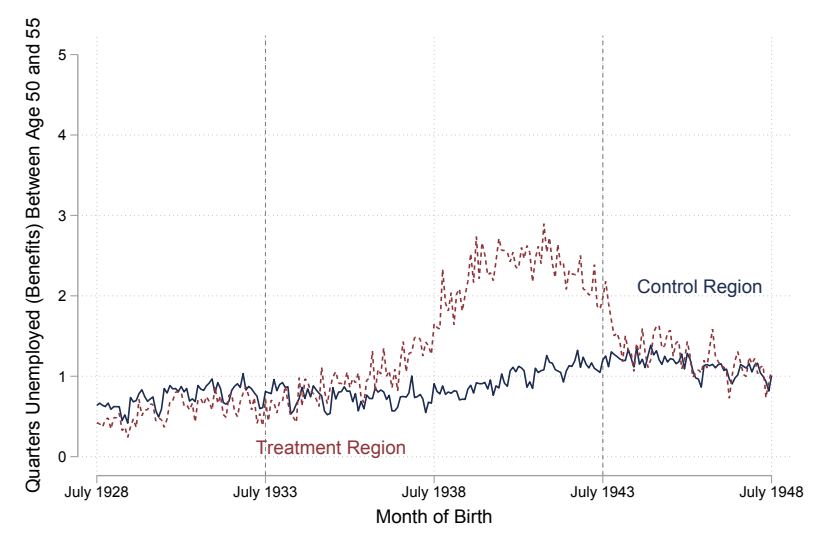

(b) Difference

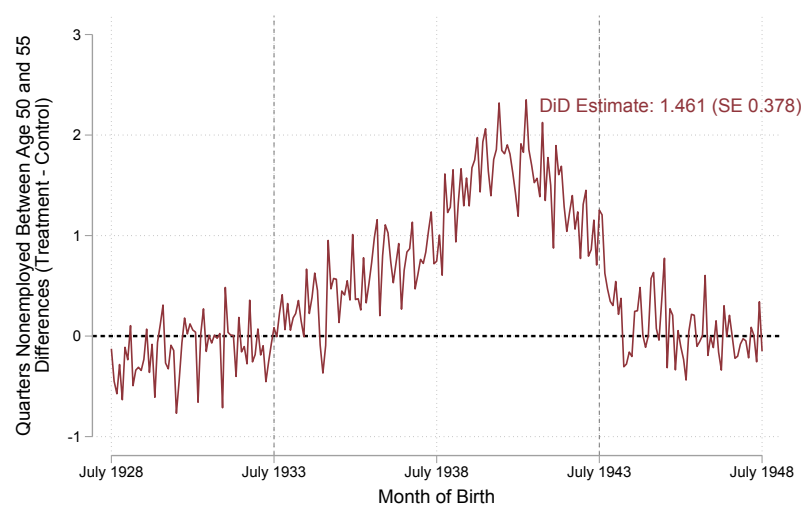

(d) Difference

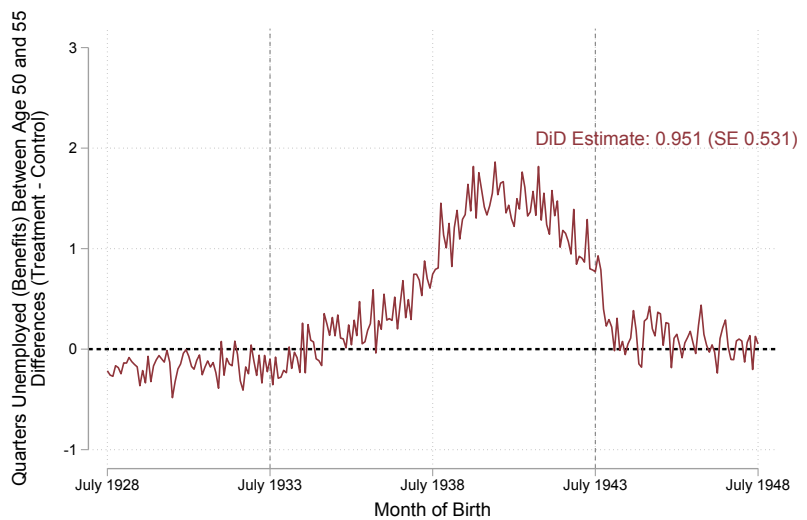

Note: Panels (a) and (c) show the average number of quarters that the workers are nonemployed and unemployed (UI/UA receipt), respectively, until the quarter before they turn 55, among those employed in the quarter before they turn 50. Both plot rates by month of birth and within the treatment (red, short dashes) and control (blue, solid) regions. Panels (b) and (d) show the difference between the REBP and the control region by cohort. Cohorts born after 1943 were not covered by the policy as they turned 50 after the program was repealed 1993. 
Figure A.7: Difference by Industry Growth and Establishment-Level "Hockey-Sticks"

\section{Difference in Separation by Industry Growth}
(a) Through 1995
(b) Through 1997
(c) Through 1998
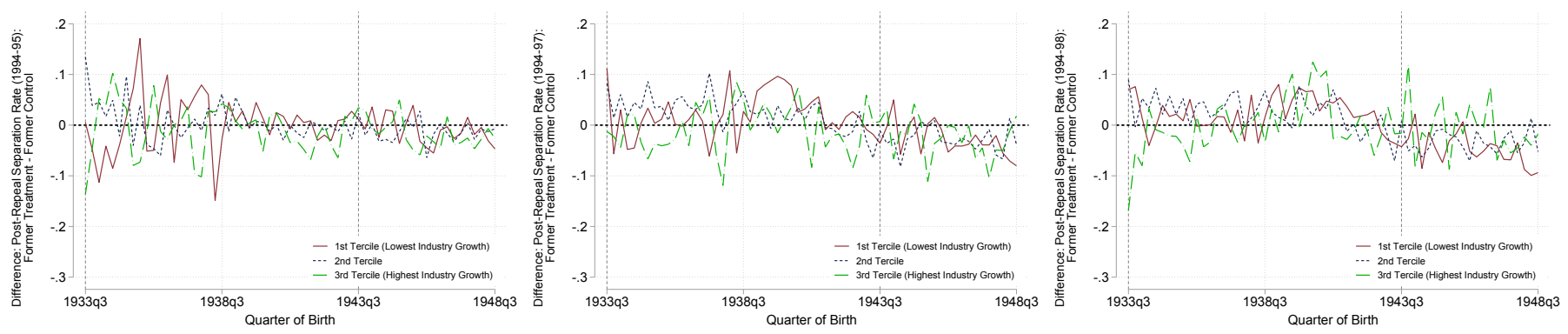

Survivor Separations by Cohort and Region

(d) Through 1995

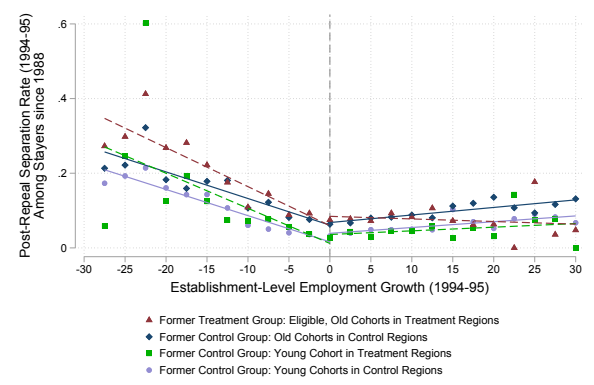

(g) Through 1995

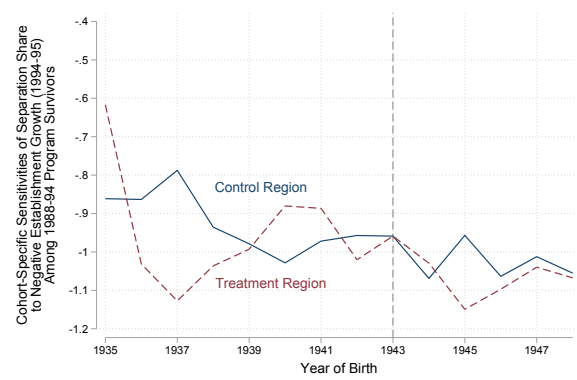

(e) Through 1997

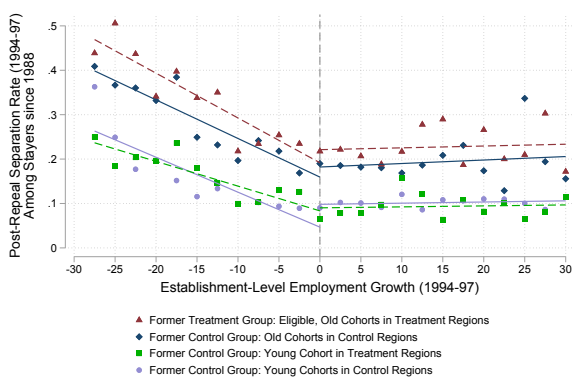

\section{Birth Cohort-Specific Slopes}

(h) Through 1997

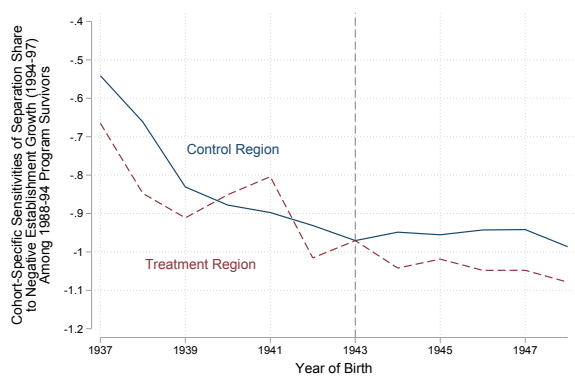

(f) Through 1998

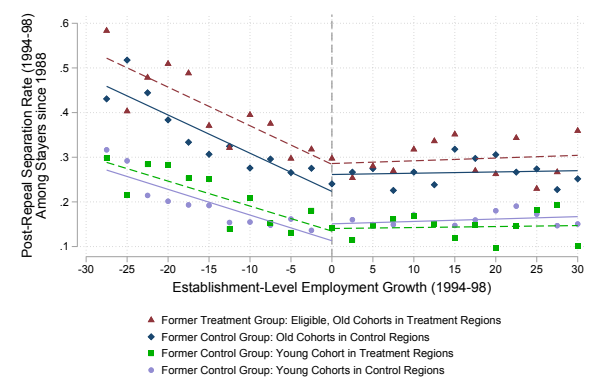

(i) Through 1998

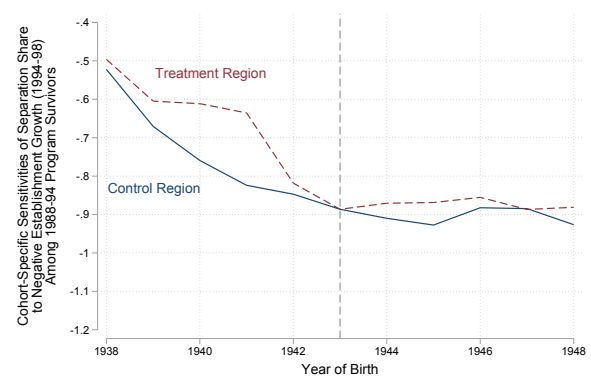

Note: This figure replicates Figure 9 Panels (a), (c) and (d) for the post-repeal separation horizons through 1995, 1997 and 1998. 
Figure A.8: No Evidence for Employer-Level Spillovers: Differences in Post-Repeal Separations by Firm and Industry Exposure to REBP (Share of Program-Eligible (Old) Workers)

(a) Firm-Level Exposure to REBP

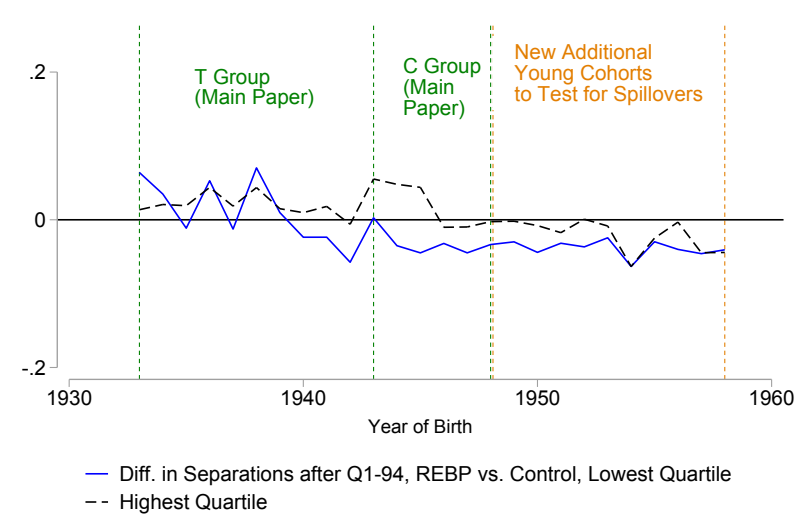

(b) Industry-Level Exposure to REBP

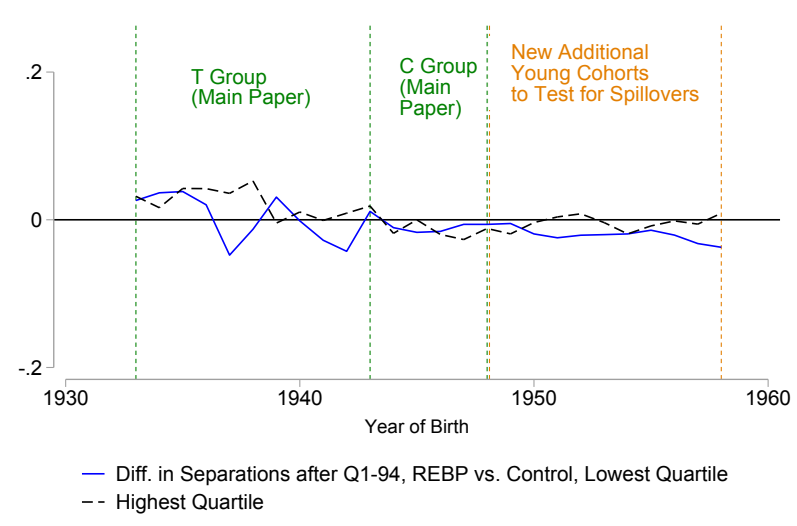

Note: The figures extends Appendix Figure A.5 (d) by splitting the sample based on firm- or industry-level of exposure to the treatment. Specifically, each line corresponds to the difference in post-repeal separation rates (1994 to 1996) between the treated and control group. The solid blue line denotes firms or industries in the lowest quartile of exposure to treatment; the dashed black line denotes the ones in the highest quartile of exposure. Exposure at the firm or industry level is calculated as the share of workers in program-eligible cohorts (1933-43) in the year before the reform (1987). 
Figure A.9: Separations by Wage Rigidity Measures (Other Horizons)

ஸ゚
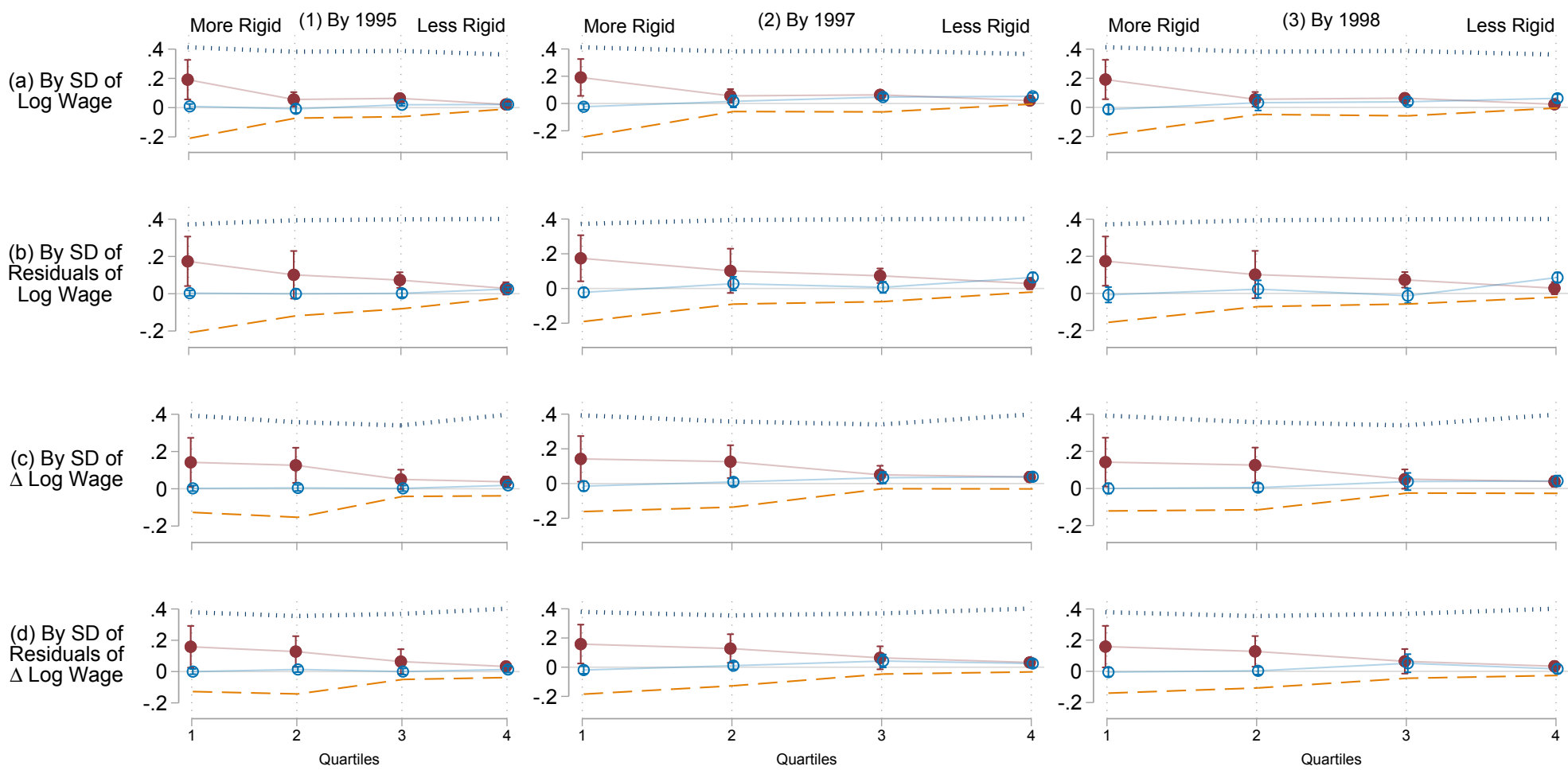

1111 Control Mean: Separation Level During Policy Period

O DiD Effect on Post-Repeal Separations: Data

- Initial Treatment DiD Effect on Separations During Policy Period

Coasean Benchmark for Post-Repeal Separations DiD Effect (Or Non-Coasean Benchmark with Worker Shocks Only)

Note: The figure replicates Figure 10 for other post-repeal horizons. 


\section{Online Appendix References}

Card, David, Raj Chetty, and Andrea Weber. 2007. "Cash-on-Hand and Competing Models of Intertemporal Behavior: New Evidence from the Labor Market." Quarterly Journal of Economics 122 (4):1511-1560.

Garibaldi, Pietro and Giovanni Violante. 2005. "The Employment Effects of Severance Payments with Wage Rigidities." The Economic Journal 115 (506):799-832.

Hall, Robert and Paul Milgrom. 2008. "The Limited Influence of Unemployment on the Wage Bargain." American Economic Review 98 (4):1653-74.

Lazear, Edward. 1986. “Employment-at-Will, Job Security, and Work Incentives." In Employment, Unemployment and Labor Utilization, edited by R. Hart. Unwin Hyman.

— 1990. "Job Security Provisions and Employment." Quarterly Journal of Economics 105 (3):699-726.

Li, Tong. 2002. "Robust and Consistent Estimation of Nonlinear Errors-in-Variables Models." Journal of Econometrics 110 (1):1-26.

Li, Tong and Quang Vuong. 1998. "Nonparametric Estimation of the Measurement Error Model Using Multiple Indicators." Journal of Multivariate Analysis 65 (2):139-165.

MacLeod, Bentley and James Malcomson. 1993. "Investments, Holdup, and the Form of Market Contracts." American Economic Review 83 (4):811-837.

Manoli, Day and Andrea Weber. 2016. "Nonparametric Evidence on the Effects of Financial Incentives on Retirement Decisions." American Economic Journal: Economic Policy $8(4): 160-182$.

OECD. 1990. Economic Surveys: Austria 1988/1989. OECD Publishing.

Schennach, Susanne. 2004. "Estimation of Nonlinear Models with Measurement Error." Econometrica 72 (1):33-75.

Schennach, Susanne M. 2012. "Measurement Error in Nonlinear Models: A Review." In Advances in Economics and Econometrics, vol. 3, chap. 8. Econometric Society.

Zweimüller, Josef, Rudolf Winter-Ebmer, Rafael Lalive, Andreas Kuhn, Jean-Philippe Wuellrich, Oliver Ruf, and Simon Buchi. 2009. "Austrian Social Security Database." Austrian Center for Labor Economics and the Analysis of the Welfare State Working Paper No. 0903. 